40 (5)

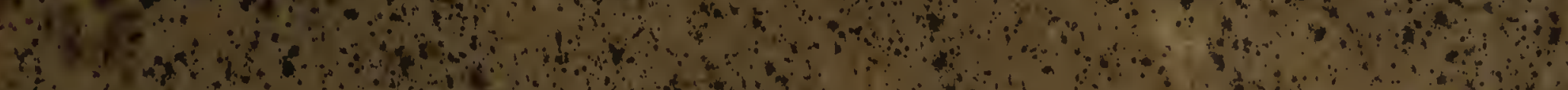
a a (

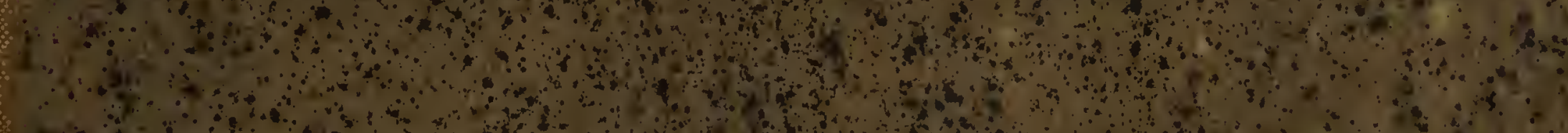

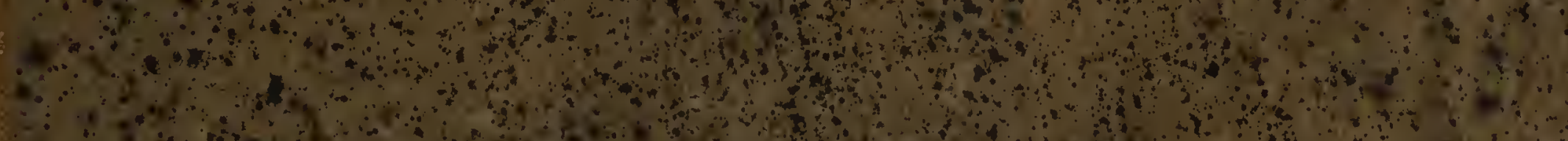
and

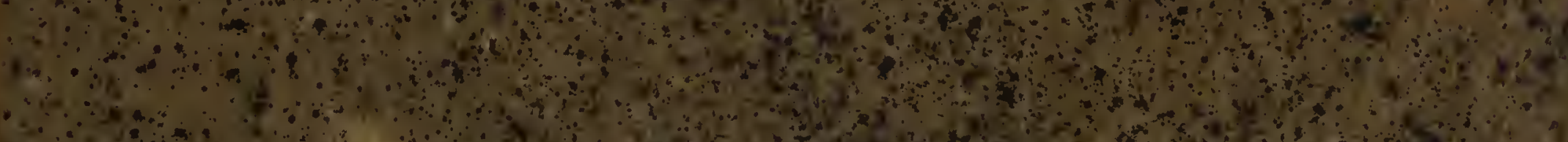

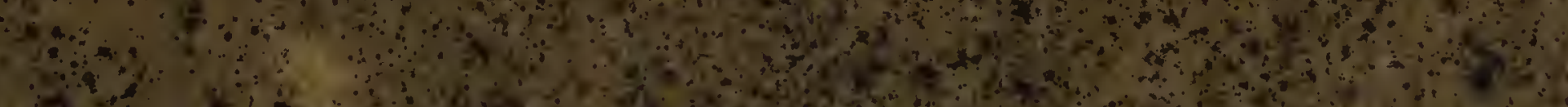

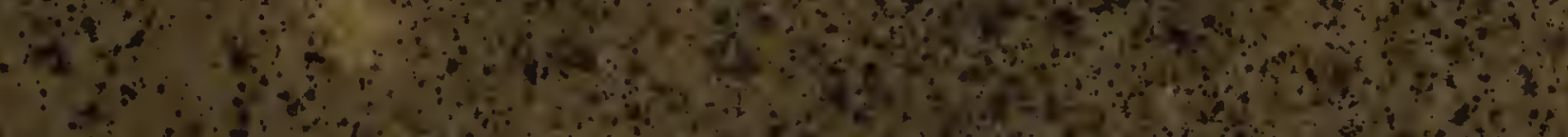

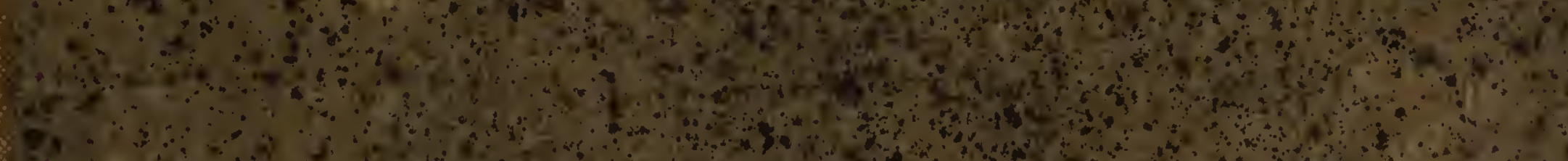

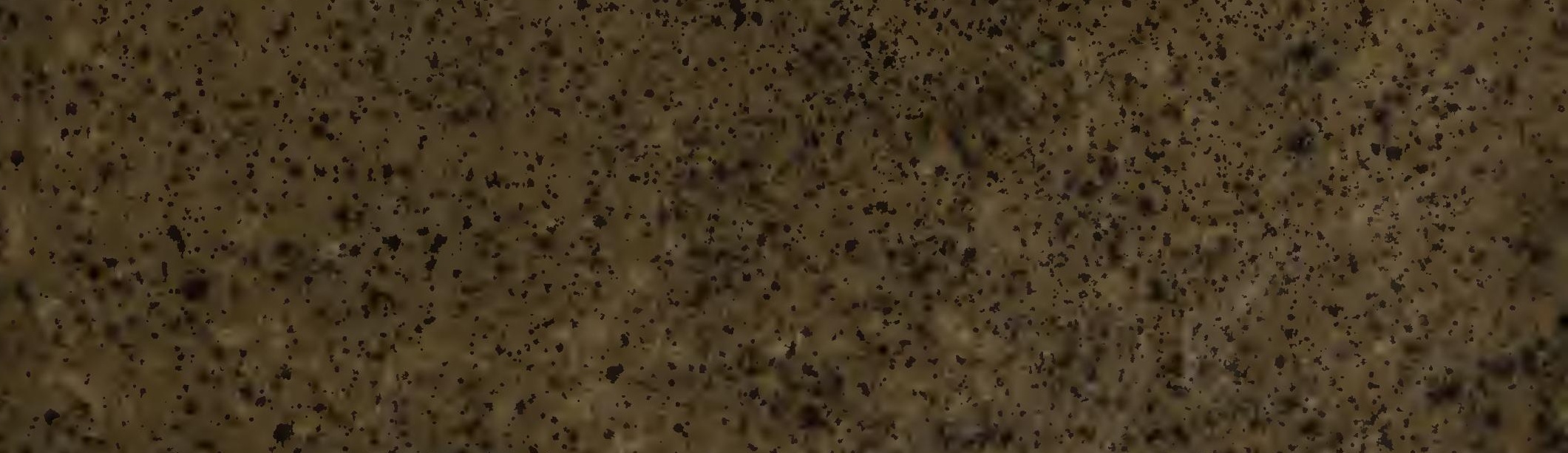

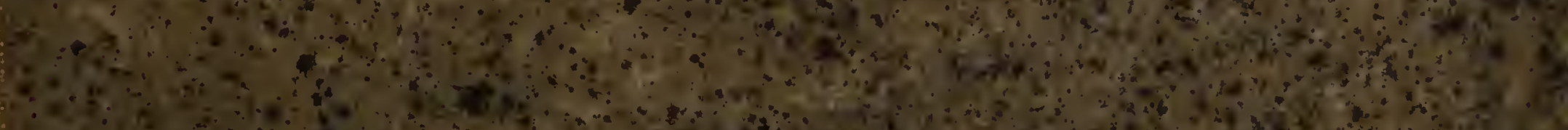

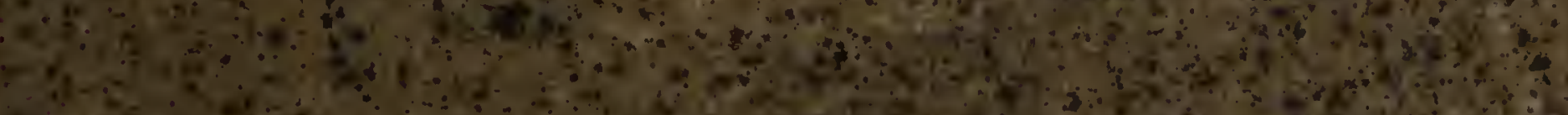
(c) 


$$
10749 / c
$$








\section{CAROLI ALLIONII}

PHIL. ET ME D.

DOCT. TA URINENSIS

E

SOCIETATE PHYSICO-BOTANICA

FLORENTINA

RARIORUM

PEDEMONTII STIRPIUM

SPECIMEN PRIMUM。

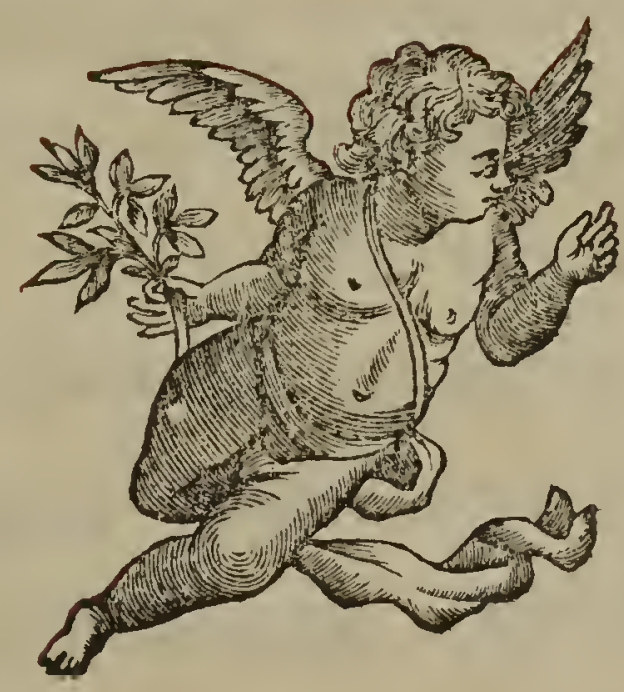

\section{AUGUST 死 TAURINORUM}

EXCUDEBANT ZAPPATA。 ET AVONDUS IMPRESSORES ARCHIEPISCORAL. et Iliustriss. Civitatis

$M D C \subset I . V$. 


\title{
TMOITIA IJORAD
}

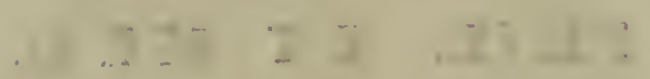

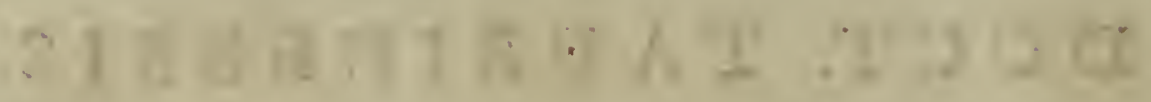

3.

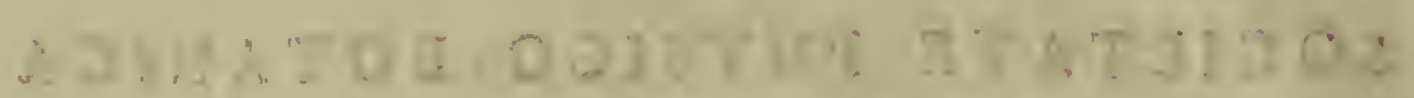

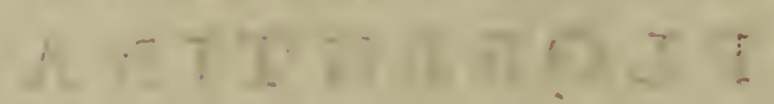

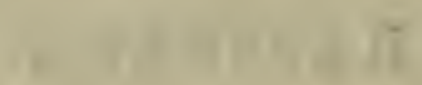

2501:3502 17\%TON3CII

-

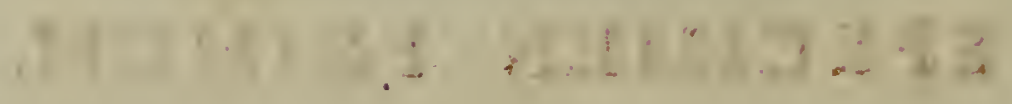

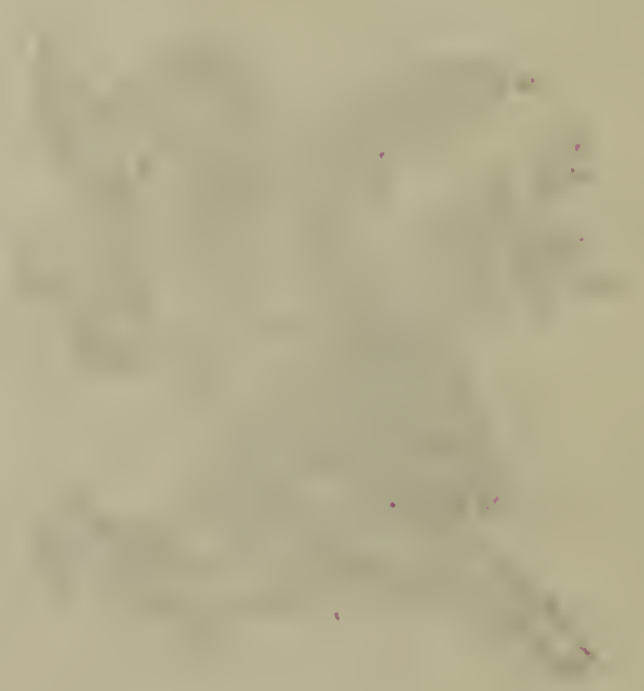

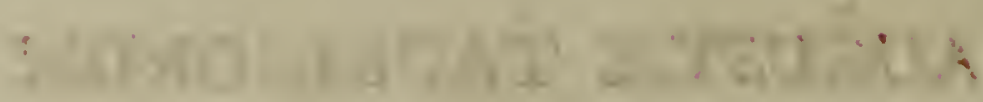

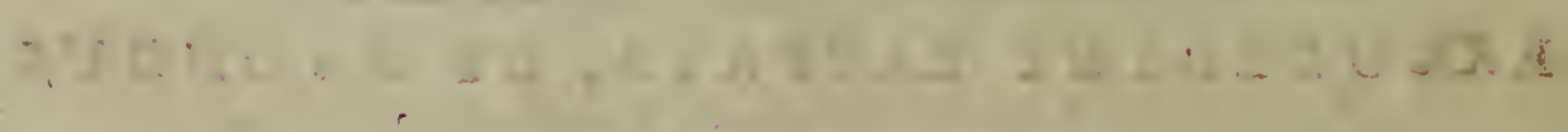

$$
\pi 40>4 \div
$$

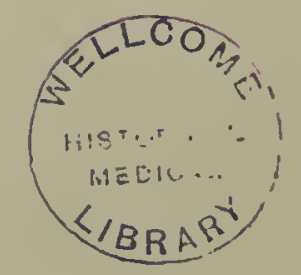




\section{(III)}

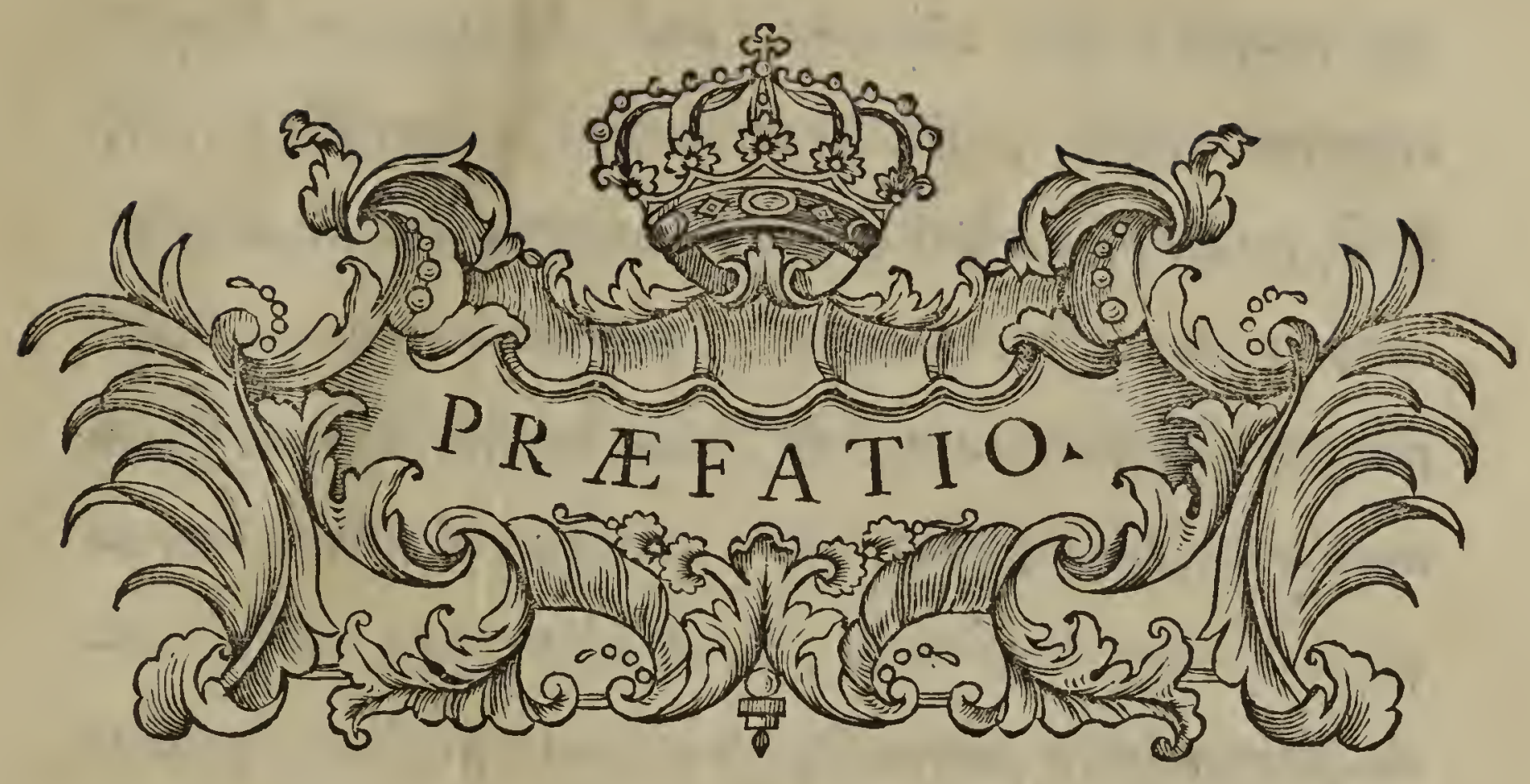

7 Andiu inchoatum, abfolutum demum Typis (3.) committo Specimen boc Botanicum, plu(1) rium, qua in Alpes noftras infitui, itinerum fructum. Quamvis autem boc opufculum lere videri pofft, uipote quod nonnifi triginta firpium iconem, Ev defriptionem complectatur, vix credibile tamen eft, quantum temporis me diftinuerit. Cum enim ageretur de Stirpibus minus notis, quarum nonnulle nove mibi ridebantur, 
eos omnes, qui Alpinas, aut Montanas Stirpes commemorafent, Auctores confulere neceffum erat, tum etiam aliarion, nec indigenarum facca $\int p e$ cimina mibi comparare, quorum utrumque $E$ temporis dippendium, $\sigma$ multam mibi moleftiam intulit. Adde, fi placet, clinice Medicine curas quotidie ingravefcentes, tum alia, que nullo modo protermitti poterant, graviora fudia, quibus borce botanici ftudii aliquo ab binc tempore plurimum coarctata funt. Hec omnia diu probibuerunt quominus poftremam operi manum citius imponerem. Vtinam vero illud runc in publicam lucem prodiret, quale diuturna confideratio poftularet; $a b$. Soluium nempe, numerifque omnibus expletum, in quo nibil effet defiderandum. Video tamen ipse quantum illud a perfectione abfit, EF quam multa forte fint reprebenfione digna, quorum tamen ve- 


\section{( V. )}

veniam ah optimis. Lectoribus facile impetraturum fore confido ob maximam argumenti difficultatem. Norunt enim optime qui per Alpes itinera aggref. fi liunt, colligendarum Stirpium caufja, quam diverfa res fit herbas domi cultas, commodifque in locis nafcenies defcribere, atque Alpinas raptim, non fone multis incommodis, ES Sape cwn vite difcrimine lectas. Rariorum, qua mibi alpefres faltus peragranti accurrerunt, Stirpium icones Lectorum oculis fubjicere opportunum vifum eft, earum prefertirn, quas ocl ab aliis pretermiffas, vel non fai is accurate delineatas animadverti : quamvis autem minus nitide, neque fatis affabre concinnate nonnuils videri poffint, Botanices tamen peritis Salisfactum iri putaverim, eo vel maxime quod fingulas firpes uberiori defcriptione profequiutus fim. Quod ad nomina fingulis impofira perinet, ab ali- 


\section{(VI)}

aliquibus profecto reprehenfum me iri fentio, quod vetera pleraque retinenda exiftimaverim, recentiorum novis legibus minime Servatis. Confulto id a me actum eft, neque reprebenfionem banc timebo, donec videam, que Recentiores nomina effingunt, ta. lia evadere, qualia ipfi pracipiunt; dum vero in bis nominibus Jpecificis conftimendis Botanici diffentiunt, Ev ab unoquoque, pro ut ei lubet, immutantur, liceat mibi vetera uf recepta nomina con. fervare. Novis interea ubi Stirpibus nomina danda fuerunt, omnem in id diligentiam, industriamque contuli, ut pracipuas defcripte berbe differentias includerent; minime tamen optima fore, vel femper futura effe fidenter affirmo. 


\section{(VII.)}

\section{NOMINA LIBROR UM, QUI IN HOC OPERE CITANTUR.}

Mmanni Jonnnis Stirpium rariorum in Imperio Rutheno A sponte provenientium icones, \& defcriptiones. Petropoli I 7.39 .4 .

Acta Medicorum Berolinenfum - Berolini 1718. ad $173 \mathrm{r}$. Vol. 21. 12.

Bauhinus Gaspar Pinax Theatri Botanici. Bafilez 1671. 4. Ejusdem Pradromus Theatri Botanici.

Bauhinus Joannes Hiftoria univerfalis plantarum. Ebroduni 1650. in fol. 3. Vol.

Barrelieri Jacobi Plantee per Galliam, Hifpaniam, E Italiam obfervate. Parifiis 1714 . fol.

Spicilegro Botanico di Baltafjar, e. Michele Campi. in Lucca I669. 4 .

Cupani Hortus catholicus. Neapoli 1696. 4. cum Jupplemento Ejusdem Supplementum alterum. Panormi 1697.4.

Caroli Clusir Rariorum plantarum Hiforia. Antvverpia $160 x$. fol. 


\section{(Vili.)}

EJUSDEM Rariorum aliguot firpium per Pannoniam, Auftriam; E vicinas Provincias obfervatarum Hiftoria. Antvverpiæ 1583.8 .

Columna Ecphrafss Stirpium minus cognitarum pars I. , E x I: Romæ 1616.4 .

Dillenir hortus Eelthamenfis: Londini 1732. fol. maximo vol. I I.

EJusdem Jo. Raji Synop/ss methodica Stirpium Britannicarum a - Dillenio emendata, E aucta. Londini 1724.8.

Remberti Dodonei Stirpium hiforia Pemptades vi. Antvverpia... $\therefore$ I GIG. fol.

Jo. Georgin Gmelini Florá fibirica. Petropoli 4. Tom. x: 1747 .

Hortus Regius Parifienfis. Parifiis i665. fol.

Alberti Haller Enumeratio methodica Stirpium Helvetice indige" narum. Gottingæ 1742 . fol. vol. I I.

EJUSDEM Iter helveticum anii 1739. Gottinga 1740.4 .

Ejusdem Opufcula Botanica. Gottingæ 1749.

Hoffmanni Mauritir Delicice hortenfes, E falveftres. Altdorffi. I662. 4.

Dionisit Joncquet Hortus. Parifiis 1659.4.

Caroli Linnei Fundamenta Botanica. Amftelodami 17.35 . 12.

Ejus- 


\section{(IX)}

Ejusdem Flora Lappoñica. Amftelodami 17.37. 8.

EJUSDEM Genera plantarum, earuimque caracteres. Parifisis i 7 43. 8.

Esusdem Flora Svecica. Stockolmia I 745.8.

EJUSDEM Iter Oelandicum, Es Gotlandicum. Stockolmiæ 1745.8.

EJusdem Amanitates Academica. Holmix, \& Lipfiæ 749.8 .

Ejusdem Philofophia Botanica. Stockolmix' i 75 i: 8.

Ejusdem Siftema natura. Sexta editio Halenfis.

Mentzelir Index nominum Plantarum multilinguis . Berolini 1682. fol.

Petri Antonil Michelin Hortus Florentinus a Jo. Targionio Tozzettio editus. Florentiæ $17.4^{8}$. fol.

ROBERTI MORIsON Hiftoria plantarum univerfalis Oxonienfis pars 2., E 3.. Oxonii 1680. 1699. edita fol.

Julit Pontedere Compendium Tabularum Botanicarum. Patavii 1718.4 .

Jo. Raji Hiftoria Plantarum generalis . Londini Tom. 3. fol. I686. 1688.

Raji Silloge Stirpium Europiarum extra Britannias nafcentium. Londini 1694.8 .

Jo. Francisci Seguierin Planta Veronenfes \& $c_{\text {. }}$. Veronæ Typis Seminarii I745. 8. vol. II.

Ejus- 


\section{(X)}

EJUSDEM Supplementum. Veronæ 1754.8.

Schola Botanica. Amftelodami 1689 ? 12.

Jo. JACOBI SCHEUCHzerI Itinera alpina. Londini 1708.4. vol. II.

Josephi Pitton Tournefort Inftitutiones rei herbaria . Parifiis 1719.4 . vol. 3 .

Jo. Baptiste TRIUMfetTI Obfervationes de ortu, E vegetatione Plantarum. Romæ 1686.4.

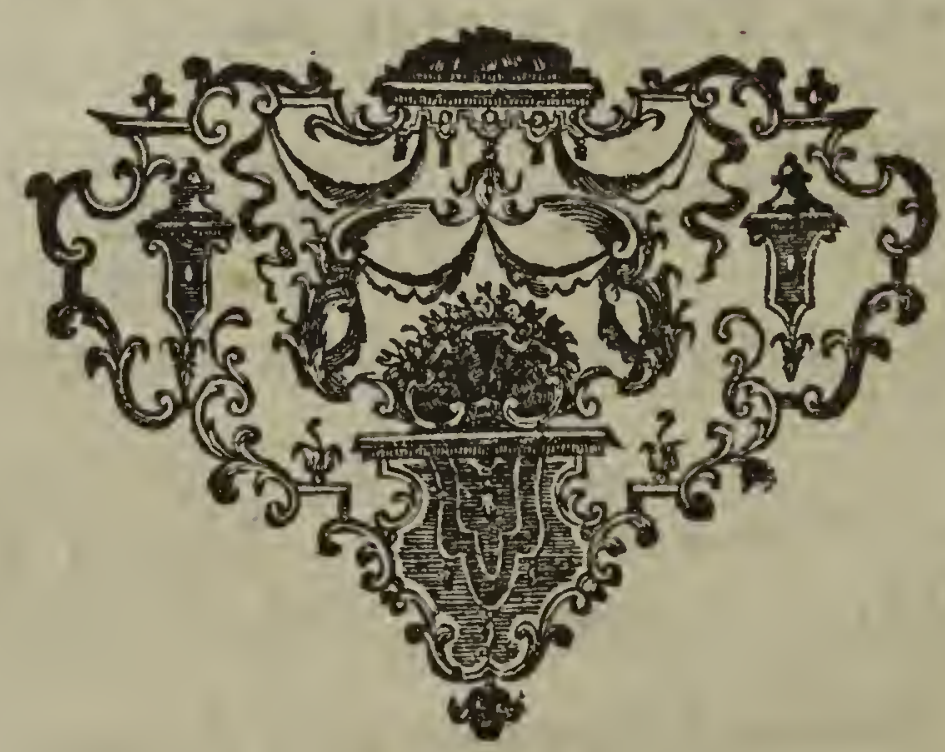




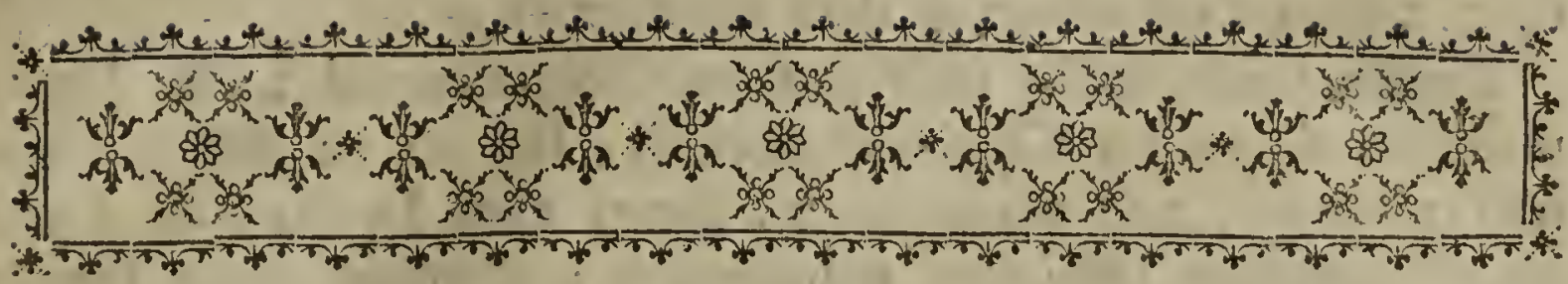

\section{ALYSSON, PYRENAICUM, PERENNE; MINIMUM, FOLIIS TRIFIDIS Tourn. In/t. 217}

T A. B. I. N O N VI.

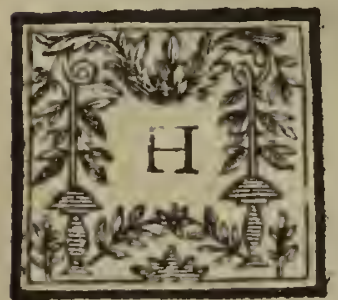

UIC, quæ prima hic defcribenda occurrit, ftirpi Tournefortii nomen adfcribitur, eo quod nulla alia cognita fit ufque nunc Alyffi fpecies, in qua memoratæ a Tournefortio notæ contineantur. Inhabitat hæc fummos fcopulos altifimarum alpium montis Cenifii, uti etiam alpium Afrette, Le-Vallon, \& La-Croix, in reliquis, quas invifi, alpibus de cœtero rara.

Ex radice duriufcula, \& inter fcopulorum rimas penetrante cefpites varii prodent; denfe autem songefta folia rofulas conftituunt. Folia tridigita funt, $\mathrm{feu}$ in tres lobos lineari-truncatos, ad baftm fere fecta. Succulenta non funt, fed exfucca, \& nitentia : ex horum medio natus pediculus uncialis, aut femuncialis, nudus, aliquot flores fuftinet umbellatos brevibus infidentes petiolis, aliquantulum odoratos, fat magnos pro plantæ ratione, purpurei, aut cinereo-purpurei coloris. Corolla patens eft, ungues petalorum calicis altitudinem metiuntur.

Calix erectus eft e quatuor foliolis concavis compofitus; qui diu perfiftit, tandem caducus. Sequitur filicula compreffa, acute ovalis, nihil emarginata diffepimento obverfe ovato valvis parallelo, cum permanente fpinula. Silicula ad fe- 
minum fitum modice tumet femen utrinque unum maturans; cum tamen in Embrione duo utrinque fint.

Fructu compreffo utrinque modice tumenti, \& loculo utrinque difpermo Clypeolæ accedit, fed ab ea differt fructu non rotundo, nec emarginato. Jungi cum Draba, \& Alyffo nequit propter feminum paucitatem; cognitæ enim fpecies polyfpermæ funt fex ad minus utrinque femina includentes. Cum Draba interim convenit fructu oblongo in acumen terminato. Intermedia igitur eft hæc ftirps Drabæ, \& Clypeolæ conftitutis generibus. Ego interim Alyfli inter fpecies fervavi nomen Tournefortii retinens, cum videam maximam in his novis generibus fpecierum affinitatem, \& notis generum charąterifticis traditis haud ita bene fpecies refpondere:

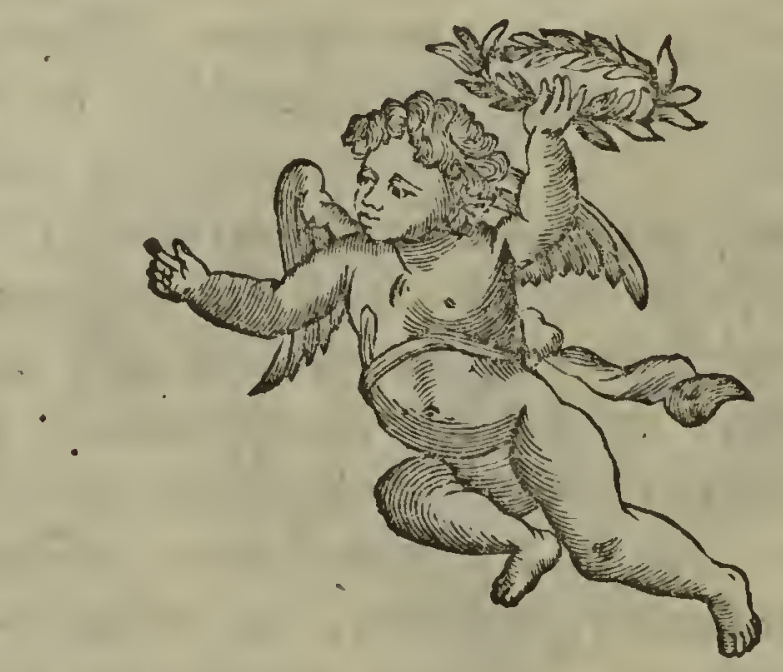




\section{ABSINTHIUM ALPINUM SPICATUM, FOLIIS PETIOLATIS BIS TRIFIDIS, CAULINIS. PIN NATIS.}

T A B. I.

Drma hic defcribitur Abfinthii alpini fpecies apud noAtrates alpicolas Genepi dicta , ftirps jamdudum Botanicis nota, fed maxime confufa. Qui varia ejus Synonima collegit Doctiffimus Hallerus (a), vocavit Artemiffam ex alis floridan, foliis petiolatis palmatis, planis; fericeis $(b)$. Ab/inthium quidem pumilum, palmatum, minus, argenteo, Jericeoque folio Barrelieri $(c)$; \& Bocconi $(d)$, uti etiam Absinihium alpinum, incanium C. B. \& Seriphium montanum candidum Scheuchzeri $(e)$ ex loco natali $(f)$ ad defcribendum Abfynthium Spectant. Non ita certo ftatui poteit de Abfinthio pumilo I. B. $(g) \& A b$ finthio umbellifero, muteliina quibufdam, ejufdem $(h)$.

Abfinthium alpinum fectundum Ponæ (i) quantum ex icone conjectari licet, non ad hoc, fed ad Abfrnthium tertio loco recenfendum potius pertinet. Demum Artemifa foliis pinnatis, ramis afcendentibus hirfutis, floribus globofis pendulis, recepta-

$$
\text { A } 2
$$

culo

(a) Enum. helv. p. 695

(b) Licet certæ notæ non adfint Abrotani, Artemifiæ, \& Abfinthii genera di. ftinguendi, antiquiffima hæc genera confundere, \& uno nomine Artemifiæ uti cum mihi non placeat, , eo quod hæc genera habitu quodam externo fa. tis diftinguantur, Abfinthium non Artemifram vocavi; \& præterea Halleria. num nomen hoc Abfinthium alpinum ab alis bene non fecernit.

(c) $1 c .462$.

(d) P. I. p. 8r. T. $7 \mathrm{r}$.

(e) It. alp. p. 29. Tab. 3. fig. I. , O. p. 328 .

(f) Defcriptio enim Scheuchzeri ita brev1s, \& icon, \& ftirps ita male expreffa ut non liceat eruere, num de hoc Abfinthio cogitaverit.

(g) De Abfintbio p. 75 .

(h) Hif. iii. p. 185 .

(i) Munte Baldo p. 218. 
culo pappofo Linnai (l); feu Artemifa caulibus fimpliciffimis foliis pinnatis, laciniis linearibus parallelis, floribus folitariis $(m)$ ejufdem diverfa eft a noftro Abfinthio.

Eft huic Abfinthio alpino radix dura lignofa: caules ad fummum Spithamæi, vix tomentofi. Folia radicalia plura, compreffa, fericeo villo nitentia, non tomentofa, duplicato trifida, laciniis linearibus, fine nunc acuto, nunc obtufufculo. Caulina folia pinnata pinnis indivifis, fumma fefflia; ex horum alis longa ferie nafcuntur pediculi ex bombacina hirfutie incani, flores folitarios fuftinentes. Flores magni funt, aurei . Calix amplus, calycis fquammæ virides ora nigra, intus citrini coloris. Calix qua parte pediculo jungitur tomentofus : receptaculum nudum. Humiliora fpecimina magis tomentofa funt .

Reperi copiofe in horrido abrupto fupercilio altiffimi collis fupra Jaillon. In Auguftæ Prætoriæ alpibus etiam nafcitur, crmilibus locis.

$A B$ -

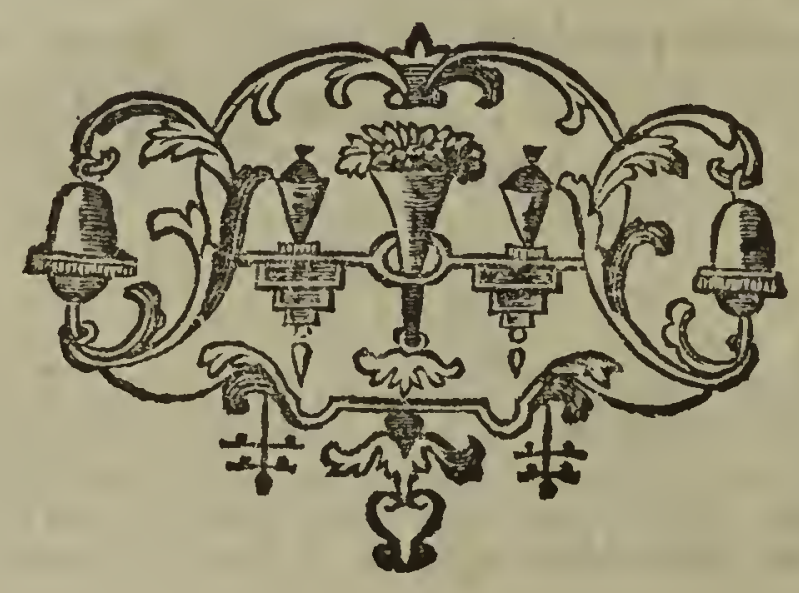

(1) It. Gotbl. jul. 13. cum fig., Or H. UpS. p. 218.

(m) Ad Stockolm. 1741. p. 205 . 


\section{ABSINTHIUM ALPINUM ; CANDIDUM, HUMILE C. B. pr. 7 r. TA B. I.}

A Ltera hæc eft Genepi fpecies, quæ in editifimis jugis A alpium Valdenfium poriffime frequentifima eft, \& a reliquis Abfinthiis alpinis difcrepat, floribus majoribus, aureis, umbellatis, quod difcrimen primus adnotavit doctiffimus Hallerus $(a)$. Nomen ei fequens indidit Artemifze floribus umbellatis foliis petiolatis palmatis, fericeis affeverans effe certo Abfinthium alpinum, candidum, humile C. B. a Burfero lectum. in M. Gletfchberg Vallefiorum .

Eo quod nulla ufque nunc exhibita ftirpis hujus figura fit, idcirco delineandam, \& incidendam curavimus, \& brevi, nervofæque Halleri defcriptioni pauca fuperaddam, quæ raram alibi hanc ftirpem magis definiant. Folia pinnata funt, ut ait Hallerus, pinnis ad duo, \& tria paria palmatis, \& hæ pinnæ fopius quinquefidæ, interdum quadrifidæ funt laciniis anguftis, \& acutis. Folia caulina, qux rara funt, non differunt nifi paucioribus laciniis, de cœtero etiam petiolata funt • Caules incani, fpithamæi quando altiores, \& aliquando ita breves ut vix biunciales fint .

Dixi oriri abunde in vallibus $V$ aldenfibus; adinvenitur etiam in Monte Cenifio, in valle Lantii, Auguffee Pretoria, aliifque alpibus, fed parcius.

$A B=$

(2) L. .. p. 694. 


\section{ABSINTHIUM FOLIIS RADICALIBUS MULTOTIES PIN NATIS; CAULINIS PINNA'IIS, LONGE.PE'TIOLATIS; FLORIBUS PARVIS, RARIS SESSI L I BUS.}

\section{T A B. II.}

TERTia hæc Abfinthii fpecies a primo difcrepat foliorum 1 radicalium pinnis tenuioribus, \& floribus fefflibus non petiolatis; a fecundo floribus minime umbellatis, ut alia. omittam difcrimina ex ejus defcriptione petenda.

Folia fericea habet tenuius, quam in præcedenti divifa fegmentis anguftioribus, \& longioribus. Folia nempe, quæ etiam longe petiolata funt, pinnis componuntur foepius ad tria paria, \& pinnulæ iterum incifæ fœpe funt, \& corniculatæ. Caulina folia fimiliter longe petiolata, \& pinnis ad duo, aut tria paria pinnatis, pinnis rariffime non fimplicibus; in alis foliorum refidet feffile floris capitulum fimile flori Abfinthii alpini Jpiccati (a) \&c., fed multo minus. Sericeo incana tota ftirps eft cauliculis tenuibus, \& femipalmaribus.

In monte Cenifio ad fcopulos infra prata Los-Laros collegi hoc Abfinthium, de quo nil apud auctores fcriptum video. Abfinthii fecundi Pone icon noftrum hoc videtur exprimere.

Abfinthia alpina apud Alpinas Gentes ubique Genepi dicuntur, \& iis utuntur ad multos morbos; egregie, \& potenter fudores cient, iifque Medici noftrates cum fucceffu utuntur is in morbis, in quibus e re eft vehementia fudorifera adhibere.

VIO.

(a) V.T. I. f. 2 . 


\section{VIOLA ALPINA MINIMA} NUMMOLARIA FOLIO.

Bocc. mus. p. 2. p. I63. Raji. hiff. tom. 3. p. 510. Viola alpina mummolaria folio Bocc. muf.

p. 2. Tab. 127.

T A B. II.

VIola, cujus hiftoriam, \& defcriptionem aggredior, nafcitur inter diffractos lapides fummi, \& editiflimi jugi Col de la Fema morta, per quod ex alpibus Valderianis ad Nicienfem comitatum via eft. Eam ibi coliegi anno 1752. cum præcipites, fæpe abruptos, planeque horridos illius montis fcopulos non fine vitæ difcrimine perluftrarem. Sola etenim inter faxa \& nivem inhabitat montis verticem reliquis ftirpibus plane defertum.

Quamvis brevis admodum fit Bocconi defcriptio, \& rudis, quam exhibet icon, utramque tamen cum mea Viola conferens eas reperio notas, quibus comprobetur - revera hanc illam Violam effe, cujus Bocconus meminit. Magnitudo totius plantæ fiquidem, foliorum forma, quæ revera inter nummolarium, \& alfinem eft, floris demum color a Boccono adnotatus fatis bene refpondent; fed quod evidentius argumentum præftat, eft ftipularum in hac Viola forma, \& pofitio, qux non obfcure ex icone Bocconi colligitur. Verum quidem eft Bocconi Violam ex montibus Corficæ, meam ex Valdèrianis natales fuos trahere; at quis ignorat alpium etfi fub diverfifinno colo pofitarum fimile ingenium effe, \& eafdem in utrifque ftirpes crefcere. Diferte admodum, \& egregie hac de re loquitur Clar. Linnæus (a) obfervans maximam pảr(a) Proleg. ad foram Lapponicam as S. 7. ad I5. 


\section{8}

partem ftirpium Alpium Lapponicarum; etiam in Helveticis Alpibus reperiri, imo in Monte Ararat ttirpes crefcere, quæ in Alpibus Lapponicis etiam nafcuntur: quid plura? Non paucas ipfe Bocconus enumerat ftirpes, quæ \& in Corficæ montibus, \& in Sabaudicis Alpibus crefcere animadverterat. Verum ad ejus defcriptionem veniamus .

Radix filiformis duriufcula, \& fubpurpurei coloris varios plerumque mittit caules, primum fubrubentes, dein virides, feu potius varia mittit capita in cauliculos abeuntia. Cauliculi erecti funt, nunc ramofi, nunc minime; toti fere fquammis teki, quæ ttipulæ funt aut novorum, aut veterum foliorum; ex alis Atipularum copiofa oriuntur folia cordato-acuminata, quæ femuncialibus infiltunt pediculis. Folia duriufcula funt, tantillum venofa, glabra, nihil omnino in ambitu denticulata, fed integerrima. Inter folia ex iifdem alis pedunculi florigeri pediculis foliofis altiores. Flos non magnus ut in Viola grandiflora, nec minimus, fed æqualis fere cum Viola martia amplitudinis; color floris cæruleus cum nigris radiis : trium inferiorum petalorum ungues albicant. Nectarium breve: floris odor vix aliquis. Ad fingulos pediculos hæret ftipula, quæ foliolum eft lineari-tridentatum, dente medio longiori. Fructum maturum non vidi. Tubæ apicem craffum, \& perforatum memini obfervaffe.

Nullam Auctores Botanicos diligenter evolvens Violam inveni, quæ ad hanc referri poffit . Notas, quibus a reliquis difcriminatur, conftituunt, folia omnia cordato-acuminata integerrima, ftipulæ tridentatæ, \& ramofus, feu caulefcens, licet humilis, plantæ habitus. Ex hifce omnibus perfpicuum erit neutiquam confundi poffe cum Viola paluftri rotundi-folia glabra Morifoni (b), qua ab Hallero (c) Viola acaulis foliis zeniformibus appellatur. Qui noftram cum ea confer $\in t$, jam apertiffime diverfam effe concedet.

ACHIL -

(b) Hif. Oxonienf. Tom. II. p. 475 .

(c) Enum. .l. helvet. p. sol. 


\section{AC.HILLEA FOLIIS PINNATIS, LANUGINE TOTIS OBDUCTIS , FLORIBUS ALBIS UMBELLA'TIS. Hall. En. helv. pag. 7 I 3 .}

T A B. II.

F $\mathrm{X}$ radice repente fubnigra, \& fere lignofa oriuntur cauE liculi quandoque plures, quandoque unus, quorum altitudo palmum non excedit. Folia ad radicem plurima, eaque ex longo plano petiolo elliptico-oblonga forma figurata. Caulina fimilia funt, fed breviori nituntur petiolo, ita ut fumma feffilia fint. Omnia pinnata, \& pinnas exhibent nunc lineares indivifas, nunc trilobas, aut tribus dentibus profunde fectas . Maximopere tomentofa ftirps eft tam denfo villo prædita, ut fub illo pinnæ, \& earum dentes ferme occultentur. Idcirco, quo foliorum figura, $\approx$ pinnarum varia compofitio pateret, duo foliola diftincte delineari voluimus. Cauliculos umbella terminat, quæ fit ab octo perfope floribus femunciali pedunculo gaudentibus. Calycem floris componunt plurium ordinum fquammæ, quarum exteriores tomentofæ. Omnes pallide virent oram habentes nigram, criftatam, feu potius fimbriatam; femiflofculi octo, vel decem, albi, ad limbum incifi, fere quadranguli; flofculi lutei viginti circiter; femina fequuntur tetragona nuda fufci coloris : flofculis, \& femiflofculis interjacent fquammæ memoratis calycinis fimiles, unde receptaculum paleaceum .

Primus omnium hujus herbæ meminit Folix Platerus, ex quo habuit Joannes Bauhinus, \& appellavit Millefolium alpinum, incanum flore $\int$ peciofo $(a)$. Sub hoc nomine etiam indicarunt Robertus Morifon ( $b$ ), Rajus (c), Tournefortius B

(a) Hif. pl. iii. pag. 148. (d),

(b) Ox. iii. pag. 39. T. xi. f. 2.

(c) Hif. pl. 347., or Syll. ext. p. 18 . 
10

(d), \& Joannes Jacobus Scheuchzerus (e). Sub eadem etiam appellatione venit in Chabræi Sciagraphia cum eadem prorfus icone, \&x defcriptione. Bocconus eam diverfe indicavit fequentibus nominibus Millefolium alpinum tomentofum, odoratum nanum $(f)$, millefolium tomentofum odoratum $(g)$, Millefolium alpinum, huimile, incanum, odoratum flore albo $(h)$. Prima duo Bocconi Synonima etiam enumerat Joannes Jacobus Scheuchzerus, fed Bocconus nullum de Bauhini nomine verbum facit .

Si defcriptio excipiatur, qua Hallerus ftirpem hanc illu* Atravit, nihil boni eruere licet five icones, five defcriptiones confulantur. His de rationibus confido pleniorem, quam dedi, ejus hiforiam acceptam futuram effe.

In Valefiæ Montibus fuam invenit Fœlix Platerus, Scheuchzerus in altiffmis Averfanis, \& Prægallienfibus jugis, nec non in Furcæ altiffimi Montis boreali parte. Ibi etiam lecta fuit a Præcl. Hallero; Bocconus utriufque Montis Cenifii indigenam facit, fed copiofias adhuc nafcitur ubique in fummis fcopulofis, \& nivolis Alpium Cottiarum jugis. Alpicolæ Montis Cenifii cum Genepi confundunt, \& herbam della rotta etiam vocant, quod etiam jam fuo tempore adnotaverat Bocconus (i). Cæteri alpicolæ diftinguunt Herbam della rotta, \& Genepi, fed Genepi nomen neque unam eandemque $A b / i n-$ thii alpini fpeciem perpetuo frgnificat; hac Herba della rotta longe differt ab.ea, quam Matthiolo indicavit Cortufus, \& polt J. Bauhinum Chabræus in fua feiagraphia recenfuit, \& hoc quidem de difcrimine jam dubitaverat Bocconus $(l)$. Hujus Herbæ della rotta integra, \& abfoluta defcriptio infra tradetur.

Aro-

(d) Inft.p. 496

(e) It. 2. p. 138 , in itinere vero iv. $p .338$.

(f) $\mathrm{Mus} . \mathrm{p} \%$ p. I66.

(g) L. C. Tab, I 20.

(h) Mis di fper. pag. I9I.

(i) Mul. pl. p. 166.

(1) Muf. di jper. pag. IgI. 
Aromatica ftirps eft hæc Achillea guftu acri, \& amaro; magnæ eft aftimationis apud omnes Alpicolas. Utuntur ea ficuti $G e$ nepi ad fudorem pellendum, ad ventriculi \& abdominis dolores, quos non raro afferunt gelidæ nivales aquæ, quas bibunt. Nulla domus ea caret, \& ipfis eft tamquam medicina quædam univerfalis .

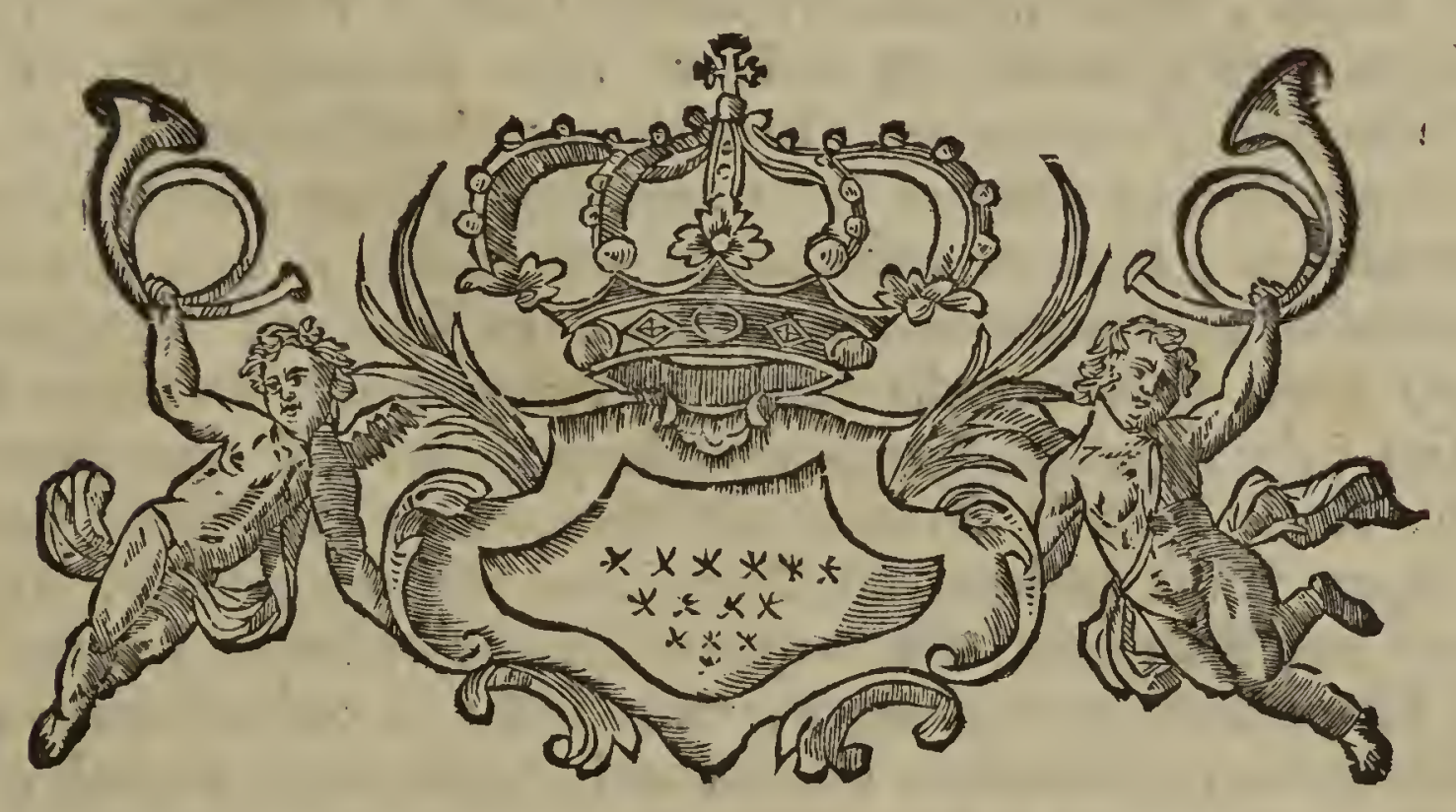




\section{ACHILLEA FOLIIS INTEGRIS, ODORATIS, CUNEIFORMIBUS, IN APICE DENTATIS.}

\section{T A B. II.}

$\mathbf{P}$ Aucr Botanici eam viderunt Achilleam, quam nunc defcribendam fufcipio. Olim Antonius Cortufus hanc Achilleæ fpeciem ad Matthiolum mifit (a) Eupatorium Mefues flore albo vocans, eique fignificavit Herba rotta in Pedemontio, alibique vocari, \& multam nafci in Valle di Lanze, \& in Valle Sancta fidei Patavinorum. Joannes poftea Bauhinus $(b)$ a Valerando Dourez plantam hanc cum defcriptione acceptam commemorans, Dourez defcriptioni ea addidit, quæ Antonius Cortufus ad Matthiolum fcripferat. In Chabræi Sciagraphia (c) icon, \& defcriptio Bauhiniana repetuntur. Robertus Morifon $(d)$ appellat Ageratum Alpinum latiore, \& rotundiore folio: Rajus Joannis Bauhini defcriptionem (e) referens monet propter flores radiatos ad Ptarmicam effe referendam. Neque poft hos Botanicos ulla amplius facta hujus herbæ mentio eft.

Ex radice lignofa, nigra, varie inflexa, cefpitis inftar caules oriuntur fpithamam circiter alti, filiformes, rotundi, virides, ad quorum radices folia plura congeruntur, in caule cæterum rara. Craffula, fuccofa, glabra, cuneiformia, feffilia funt, ex angufto principio fenfim in fubrotundam formam ampliata. Foliorum apex in primis foliis feptem dentatus; quinque dentatus vero in fecundis; in fummis tridentatus, aut etiam integer.

Cau-

(a) In Epiftola editu in Commentariis Mattbioli polt Aubtoris prefationem.

(b) Hift. iii. p. I. p. 144.

(c) $P .368$.

(d) $O x_{0} 42$.

(e) Hift. 364 . 
Caulis terminatur corymbo florum, feu radiis fex, aut novem, aliquando etiam paucioribus, fubincanis, uncialis, aut femuncialis longitudinis, quorum quilibet fert florem unum, rariflime duos. Calix cylindricus potius eft, quarn hemifphæricus, ab inæqualibus, viridibus, imbricatis fquammis conftitutus. Semiflofculi ovato - quadranguli, albi, ofto plerumque, nunc uno, nunc duobus dentibus incifi cum tuba bicorni. Flofculi autem albi etiam funt a 10 . ad 20., quinque partiti, eorumdemque ftamina quinque fuftinent antheras luteas coalitas, quibus interjacet tuba bicornis, lutea, flofculis altior. Thalamus floris paleaceus eft.

Placuit Achilleam, non Ptarmicam, vocare, Clariffimorum in re Botanica Virorum veftigiis infiftendo, qui Millefolii, \& Ptarmica genus conjunxerunt; nulla enim fuppetit nota hæc duo genera diftinguendi five folia, five calycem fpectemus; a quibus unice peti poffet. Achillea ex. gr. foliis pinnatis, lanugine totis obductis, floribus albis umbellatis Hall. calycem habet hemifphæricum, folia vero millefolii æmula, \& inter millefolia recenfuit Tournefortius. Quæ. vero eidem Auctori Ptarmica alpina, tünaceti folio, fl. purpureo eft, calycem oftendit cylindricum; in Ptarmica demum alpina matricaria folio Triumf. obf. 88. calycem conico cylindricum effe animadverti ; unde patet optimo omnino jure Ptarmicæ, \& Millefolii genera in unum reduci .

Oritur in locis ficcis, \& faxofis fecus torrentes in Valle Lantii, uti quoque in Alpibus Valderianis, \& Vinadienfibus, ubi maximi habetur pretii ad omnes morbos. Vehementem aromaticum odorem tenet, qui omnino exhibet odorem Ballamita minoris Dod. pempt. 295. ejufq. vires habere obfervatio docet. 

UNIFORMIBUS, PEDUNCULIS CAULINIS.

\section{T A B. II I.}

F ODEM prorfus loco, quo Campanula plerumque multicauH lis, uniflora, foliis ovatis feffilibus integerrimis, collecta \& eft hæc Violæ fpecies, quæ radicem habet longiffime inter diffractorum fcopulorum lapides repente, \& varia dein funderitem capita, ad quæ multa nafcuntur folia ovalia, tenera, fuccofa, glabra, minime venofa, obfcure virentia, \& longe petiolata. Hæc folia cauliculum fine ordine exornant uncialis ad fummum altitudinis, qui deinde in fummo producit ex alis foliorum duo, fed frequentius unum pediculum. uncialis longitudinis cum flore magno nitide purpureo; Viole montance cerulese grandiflore H. R. Par. adinftar, fed paullo majoris \& obfcurioris coloris. Calyx, flos, tuba nihil differunt \& nifi folia diverfitatem oftenderent, eamdem diceres.

Folia tenera cum fint, ad ambitum uno, alterove loco nonnunquam erofa funt, ut crenas mentiantur; videant ideo Botanici num ad noftram fit deducenda Viola petraa, bufambarenfis, crafulo, crenato ocymi folio flore majore inodoro caruleo venis candidis diftincto Cupani $(a)$.

Viola acaulos flore foliis multo majore Hall. en. 502. diverfa a noftra eft foliis folidioribus, \& dentatis .

(a) Hort. catho. 230 


\title{
SEDUM ERECTUM, RAMOSUM, FOL IIS PLANIS, FLORIBUS ALBIS LONGE PEDUNCULATIS.
}

\author{
T A B. III.
}

R Arissimam exhibeo Sedi fpeciem, de qua nullam plane 12 notitiam apud rei Herbaria Scriptores reperire datum eft.

Cauliculus ei tenuis, filiformis, erectus, ramis hinc inde $\&$-fine ordine diffufis; folia ad ramificationes potiffimum apponuntur fere feffilia, tenera, fuccofa, venofa funt, \& veluti ex adfperfa pruina Mefembryanthemi, chryftallini plantaginis folio undulato $(a)$, adinftar pulchre nitentia. Foliorum forma ex elliptico acuminata, fed hæc forma quidem in primis \& fecundis potiffimum le fe monttrat; nam poftrema admodum variant nunc angufta, nuinc fere rotunda. Rami finguli in tenuifimos pedunculos abeunt femuncialis, aut etiam uncialis longitudinis, qui florem fuftinent album pentapetalum, calyce quinquefolio exceptum . Corolla patens eft, \& calyce amplior. Petala elliptica funt, paullifper acutiora, quam ico ne repræfentetur, extus levifime virent cum in interiori facie albiflima fint; ftamina decem funt, alternis brevioribus, \& circumdatur ab is ovarium, quod ex quinque coalitis vaginulis fit. De'fructu, \& femine nihil licet addere, quoniam maturitatem femina nondum caperant, quo tempore ftirpcm hanc collegi, quæ nullibi deinceps obvia fuit, nec illius loci denuo invifendi fe fe poftmodum obtulit occafio. Eam reperi anno 1746. fub initium Augufti menfis in Valle Valdenfum S. Martini fecus viam, quæ ab oppido Le perrè ducit ad

(a) Dill. Hort. Eltb. 
16

ad oppidum Pralles. Viam ibi importuni impediunt ingentes lapides ex altiffimis proximis rupibus decidui, fub quorum concamerationibus fe fe abfcondit.

Quandoquidem Sedi hujus folia aliquomodo ad Lentis fructus figuram accedunt, dubitare aliquis poffet, num de hoc Sedo intellexerit Mauritius Hoffmannus, qui Aizoi, feu Sempervivi fpeciem ex Monte Baldo fequenti nomine defcribit. Aizoum, five Sempervivum alpinum M. Baldi fol. lenticulatis flor. non punctatis $(b)$. Hujufce Sedi, quod Baldi Montis indigenum facit Mauritius Hoffmannus, nulla plane cognitio $a b$ iis, qui Veronenfes thirpes defcripferunt, eruitur ; \& præclariffimus, amicifimufque vir Joannes Francifcus Seguier, qui Veronenfem agrum, montemque præcipue Baldum diligentiffme perquifivit, doctiffimeque illuftravit; cum eum de Sedo hoc Mauritii Hoffmanni per literas interpellaffem, certiorem me fecit nullum fibi adhuc Sedum occurriffe, quod cum memorato conveniret. A clar. Hoffmanno recenfitum Sedum minime filuit Chriftianus Mentzelius, fed Hoffmanni nomen repetens albis floribus effe fuperaddit $(c)$.

Quod pluribus ftirpibus , 8 nonnullis etiam Sedi fpeciebus contingit, ut foliorum color per ætatem ex viridi in rubrum colorem degeneret, id mihi domum, itinere abfoluto, poftmodum repetenti in Sedo hoc contigit obfervare; $\&$ fi ruber color acidum indicat quemadmodum a doctiflimo Linnæo ( fund. bot. 364. , Sift. nat. editio Lipf. anni 1748. p. 218 ., P.hil. bot. 286.) affirmatur; optimo jure conjicere licebit communes cum hoc Sedo eas omnes virtutes effe, quas habent non paucæ Sedi fpecies, quæ acido fapore donantur.

(c) Ind. Uniw. 


\title{
SAXIFRAGA FOLIIS PALMATIS, CAULE DENSE FOLIOSO, ET FLOR I GERO.
}

\author{
T A B. II I.
}

A Uctores, qui de re Botanica feripferunt, quotquot haA bere potui, diligenter evolvens nullum $a b$ iis fieri verbum video de hac Saxifraga, cujus locus natalis eft Alpis Albergian in quodam humido, \& fcopulofo receffu .

Villofa, \& vifcofa in univerfum eift; folia ad rádicem multa in orbem congefta, craffa, profunde, \& obtufe quinquedentata. Caulis vix digitalis, foliofus, foliis longe petiolatis. profunde; \& inæqualiter aut quinque, aut tribus etiam den tibus fectis. Ex alis pedunculi foliofi nunc fimplices, nunc ramofi, flore albo fingulis ramis infidente. Folia floralia ad ortum florum pofita integerrima: ovarium fub flcre eft, maturum non vidi .

A notis huc ufque Saxifragis, ut exiftimo, difcriminatur caulibus denfe foliofis, $\mathcal{E}$ florigeris. Saxifraga foliis brevibus palmatis denfiffrme congeftis Hall. (a) humilior eft, flores habet potius umbellatos petiolis unifloris, præterea nullam nec villofitatem, neque vifciditatem oftendit. Saxifraga tridactilites groëlandica, cauliculis valde foliojis Dill. (b) folia triloba habet cauli appreffa cauliculis, poftquam nudi facti funt, umbellas florum fuftinentibus. Saxifraga demum foliis omnibus

C

an-

(a) Enum. belv. 404 .

(b) El:h.p. $337 \cdot T \cdot 253 \cdot f \cdot 329$. 
18

angufis, petiolatis in apice tridentatis; Caule foliofo; ramofo; vifcido (c) a noltra difcrepat foliis longe petiolatis, profunde trifidis $\mathcal{E}$ ramis nudis.

Pleræque alpinæ Auctorum Saxifragæ noftris etiam in Alpibus reperiuntur; duas alias teneo plane novas, \& alio opere, fi Deo placuerit, defcribendas cum aliis non paucis noviflimis noftratibus tirpibus.

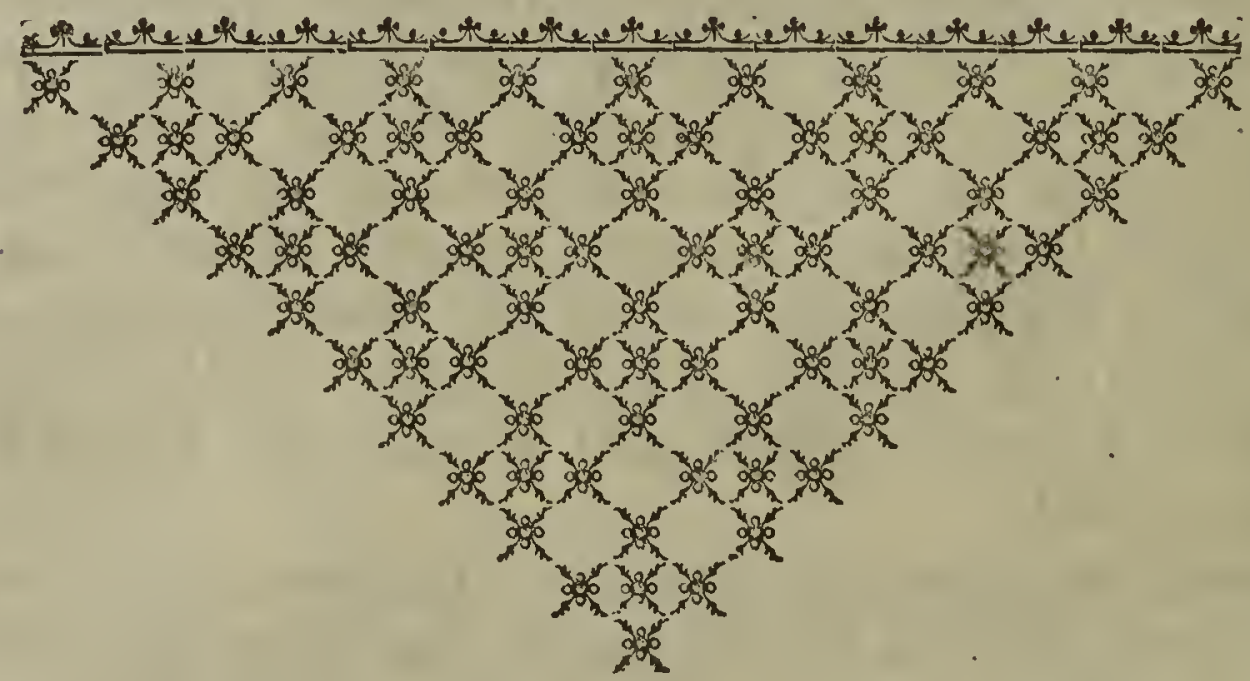

VE-

(c) Hall. bo co 


\section{VERONICA C A ULE SIMPLICI, FLORIBUS CONGESTIS TERMINATO, FOLIIS OVA'TO-ACU'TIS, DENTATIS.}

\section{T A B. III.}

F Irmis, duriufculis cauliculis fe fe erigit Veronica hæc, If quam in faxofis fummæ Alpis Albergiam dictæ fupra oppidum Fæneftrellarum pofitæ adinvenimus . Cauliculi rotundi funt digitalis altitudinis, tria plerumque ex oppofito nafcentium foliorum paria habentes, folia feffilia funt, erecta, ovato-acuta, quinque aut fex dentium paribus. In fuperiori facie ferme glabra funt, in averfa rugofa, nihil hirfuta; flores in fpicam laxam breviorem congefti, capfula cordato-ovalis cum multo femine.

Non video ab Auctoribus Botanicis commemoratam hanc Veronicam, nifi aliqua ex Michelianis num. Io. II. I2. (a) recenfitis ad hanc fit referenda. Procul dubio diver$f a$ eft a Veronica, caule non ramofo, floribus congeftis terminato, foliis ovatis pene glabris Hall. (b), foliis non crenatis, firmioribus, fed dentatis, \& in averfa parte rugofis. Folia deinde in Veronica memorata Halleri lices $\mathrm{C}_{2}$ mul-

(a) Mich. H. flor. p. 99.

(b) Enum. p. 53., Tab. xii, fo 2. 
20

multum varient $(c)$; non tamen eam formam ovato -acutam acquirunt. Præterea Veronica illa fæpius cauliculos habet inflexos, \& refupinos; hæc recta frme fe fe erigit.

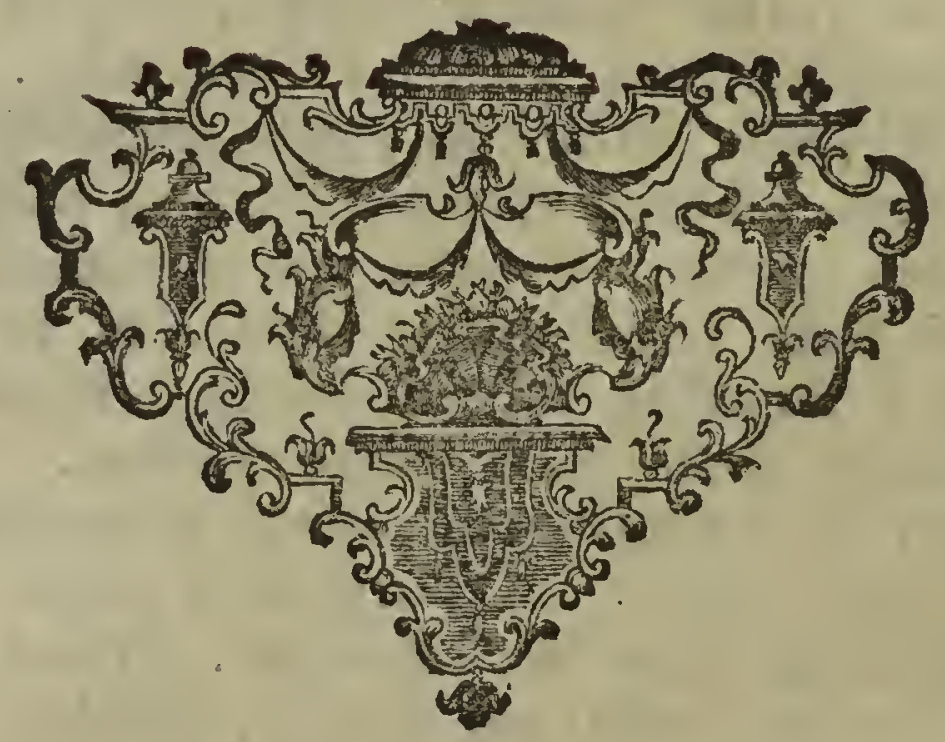

VE-

(c) Mirum diqu, quantum variet hæc Veronica: nunc folia fenfim decrefcunt, ut fuperiora lineari elliptica fint; nunc æquali fere magnitudine progrediun. tur; nunc contraria omnino ratione prima cum parva fint, qux fequuntur majora fiunt, poftremo florum capitulo fuppofito, omnium maximo. Foliorum crenæ quoad numerum etiam inconftantes, \& in quibufdam fpeciminibus fere deficiunt. Alritudo incerta eft: teneo fpecimina a femunciali ad digisalem. 


\section{VERONICA REPENS, EX ALIS SPICATA, FOLIIS RO'TUNDIS, FIRMIS, GLABRIS, DENTICULATIS.}

\section{T A B. IV.}

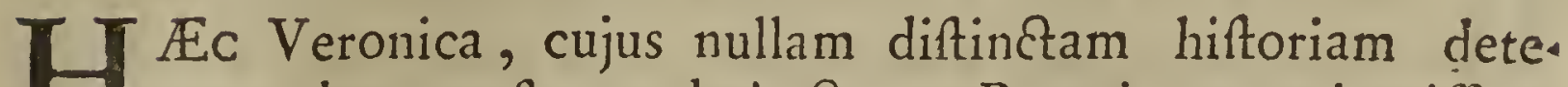
1 gere datum eft apud Auctores Botanicos, vulgatifima eft in Alpibus Pedemontanis. Alpes Cottia, Valderiane, Vinadienfes, Sabaudice $\&$ c., ubique copiofe habent, nec ea defideranda venit in Alpibus etiam Nicienfibus . Magnæ æftimationis eft apud nos, \& antefertur feu Veronice fupine vulgatiffime officinarum C. B., feu Veronicæ teucrii veri nomine (a) a Berolinenfibus Medicis celebratæ.

Duris, rubentibus, nodofis, \& lignofis virgis, \& fæpe ramofis repit, uti Veronica fupina vulgatifima, folia oppoitia nafcuntur, firma, dura, utrinque glabra, nitentia, minutiffime denticulata; ex nodis, ad quos folia oriuntur, radiculas fæpe demittit, quibus firmiter telluri inhæret, \& ex fummis alis florum denfa fpica cum pedunculo unciali. Flores in icone male exprimuntur, nec optime in flore, quem rejunctim pingi curavimus. Flos, qui colcrem exhibet cæruleo-violaceum, difformis eft; fegmentum nempe fuperius ovatum, amplum, minora, \& angufta lineari-rotunda lateralia, cum infimo adhuc anguftiori. Fructus fequitur oblongus, cordatus, polyfpermus.

Foliis maxime glabris \& duris nihil omnino aut ftrigofis, aut hirfutis differt a Veronica Jupina, \& vulgatiflima. Videndum num ad noftram pertineat Veronica mas repens pirenaica, folio longiori, glabro fchol. Bot., Plukn. phitogr. Tab. 233. fg. I. Tourn. inft. 143.

[a] AEt. Berolin. Vol. 11. n. s. 


\title{
An ARETIA GLABRA, OBTUSI-FOLIA; UMBELLIFERA. Hall. helv. 486 .
}

\author{
T A B. IV.
}

$R$ Adicula eft huic Aretia fubfufca, \& repens, ex qua folio1 rum rofulæ plures aliquando, fed fæpius unica. Lingulata folia funt, elliptica, fine obtufe acuminato, tenera, venofa, dilute virentia, \& glabra. Inter hæc, fed non e rofularum centro, fcapi exeunt filiformes, variæ altitudinis ab unciali ufque ad palmarem altitudinem umbellam florum ferentes, quorum radii, feu pedunculi florigeri, inæquales. Frequentius duo, aut tres funt, raro plures, \& ad ortum pedunculorum ftella ex quinque foliolis acutis inæqualibus. Calix floris femiquinquefidus luteo-virefcens . Tubus floris cylindricus, brevis fegmentis ovatis integerrimis. Antheræ in collo corolla fitæ. Floris, qui cum umbilico luteo pallide rubet, centrum ut in heliotropio plicatur, plicis glandulas.nectariferas occultantibus. Fructus intra calycem maturat rotundus, qui quinque valvis aperitur, \& femina nigra, quodammodo reniformia continèt .

Flores in hac Aretia conftanter fatis nafcuntur umbellati ; varietas tamen flore fingulari mihi $\mathrm{fe} f \mathrm{fe}$ obtulit in Monte Cenifio ad fummas rupes la Turra, eaque carebat calyce communi. In jugo etiam editiffimo Alpis $J$ aillon mixtim nafcitur utraque Halleri (a) Aretia villofa, Scapis nempe unifloris, \& multifloris, quæ cum folo numero floris radiorum differant, in reliquis fimiles, in unam jungi fpeciem poffe exiftimarem, eo vel maxime quod in duabus etiam aliis Aretiis eandem variationem deprehenderim: in Aretia, nempe, foliis linearibus,

(R) L. Ga 
bus, fcapo paucifloro Halleri ( $b$ ); quæ varietas jamdudum Botanicis nota elt; \& in altera Aretia (c) in fummis noftrarum Alpium herbidis jugis frequentiflima, \& cujus copiam mili fecit amicus meus fingularis D. Gagnebin in fummo Pyrenæorum Monte du Canigou repertam . Ea omnino accedit Aretice foliis ciliatis, linearibus, floribus umbellatis Hall. (d) foliorum durorum obfcure virentium rofulis, umbellarum conformatione, floribus, qui purpureo-violacei funt ; fed differt folits ne minimum quidem ciliatis.

Quæ a nobis exiftimatur effe Aretia glabra, obtufi-folia, umbellifera Halleri, multa nafcitur in herbidis, nivofis jugis $D u$ $V$ allon fupra cels in Valle Exilliarum, \& copiofe etiam in utroque Monte Cenifio-. Dominus Välle (e), qui infignis

ex-

(b) L. c.

(c) Raro apud nos occurrit Aretia foliis linearibus, glabris, fcapo pawcifloro Hall.

(d) L. c. num 5.T. 7 .

(c) Hujus egregii Viri cum in rem herbariam merita non cxigua fint mihi liceat hic ejus vitan breviter indicare. Fuit is Medicinæ Doetor Taurinenfis, qui tum Alpium, tum agri Taurinenfis plantas fedulo inquifivit. Cum magna flagraret herbas, \& naturalia quxque nofcendi cupiditate, avide occafionem arripuit, quæ ipfi fe fe obtulit Corficam petendi: anno enim 1747. exercitum noftrum fecutus eft Medici munere fungens. Quanta diligentia poruit, \& quantum per ipf concreditum officium licuit, herbas, femina, conchilia, infecta, \& quæ reliqua fibi obvia erant, collegit. Sibi interim non cavens, \& nulli labors parcens fub fervidó cœ!o, \& calidiffima tempeftate, febri ardente corteptus, trium dicrum fpatio mifere e vivis fuit ereptus. Collectio herbaria ad barbaras ignorantium manus polt ipfius obitum cum perveniffet, a quibus res inutilis habebarur, peffumdata fuit, ut ne ejufdem quidem fiuftulum in Pedemontium devenerit. Qux reliqua reperta domi fux funt hic Auguftæ Taurinorum feu collektiones, feu manufcripta ab illius heredibus coémi Doleo tamen non omnia fua adinveniri potuiffe. Collectiones duæ ad manus meas pervenerunt tantummodo; una herbarum quas circa Savonans reperit, \& raras aliquot continet. Altera illarum ftrpium eft, quas anno 1744 obfervaverat, dum Montes, \& Alpes Segufii, Exilliarum, \& Fenefirellarum perluftraret. Illarum hiftoriam fcripfit juxta Tournefortii methodum difributam, \& compleetitur ornnum, quas repererat, ftir. pium defcriptionem cum loci natalis adnotatione; fed hujus urilis, \& operofi laboris libellus unus folum. repertus eft, quatuor prioium clafiums herbas recenfens, \& defcribens: 
24

extitit Taurinenfis Botanicus eamdem Aretiam legit ad dexteram viæ, quæ ex Monte $V$ allon de Chaumont ad alium fuperiorem ducit Craye du credenage appellatum.

Apud Auctores Botanicos Synonima nulla invenio. Hallerus $(f)$ dubitat hanc effe pofle Androfacem perennem, alpinam, anguflifoliam, glabram, \& multifloram Tournefortii, quam Tournefortii Androfacem ad aliam alibi refert $(g)$ fed memorata a Tournefortio fpectare potius videtur ad Aretiam foliis linearibus glabris, fcapo paucifloro Halleri .

Aretia genus ab Hallero eft inftitutum, qui vidit has androfaces fpecies ab Androface Matthioli differre tubo floris cilindrico, calyce non ferrato, E corolla decem glandularum fub origine fegmentorum poftarum quibus ftatutis \& inter Aretiæ fpecies locum mereri poffe videtur rara quædam plantula, in Helvetia nondum obvia, \& in Alpibus, quæ Monte Vefulo, \& Monte Cenifio interponuntur longe frequentiffima, de qua liceat nonnulla hic fubjicere.

„Ex tenui radicula ea oritur, \& humi jacens cauliculis re"ptat valde ramofa; rami pene nudi funt, \& rubent; ad ra"morum divifionem denfus eft floccus foliorum, quæ lanceata " funt, fefflia, ex viridi cinerea, breviffime hirfutula, unciæ "Parifienfis trientem longa, dimidiæ lineæ latitudine in am"pliori parte. Inter folia ad ramorum originem unus, aut al"ter oritur pedunculatus flos magnus, Luteus Jafmini Lutề "vulgo dicti bacciferi C. B. fere forma, \& amplitudine. Intun"dibuliformis flos eft, limbo in quinque lacinias lineari-elli"pticas, crenulatas, foepius inflexas, fecto: ad fingularum Laci"niarum originem fquammula, \& fub ea glandulæ nectarifera

oc-

(f) L. C.

(g) It. helv. I739. xxxix. Refert nimirum ad fedum alpinum alterum lackeo flar: pannonicum Cluf. pannon. p. 4\%9. 490., h. e. ad Arefiam villofam; nec aliter. habet in nova opufculorum fuorum Botanicorum editione, que prodit Gottingæ anno 1749. 
, occultantur. Antheræ quinque cum filamentis breviffimis ad ", collum corollæ fitæ, erectæ, conniventes. Stylus tubo floris ", longior: Atigma rotundum. Calix tubo floris paulo brevior, ", erectus in quinque longa lineari-acuminata fegmenta divifus. „Fructus intra calycem maturat, qui fit capfula globofo-acu„; minata, calyce non omnino tecta, femina nigra pauca, mà"gna, ex una parte triata, altera concava continens.

Hanc Atirpem primus defcripfit Fabius Columna (h) Sedi alpini $F$. Gregorii Regienfis nomine. Deinde vero eamdem. Tournefortius ( $i$ ) recenfet (l) vocans Auriculam urfi alpinam, gramineo folio, Jafmini Lutei flore, quo nomine fed vitiato $(m)$ enumerat Tilli in Horto Pifano.

Novum tandem ex hac ftirpe $(n)$ genus conftituit Leonardus Sesler $(0)$ a celeberrimi viri, nunc in Univerfitatenoftra Botanices Profefforis, nomine Fitaliana dicta, appellaturque ei Vitaliana, perennis, repens, foliis oblongis, integris, anguftis, acutis, caule laxe ramofo, floribus magnis folitariis luteis, petalis inflexis. Columnæ fynonimum addit hic Auctor, nil vero innuit de Tournefortii nomine, quod ad hanc plantam pertinere adnotavit Vir naturalis Hiftorix maxime gnarus Jofephus Monti Bononienfis Botanices Profeffor in noviffima $(p)$ quam fecit fuorum indicum editione.

(h) Ecpbr.p. alt.p: 63 .

(i) Inft. 122 .

(1) It 2 fpecifice gramineo folio, \& flore Jafmini Lutei indicatur ftirps hxc, ut pro certo haberi poffit de hac, \& nulla alia Tournefortium intellexiffe.

(m) Ibi legitur Auricula urfi, alpina gramineo folio, Jafmini odore, flore luteo Tourn.

I (n) Agg. al Saggio della ftoria natur. del mar. adriat. del signor Vitaliano Donati pag. 71 .

(o) Diu dubitavi num Leonardi Sesler ftirps eadem omnino cum noftra effet, fed omnem dubitationem fuftulit in re Botanica maxime verfatus Julius Cafar Moreni Pharmacopeus Veronenfis, qui Vitaliane ficcum fpecimen mifit, quo certior hac de re factus fum, \& omnis mea fublata eft dubitatio.

(p) Indices Botanici, to matcria medice Oc. Bononice 1753. quarto p. 74 . 


\section{6}

Videant Botanici, num fedum montanum, perpufillum luteolis floribus Parkinf. $(q)$, \& Primula flore fubfe frli foliis linearibus Linn. $(r)$ ad nottram ftirpem pertineant.

Dixi fub Aretiæ genere poffe comprehendi, ita etiam exiAtimat Illuftris D. Gagnebin, qui præterito anno hujus ftirpis exemplar ad me mifit a fe collectum anno 1730. in fummis Alpibus Embroduni in monte quodam Abbatiæ de Bofodon, \& miffa Atirpi fequens nomen fecit Aretice cauliculis teretibus, foliis linearibus villofis, floribus magnis luteis, feffilibus, fere umbellatis.

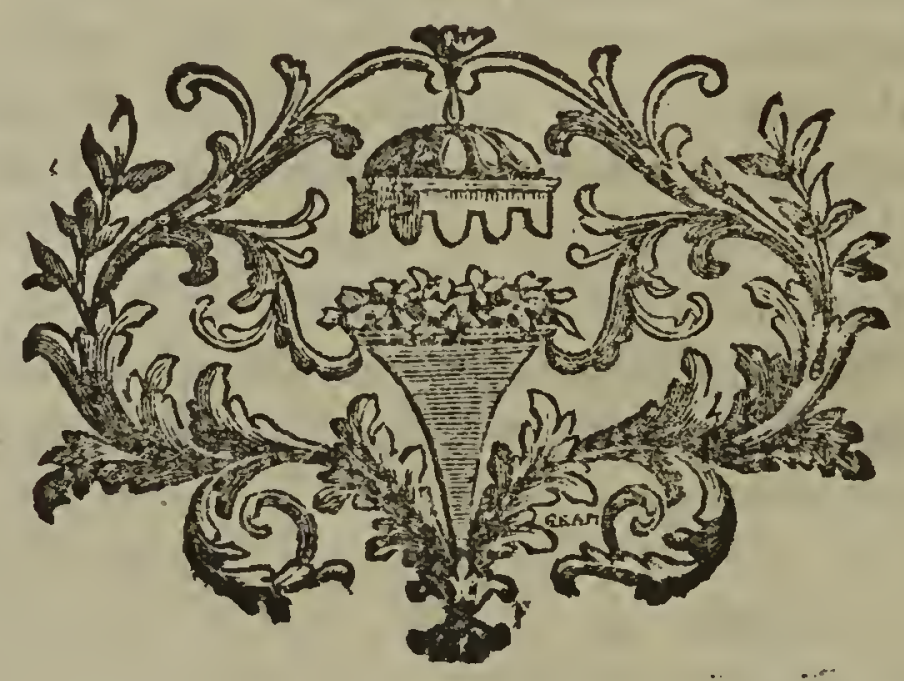

(q) Tbeatr. Botanicum p. 737 :

LE-

(r) Linn. Amoen. Acad. p. 160. 


\section{LEPIDIUM CAULE REPENTE FOLIIS OVATIS AMPLEXI-CAULIBUS Hall. helv. p. 546 .}

\section{T A B. IV.}

T. Ongissime radiculis varie ramofis, \& filiformibus inter lapides repit hæc ftirps, cujus bonam defcriptionem primus dedit Joannes Jacobus Scheuchzerus $(a)$, \& nomen ei dedit Thlafpi alpini, folio rotundiore carnofo, flore purpurafcente Tournefortii, nec Alpina hæc herba fugit egregium Barrelierum. Thlappi etenim ejus montanum, ferrato cepeca folio, flore purpurafcente umbellato $(b)$ huc videtur referendum, uti etiam Thlafpi fubrotundo folio, utriculo gruinali ejufdem (c) ex Halleri obfervatione $(d)$, qui poltremo eam defcripfit, \& novo inftituto géneri Lepidii accenfuit .

Barrelieri icon cum minime bona fit, novam ponimus, cui \& noftram defcriptionem addimus, quod nonnulla etiam adjungenda habeamus .

Radix igitur, ut diximus, tenera \& fuccofa longiffime repens ei eft, multiceps. Caules digitales funt, aut vix ultra, fungofi, fuccofi, ftriati, fimplices, incurvi. Folia ex radice aliquot elliptica petiolata, margine integerrimo, aut modice ferrato ; caulina feffilia fæpius triangularia, apice rotundo, cum alis duabus caulem amplectentibus : omnia craffa funt, fuccofa. Umbella denfa florigera; flores coloris dilute violacei; petala ex longis unguibus lineari-ovata; Flores, qui D 2

ne-

(a) It. Alp. 50.

(b) Icon. $848 \cdot 06 \int \cdot 3^{65}$.

(c) Icon. I 305 . n. I1.

(d) Clar. Juflexus Synonimum effe credidit burfæ paftoris, montanæ; giobulariz folio Tuurn. Hallerus autem ex filicula acuta figura ad lepidium rotulit. 
28

medium umbellæ teinent feriores. Umbella, poftquam flores deciderunt, fpica fere evadit. Siliculæ funt incurvæ, utrinque acutæ cum fpinula; ex duobus valvis navicularibus componuntur. Semina habent utrinque duo, rariflime plura.

Crefcit copiofe in Monte Cenifio in faxofis jugi Ronche dicto; in fummis jugis Alpium Valdenfum etiam collegi.

Siliqua elliptica acuta in fpinulam abeunte differt a Thlafpi, fed nonne inter Drabe, aut Aliffe fpecies enumerari poffet?

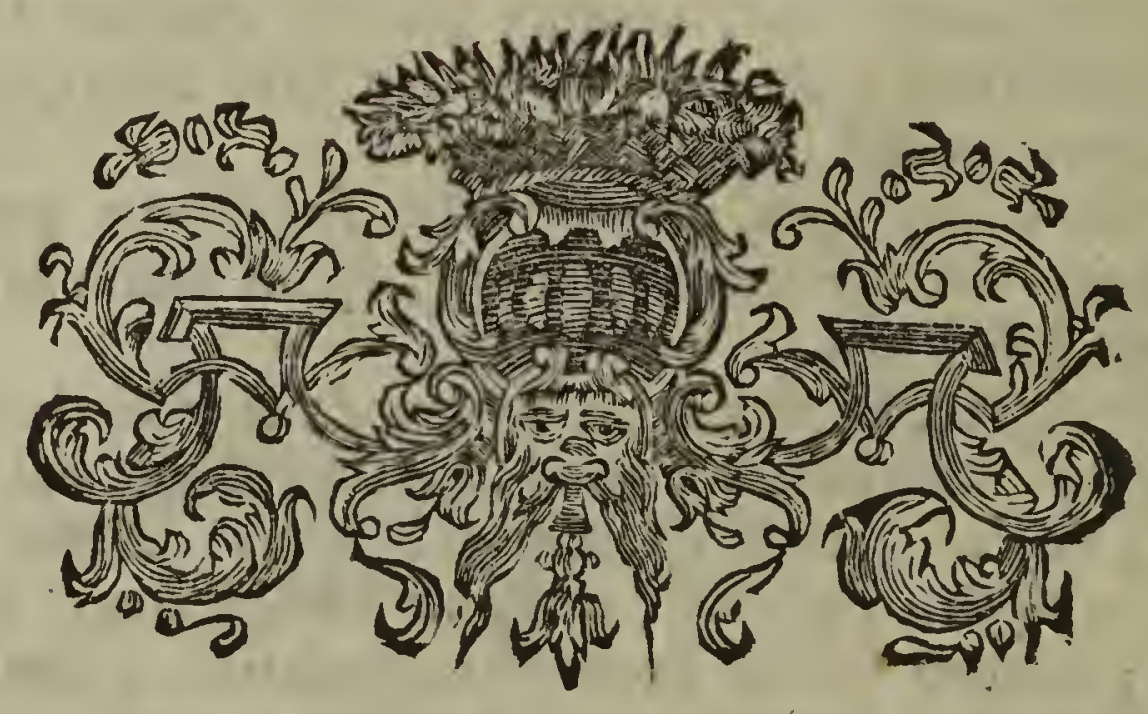




\title{
LYCHNIS FLORIBUS UMBELLATIS OCHROLEUCIS, PETALIS OVA'TIS, FILAMENTIS NIGRIS.
}

\author{
T A B. V. F. II.
}

R Adrx huic Lychnidi eft digitalis, pro plantæ modulo $R$ craffa, obfcure albefcens, fere lignofa, varieque intorta, cefpites rofularum plures fuper terram extendens, quas componunt folia lingulata, fine plerumque elliptico - acuto prædita, \& cofta, feu fulco divifa, uncialis præter propter longitudinis. Inter folia oritur infirmus cauliculus digitum altus, nodofus, \&x ad nodos folia habens conjugata, caulemque amplectentia. Conjugationes tres, quatuorve funt. Cauliculus rotundus eft, \& ejus fummitati infidet florum umbella ; ultimæ nempe foliorum conjugationes porrigunt pediculos, nunc fimplices, nunc femitrifidos fingulos gerentes florem luteo-pallidum, feu ochroleuci coloris. Petala quinque, plana, integra, non emarginata, fed oblongo-ovata unguibus longitudine calycis. Ad Limbi petalorum initium in quolibet petalo fquammulæ duæ erectæ. Filamenta decem, quorum quinque corolla altiora erant; omnia vero ex receptaculo orta nullis cum unguibus adnatis, \& nigri coloris, cujus coloris funt etiam ungues petalorum. Apices ftaminum didymi, \& e viridi cinerei, ftyli plerumque duo antheris longiores, corniculati. Calyx monophillus, tubulatus, viridis, ore quinquefido, \& fructus unilocularis. Prima folia radicalia vix hirfuta; caulina autem \& caulis evidentius, omnium maxime calyx .

Rarus eft in Lychnidum familia luteus color, fed plane nova, \& omnino fingularis hæc coloris compofitio, ut mini- 
30

me dubitaverim ex floris, \& faminum colore pecificum htjus Lychnidis nomen deducere.

$\mathrm{Si}$ attendas, benevole Lektor, ad floris, \& fruetus partes, eafque fimul compares, videbis adeffe in hac Lychnide petala oblongo-ovata, integerrima, cum duobus denticulis ad limbi ortum, Es cum calyce tubuluto, fructuque uniloculari fylos duos, aut tres, famina nulla unguibus jungi, $\mathcal{E}$ totam firper vifciditate carere; quafo igitur cuinam ex generibus Lychnidum a plerifque recentioribus conftitutis inferenda erit.

Mei non eft de Viris doctiffimis, \& in xternum colendis judicium ferre; fed meam, fi permittatur, opinionem adducere, dicam libere, quod mihi videtur, Lychnidis nimirum naturaliffimum $\&$ in fuis fpeciebus plane cohærens genus non effe in tot nova genera refcindendum, genera plantarum potius effe coercenda, quam amplificanda; neque comprobare fcio invectam apud rei herbariæ Scriptores confuetudinem, qua, ut cuilibet placet, \& prout uniufcujufque fiftemati commodum venit, fpecies in genera eriguntur, nominibus aut novis excogitatis, aut, prout arridet, commutatis in maximam ftirpium confufionem. Verum utique eft Lychnidis ampliffimum genus, tot fpeciebus onufum ulteriores diftinctiones expofcere. Lychnidis igitur familia in ordines diverfos dividatur, prout tradendæ plantarum hiftoriæ cuique videbitur opportunum, quæ diltinctio tyrones quammaxime juvabit. Id prætitit optimo fane confilio in Ranunculo ex. gr. incomparabilis Vir Hermannus Boerhavius, cujus exemplum fecutus eft Doctif. Hallerus in Veronica, Viola, Alfine, Gensiana, Pediculari, Allio $\mathcal{E}^{c}$. aliique in aliis ; fed ad ea, quæ reftant de noftra Lychnide fcribenda, deveniamus.

Locus natalis hujus plantæ ent altiflimum jugum Afjette inter Exilliarum, \& Faneftrellarum arcem pofitum; legi etiam in parvo monte Cenifio \& proximis jugis Savine, \& Jaillon.

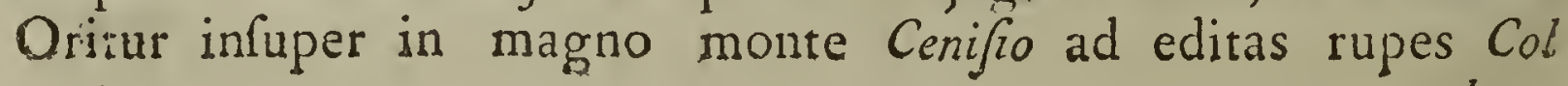


de la fenetra nuncupatas, quæ inminent vico la Ferriere?

A nemine auctorum, quos evolvere datum eft, fermo de hac Lychnide habetur, nifi fortaffe de hac intellexerit Bocconus, qui mus. p. 2. p. 75. Tab. 63. dicit Montis Cenifii incolam efle Lychnidem rubram montanam, globularice capize, $\mathcal{E}_{\text {: }}$ facie. Sed Bocconus fuam ex Barreliero defcribit, qui eodem nomine (a) exhibet ic. 498. Uterque ex Fabio Columna (b). iconem ex integro mutuati funt, ut verifimile fit nec Barre-, lierum, nec Bocconum memoratam Columnæ ftirpem vidiffe, cum iconi, quam fuffurati funt, nihil defcriptionis addiderint. Forfanne Bocconus noftram in monte Cenifio adnotavit, \& ad fuperius dictam Columnæ retulit ?

Quidquid fit certum eft globulariam, luteam, montanam Col. diverfifimam herbam effe, nec oriri in Monte Cenifio, quem attente, diligenterque plus una vice perluftravi.

Nomine Lychnidis minima, pyrenaice umbelliferce Tourn. (c) extat noftra planta in herbario eximii Medici Taurinenfis Laurentii Terranei; fuit is infignis anatomicus, \& edidit de glandulis urethræ tractatum (d), præterea Botanicem coluit, \& ejus cauffa in Alpes noftras multas fecit excurfiones. Immatura, \& acerba morte præreptus breves dies duxit vir longiori vita ornnino dignus; mortuus enim eft anno I7 I4. ætatis annum habens feptimum fupra trigefimum .

Quas in variis itineribus collegerat Atirpes juxta Tournefortii methodum in herbarium redegit quatuordecim voluminibus in folio conftans, quod herbas indigenas plures comprehen-

(a) Uti animadvertit Clar. Juffixus obf. in Barrel. n. 659. rubram pro lutea fcripfit Bocconus.

(b) Globularia lurea montana, col ecphr. p. I. p. 153 .

(c) Hallerus vocavit hanc Lychnidem Tourn., Silenem foribus in capitulum cone geftir, qux tum a noftra hac, tum a Lycbnide globularie capite, O facie Barrelieri, \& Bucconi differens eft.

(d) Laurentii Tcrranei de glandulis univerfim, So Speciatim ad uretbram virilem no. vis Taurini 1709.8. 
32
hendit cum non paucis fuper eas obfervationibus. Optimi viri pretiofum hoc monumentum meum fecit meritiflimus Terranei difcipulus D. Maffola celebris Taurinenfis Medicus, cui ab auctore teftamento fuerat relictum. Ex hoc herbario colligitur optimum hunc virum herbarum cauffa peragratum effe Montem Vefulum, Montem Cenifum, Alpes. Bugellenfes, Canapicienfes, Stamadienfes, Maurianenfes, Augufae Pratoria, $\mathcal{E}$. Sabaudia, Montisferratum; Albigaunii , Garexii, \& Taurinorum agrum.

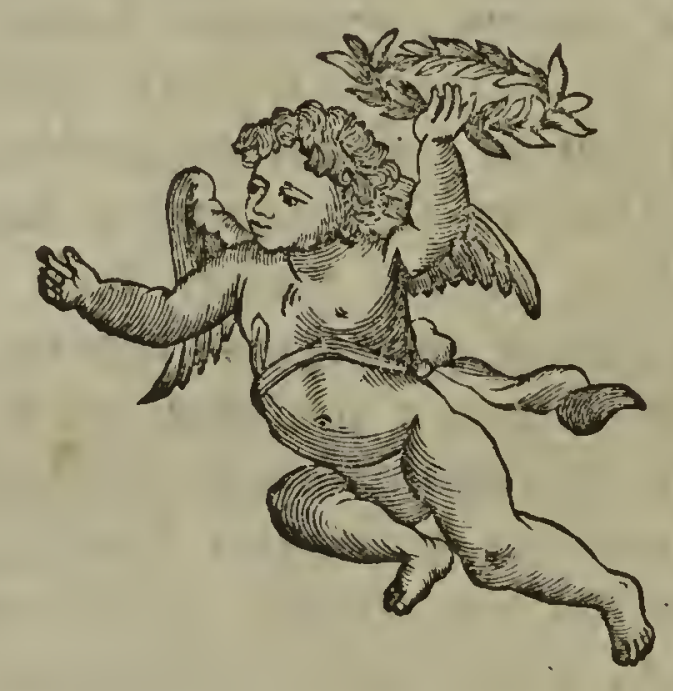


LYCHNIS ALPINA REPENS SAXATILIS, que BEHEN ALBUM VULGO, FOLIO LA'TIUSCULO, ET BREVIORI Ponted.

Comp. 128. eadem fl. purpurascente $e j$. ibidem .

$$
\text { T A B. V. }
$$

$U_{Æ}$ nunc defcribenda venit Lychnidis fpecies, ea ficuti mera Behen albi vulgaris varietas enunciatur a doctiffmo Hallero ; fed reapfe diftincta fpecies eft, uti ex plantæ defcriptione, aliifque animadverfionibus evidenter oftendemus .

Habet hæc Lychnis cauliculos plures repentes, glabros ; nodofos, varie diftortos; qui ex una flexuofa radice exoriuntur: ad nodos ponuntur folia oppofita bina, rotunda, modice acuminata, glauci fæpe coloris, pilis breviffimis evidenter ciliata. Cauliculi nunc fimplices, nunc ramofi, rami ex alterutra ala prodeunt fimplices longis intervallis; rami onnes fuftinent unicum florem Behen albi floris omnino fimilem. Calyx inflatus magnus, ore quinque-dentato. Petala appendiculata, \& in duas lacinias profunde fecta. Hæ Laciniæ nunc lineares funt extremo bi-vel tri-dentato, alias ex angufto fubrotunde finiunt limbi extremo levifime crenulato. Filamenta decem alternis brevioribus, \& cum petalorum unguibus connatis, corollam fuperant paniculatim pofita. Antheræ fimplices viridiufculæ albis filamentis incumbunt. Styli tres primum corolla breviores; deinde antheris tabefcentibus extra florem longiffime producti . Fruetus rotundo - conicus tribus valvis dehifcens, femina angulata, obfcura copiofe includens.

$$
\text { E Na- }
$$


34

Nafcitur copiofe inter mobiles lapides; quibus abundant fæpiffime Alpium fcopuli; frequentior eft in Alpibus Valdenfibus, quam in reliquis.

In rudetis altifimorum Montium Baldi, \& in Vette reperit Doctiffimus Vir Julius Pontedera. Noftram vero cum illa eamdem effe omnino certus fum, eo quod certiorem humanifime per litteras me fecerit laudatus celeberrimus Vir, ad quem olim noftræ Lychnidis fpecimen miferam .

Nunc ergo ad eas veniam tradendas differentias, quibus hæc Lychnis a Behen albo 'diftinguatur ; fi aliquod quidem argumentum ex loci natalis differentia peti poteft, adnotabo in primis hanc nonnifi alpinam effe, \& alpium editiora inhabitare, cum Behen album vulgare fummas alpes non attingat. Ex alpibus in hortum translata nullam fubit mutationem; \& culturæ etiam renititur. Behen album vẹro, uti omnes norunt, ita fe fe propagat ut difficile etiam extirpari poffit; alia certiora difcrimina planta ipfa fuppeditat. Lychnis hæc conftanter cauliculis repetat, nec fe fe erigit. Folia fubrotunda funt, \& fæpe ciliata. Cauliculi, eorumque rami, qui fingulares funt, unico magno flore terminanrur. Behen albi vulgaris folia, licet variæ interdum amplitudinis, numquam fubrotunda evadunt, \& ampliori bafi caulibus adhærent. Caules erecti funt, non repentes, \& ex alis caulium poftremis nati pediculi, fimplices, aut femitrifidi, flores fuftinentes, caules finiunt . 


\title{
CAMPANULA PLERUMQUE MULTICAULIS, UNIFLORA; FOLIIS OVATIS, SESSILIBUS, IN'TEGERRIMIS.
}

\author{
T A B. V.
}

UÆ nunc defcribenda occurrit Campanula, montis $C_{e-}$ niffi incola eft, \& fignatim nafcitur in editiflimo jugo ronche dicto eodem loco, quo inventa eft Viola, quam vocavi folits ovalibus, integerrimis, uniformibus, pedunculis caulinis.

Longa filiformis radix pluribus ortum præitat cauliculis unciam altis, qui foliis ftipantur alternatim nafcentibus, feffilibus, ovatam amplam formam poffidentibus. Quemlibet cauliculum flos unus finit pro plantæ ratione magnus, femiquinque-fidus, patens, cujus Calyx in quinque longos dentes fecatur, \& evidenter hirfutus eft. Antheræ funt longæ cum ftilo adhuc longiore tricorni de mote gentis. Tenera, \& glabra in univerfum planta eft. Folia in ambitu leviflime, \& fubtiliffime hirfuta.

Nihil de hac Campanula commemoratur apud Auciores Botanicos, nec Synonima invenio, quæ ad hanc effe referenda videantur. Campanula caule unifloro Linnæi (a) nulla ratione ad noftram referri poteft . Campanula alpina, minima, integro acuminato folio, flore albo Pontederæ $(b), \&$ Seguierii (c) ut omittam floris colorem, differt evidentiflime floribus in capitulum congeftis.

E 2

CAM-

[2] Fl Lapp. n. 85. Tab. 9. fig. 5.6.

[b] Comn. p. 755 .

[c] Pl. Veron. P. 178. 


\title{
CAMPANULA FOLIIS HISPIDIS, CAULE UNIFLORO Hall. helv. p. 493.
}

\author{
T A в. VI.
}

Ova minime eft hæc Campanula, fed a præcldriffimo 1 Hallero in fua ftirpium helveţicarum enumeratione recenfrta, \& defcripta. Confido tamen acceptam Botanicis futuram ejus, quam hic fifto, defcriptionem icone illuftratam .

Folia linguiformia, acute terminata, læte virentia, pilis afpera, tertiam pollicis partem ad fummum lata rofulam efficiunt, ex qua fæpe unus, interdum geminus, digitalis, aut minoris longitudinis oritur Cauliculus, plerumque leviffime pilofus. Cauliculus nudus non eft, fed uno alterove folio donatur, quod radicalibus fimile in fua origine Caulem amplectitur. Flos unicus, magnus, violaceus, in fauce potiflimum lanuginofus, lacinias habens quinque obtufas ad extra revolutas ad medium floris ufque non perringentes. Calycem folia quinque componunt lingulata hyfpida, \& finuofa, appendiculata cum appendicibus etiam hifpidis, \& finuofis. Anthe$\mathfrak{x}$ longifimæ funt, compreffæ, \& inflexæ per brevifima filamenta cum fquammis, feu valvis nectarii coalitæ: cum in hac campanula etiam quinque fquammis violacei cum flore c loris embrio, feu ovarium tegatur, \& comprehendatur. Stylus antheras longitudine fuperat, coloris primum albi, dein l. teo - virefcentis, ftigma trifidum gerens cum fegmentis revolutis, \& corniculatis. Fructus immaturus diffectus tria loc ula exhibuit. Radix longa, filiformis eft, flexilis, alba, ex qua fæpius una, aliquando plures foliorum rofulæ proficifcuntlir.

Neu- 
Neutiquam filentio præteream villos, qui folia, \& calycem. hifpidum reddunt, in prona foliorum parte, \& eorum ambitu præcipue confpicuos effe, \& retrorfum duci fubtilem hoc pacto ferraturam mentiendo, eandemque plane villorum, aut, fi velis, fpinularum difpofitionem in calycis etiam foliis obfervari.

Pro locorum ratióne firmiores, \& denfiores villi funt, aut debiliores. Cauliculus etiam fua altitudine maximopere vatiat. In editiflimis jugis, quæ perpetua fere nix obfidet, propter Cauliculi brevitatem acaulos apparet hæc Campanula . Altitudo, quæ icone monftratur, fumma eft .

Inhabitat fumma Alpium juga amans nafci inter fractos lapides , \& paffim in omnibus fere Alpium, quas invifi, fummitatibus inveni. Rara vero in Helvetia eft $(a)$.

Varietas flore albo in Monte Ceniforo reperitur, ubi hæc mutatio frequens eft; præter vulgatas, \& ab aliis Auctoribus jam memoratas, fingulares alias his in Alpibus obfervavi. Alba Corolla ex. g. nitent Gentiana foliis amplexi-Caulibus, floris fauce barbata Hall. enum. p. 473. Gentiana Afclepiadis folio Cluf. pann. p. 280. Gentiana Alpina, pumila verna, minor Tourn. inft. 81. Vulneraria ruftica flore albo Tour. Inft. 391. Anonis Alpina humilior radice ampla, E dulci Tourn. Inft. Tourn. $40 \mathrm{r}$. Campanula Alpina urticre folio minor, floribus reflexis, E unico ordine difpoftutis caruleis Ponted. Comp. tab. 74. 8xc.

Vix a Campanula foliis echii , floribus villofis C. B. Prodr. p. 37. differre affirmat Doctiffimus Hallerus, \& memoratæ campanulæ meram varietatem effe dubitat, quoniam autem conftanter uniflora eft, nec unquam diverfa foliorum figura invenerim, eâ nempe, quæ ad folia Campanula foliis echii \&zc. accederet, puto diverfam revera fpeciem con-

(a) Vide Hall. 1.6. 
38

Atituere, differentiam vero Specificam præftant folia in noAtra linguiformia acute terminata, in altera lingulata fine fubrotundo denticulato. Scapus, aut Caulis in poftrema multiflorus floribus pendulis; in prima flos femper unicus, \& etiam major.

Commodum interea videtur præeunte Hallero $(b)$ huc referre Campanuiam, quam Tournefortius dicit faxatilem echii folio, flore magno.

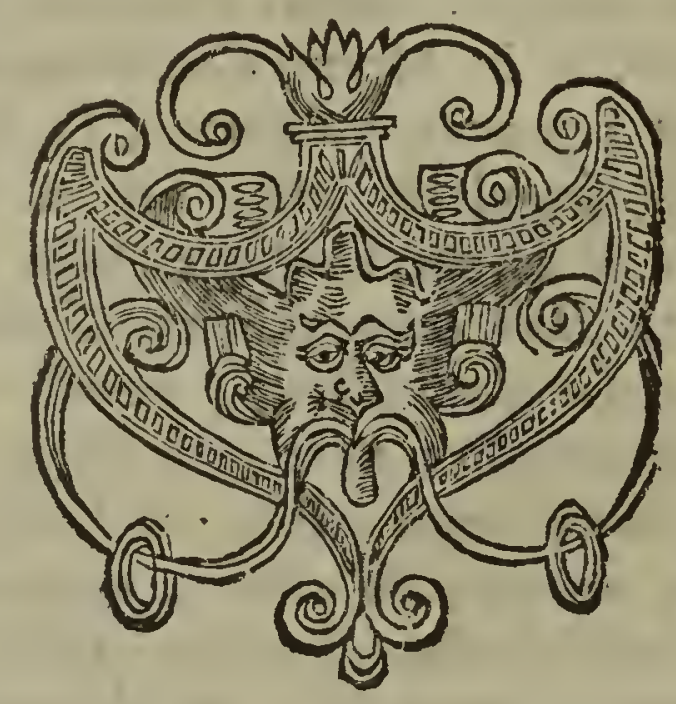

(b) Inft. Iro. 


\section{CAMPANULA HIRSUTA, FOLIIS ELIPTICO. LANCEOLATIS, RARO DENTICULA'TIS, CAULE UNIFLORO.}

\section{T A B. VI.}

Aulis in hac Campanula palmaris \& ultra, erectus, filiformis, fat durus, ex dura radicula prodit, in quo alterne, \& fine ordine nafcuntur folia primo elliptica, dein-. de anguftiora, \& acuminata, omnia hirfuta, ex utraque parte Atrigofa, \& raris obtifis dentibus prædita. Summus caulis, qui florem gerit unicum plerumque nutantem, glaber eft, cum planta tota de cœtero valde hirfuta fit. Calyx etiam glaber aut vix hirfutulus; Lacinix calycis capillares; flos Campanæ forma longus, ore obtufo, \& leviter quinquefido. A reliquis Campanulis, quæ ad iftam accedere videntur, fatis bene, ut mihi videtur, diftinguitur ; etenim foliorum forma, \& magnitudo per gradus immutantur, neque ima folia cordata funt aut fubrotunda. Omnia deinde funt denfe, \& fubtiliter hirfuta, atque Atrigofa, ut evidenter pateat diverfam plane effe a Campanula uniflora, foliis imis cordatis, ferratis, fuperioribus integris, hirfutis Hall. enum. helv. 495. cum qua aliquomodo convenire videtur .

Oritur in umbrofis ad radices Alpis Albergian prope arcem Feneftrellarum. 


\section{ALLYSSUM FOLIIS PINNATIS; MUL'TIFORMIBUS, FLORIBUS RACEMOSIS, LUTEIS.}

\section{TA B. VII.}

F Nunciata Allyffi fpecies nova prorfus mihi vifa eft, \& I. Botanicis invifa, in qua illud eft peculiare, ut folia pinnata fint, formæque multiplicis.

Prima, feu radicalia burfæ Paftoris folia repræfentant, pinnata pinnis fere alternis confluentibus, atque dentatis ; caulina vero pinnata funt pinnis nunc integris, nunc lacinulatis. Caules fæpe plurimi, ramofi, confeftim nafcuntur ex una radice fibrofa albefcente, tortuofi funt, varie inflexi, \& quandoque in folo lætiori inter fe impliciti. Caulina folia alis duabus aucta caulem amplectuntur ; \& pinnas exhibent (in primis) femel vel bis lacinulatas: (in fecundariis) integras abfque laciniis. Pinnulæ etiam continuo anguftiores fiunt in poftremis capillares evadentes. Summitates caulium, \& ramorum definunt in florum racemum, quorum unufquifque capillari nititur petiolo. Flos cruciformis, petalis ovalibus non emarginatis. Stamina fex diffita apicibus luteis ornata germen oblongum circumftant, quod evadit filicula ovata, turgida, quatuor aut fex obfcuri coloris femina diffepimento affixa utrinque includens. Stylus in embryone germinis. longitudinem æquat, brevior deinde fit in filicula matura. Calyx eft lutei coloris, quem efformant quatuor foliola elliptico-acuta cito cum flore caduca .

Nafcitur abunde circa thermas Valderianas in faxofis , \& pratis fecus torrentem. Pro locorum varietate folia aut vix hirfuta, aut quam maxime, \& Atrigofa. 
PERSICARIA ALPINA FOLIO NIGRICANTE, FLORIBUS ALBIS Bocc. mus. p. 2. tab. 27.

\section{$\mathrm{T}_{\text {A B. }}$ VIII.}

$N$ pratis Cottiarum Alpium, \& ad earum convalles infre直 quens non eit Perficaria, de qua fermo inftituitur. Ejufdem primus, ut puto, monuit Balthaffar Campi Lucenfis (a) iifdem locis repertam deinde recenfet Bocconus, cujus Synonimum repetunt Rajus ( $b$ ), \& Tournefortius $(c)$. Bocconiana porro icone bene planta non exprimitur, \& Campi defcriptio licet hanc effe commontret, breviffima tamen elt, \& pauca complectitur. Novam ideo, \& accuratam defcriptionem cudere optimum duxi .

Ex una radice Caules multi nafcuntur, cubitales, \& fefquicubitales quaquaverfum pofiti, fere procumbentes, flexuofi, virides, aut etiam rubri, cavi, \& nodofi ; ad nodos vagine plerumque refętæ oram ciliatam habentes, in adultis, \& deflorentibus aridæ, folia vix petiolata, parum finuofa in longum acumen fenfim extenuata margine integerrimo, venofa, cofta foljum dirimente, læte virentia, fubtus $\&$ in ora fubtiliter incana.

Folia per fafces nafcuntur, \& cum iis fcapi longi numerofifimos flores habentes; flores magni, albi profunde fecti in fex, quinque, aut quatuor ovalia fegmenta: ftamina etiam numeravi incerto numero, octo, feptem, aut etiam quinque; germen trigonum cum duobus, aut tribus ftigmatis, \& has fingulas feu florum, feu ftaminum $(d)$ varietates icon demon$\mathrm{F}$

ftrat,

\footnotetext{
(a) Spicilegio Botanico di BaldafJar, e Micbole Campi. in Lucca 1669. 4.

(b) Suppl. bif. pl.p. 117.

(c) In $\beta .5: 8$

(d) Patet hinc ex numero flaminum, aut petalorum fpecificas in Perficaria genere dıfferentias erui non polfe.
} 
frat. Summe demum ramora plarta eft foliis, ramis, foribus tafciculatim nafcentibus, \& unam partem fpectantibus.

Saporem habet tantifper amarum cum manifefta aciditate. In dyfenteria quadam epidemica felici cum fucceffu ejufdem decoctionem confuluit D. Bartholomæus Caccia quondam Botanices in Horto Medico Taurinenfi Profeflor, cum Alpes herbarum legendarum cauffa inviferet.

Difcrimen, quo a cæteris diftinguatur hæc Perficaria, præftare mihi videntur folia integerrima fubtus incana, E habitus univerfus per fafces ramofus, E floriger; demum floris infignis magnitudo: confundi nequit cum Perficaria folio fubtus incano Raii (e), neque haberi veluti varietas Perficarice mitis maculofe $E$ non maculofe Tourn. In prima folia tomento fericeo denfe obducuntur \& flores plerumque quadrifidi, Hallero adnotante $(f)$. In fecunda fpica longe rarior, flores multo minores, habitus totius plantæ frigofior, \& præterea folia fæpe maculata, quarum màcularum veftigium nunquam vidimus in noftra.

Dictis in Perficariæ hujus defcriptione adde glandulas neEtariferas ad unguem fegmentorum pofitas deprehendi. Ex illarum præfentia erit hæc Linnæo Fagopyri, feu, ut ipfe vocat, Helxinis fpecies ( $g$ ).

(c) Syn. ed. 3.p. 145 .

(f) Enum. p. I $8 \mathrm{r}$.

(E) Gen. plant. 2. 392. 
An HELIA NTHEMUM A L P I U M, MIRTHIFOLIUM, HIR SUTU M

Hall. helv. 780 .

T A B. IX.

R Adrx lignofa, rubens, \& craffa repens plures præbet $R$ caules erectos, minime ramofos, digiti, aut palmi altitudine, quibus folia per conjugationes adnafcuntur elliptica , aut oblongo-elliptica, firma, dura, hirfuta, \& fubtus brevi tomento incana; ad quamlibet porro conjugationem bina juniora folia exeunt. Caules finiuntur quinque, aut $\mathrm{fex}$ floribus luteis in racemum pofitis, qui ex fuis pedunculis pendent cum foliolo unicuique fuppofito. Flos calyx, fructus cum Helianthemo vulgari convenit . Cauliculi ex viridi rubent, \& multa hirfutie teguntur.

Collegi hoc Helianthemum loco Pràtavan dicto Alpis Afrette. Foliis firmis fuperna parte valde hirfutis, nihil acuminatis, averfa tomentofis, caulibus erectis duris, \& per conjugationes æqualiter foliofis, ea ratione, mea fententia, diftinguitur, ut nec Helianthemi vulgaris varietas cenferi poffit, nec ad Helianthemum foliis ad terram congefis fuperne pilofis, inferne tomentofis Halleri (a), aut ad Helianthemum alpinum, vulgari fimile, latioribus foliis Seguierii ( $b$ ), reduci, fed pro fui generis diverfa Helianthemi fpecie confiderari.

(a) Enum. f. belv. p. 359 .

(b) Pl. Veron. Suppl. p. 193. Tab. VI. fig. T. 


\section{4 \\ LEUCOJUM ANGUSTIFOLIUM, ALPINUM, FLORE SULPHUREO. \\ H. R. Par. \\ TAB. IX.}

$\mathrm{N}$ faxofis, \& apricis tummarum Alpium apud nos frequen1 tiffma Rirpis primus meminit Dionyfius Joncquet $(a)$ cui nomen fequens impofuit, Leucojum, five Keiri Alpinum flore fulphureo odorarifimo; ex Joncqueto Tournefortius in fuis Inftitutionibus recenfuit. Hallerus in enumeratione ftirpium helveticarum eandem ftirpem commemorans eam profert veluti varietatem Leucoii Sylveftri.s, \& ego etiam pro variis locis, quibus nafcitur, Leucojum noftrum Alpinum multum differre obfervavi, caulibus aut vix digitalibus, aut fpithameis iifdemque aut multum, aut parum foliofis, foliis demum vel ellipticis, vel linearibus, denticulatis, aut integerrimis ad Leucojum filveftre Clufii quammaxime accedendo. Leucojum, quod tabula nona fiftit, abunde nafcitur in monte Cenifio, in loco Ronche dicto, \& ibi duas ejuldem ftirpis varietates obfervavi, quæ fig. 2., \& 3. exhibentur .

Prima quidem folia habet radicalia, longe petiolata lineari elliptico fine; folia caulina, non petiolata, linearia; flores in umbella magni, aurei, petalis cordatis parum emarginatis, unguibus albis. Calyx erectus. Filamenta fex unguium longitudine cum diobus brevioribus. Antheræ filamentis incumbentes haftatæ. Stylus brevis, ftigma bifidum, fequitur filiqaa pene quadrangularis, unciam longa. Semina compreffa ovalia rufi coloris non marginata, utrinque in fepto filiquam dirimente nidulantur. Secunda quam fig. 3. reprafentat, duplo al-

[a] Hort. p. 72 . 
altior eft. Flores minores, \& petala ovata, non emarginata habet. Folia infuper ima haftata funt, non cochleata petiolo fenfim latefcente, in ambitu dentata, dentibus femipinnata, fine acuto. Caules virides funt in utraque non ramofi, nec flexuofi. Ex filiqua conftat hanc ad hefperidis genus revera pertinere; quoad Synonima, ubi a Botanicis decernatur varietas Leucoii Silveftris, legantur apud Hallerum $(b)$.

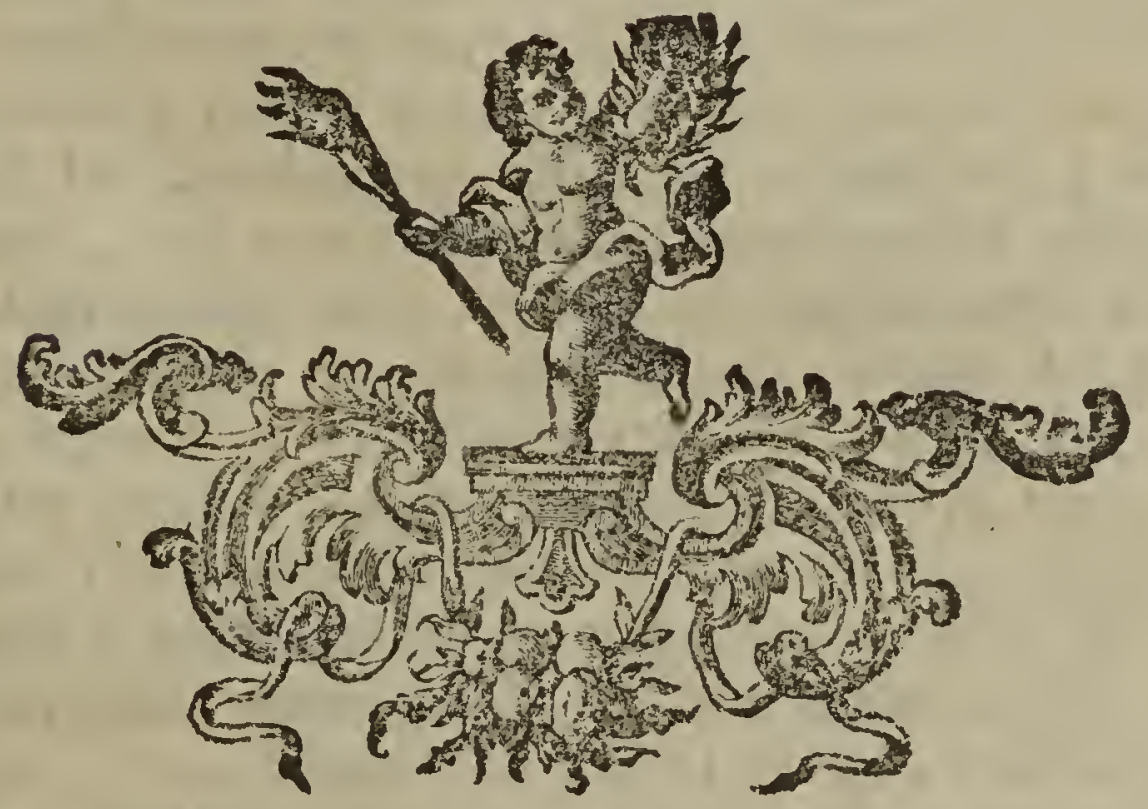

$\mathrm{AB}-$

[b] Enum. belv. p. 564. 


\title{
ABROTANUM PUMILUM, FLORIBUS MAGNIS, SESSILIBUS, RARIS, LONGE SPICATIS.
}

\author{
T в в. $X$.
}

N fupercilio altiffimi fcopuli collis La Croix fupra Mirebouc I e faxorum rimis Abrotanum hoc fuit a nobis cum vitæ difcrimine excerptum anno 1748. Augufti initio; quod nullibi deinceps occurrit .

Radicem habet nigram, exfuccam, varia capita fundentem, ex qua folia plura, \& inter hæc digitalis caulis nafcitur. Folia ex compreffo petiolo nafcuntur, ovato acuminatam circumferentia fua formam exhibent, pinnis iterum pinnatis compofita. Pinnæ non exacte fæpe fibi refpondent, fed fere alternatim pofitæ effe videntur; pinnulæ acutæ funt, acuto uno, aut altero dente aliquando incifæ. Folia glabra funt, \& pinnæ a fex ad decem. Caulis ftriatus, \& viridis, qui fere totus fpica eft florum feffilium alternatim pofitorum ; fed qui unam partem præcipue fpectare videntur : flores magni funt, Lutei, calyce amplo fquammofo comprehenfi, vehementer odorati, \& calycis fquammæ ex viridi rubent, intus citrini coloris; receptaculum nudum. Folia paulo acutiora, \& tenuius incifa funt, quam tabula monftratur.

Ammannus (a) recenfet Abrotanum quoddam a Mefer $\int \mathrm{ch}-$ midio collectum, \& appellat Abrotanum pumilum, folio tenuiffime laciniato, flofculis majoribus, odore tanaceti valido; qua nomenclatura licet noftrum defignari videatur, res nihilominus in ambiguo effe debet, eo quod nulla vel icon, vel defcriptio ultra nomen afferatur.

ANO.

(2) Rar. Rutb. n. 203. 


\section{ANONIS INERMIS, GLABRA, VAGINIS LANCEOLATIS CRISTATIS, PETIOLIS I,ONGIS, UNIFLORIS .}

\section{T A B. $X$.}

R Adix lignofa, dura, nigra originem pluribus præbet cau$R$ liculis teneris, qui varie flexuofi eriguntur ad digitalem, aut paulo ultra altitudinem, undique fere tecti ftipulis foliorum aut novorum, aut exficcatorum. Nihil fpinofi, nihilque vifcofi tenens leviflimam tantummodo in caule hirfutiem exhibet. Stipulæ cauli applicantur, \& eum amplectuntur pro plantæ modulo fat ampla, ad externum ambitum in criftæ formam incifæ angulo acuto, ex cujus finu pediculus prodit tria folia conjungens, quæ ex acuto principio in ovatam amplam figuram fenfim extenduntur. Quod intermedium eft folium, reliquis eft amplius: Folia vero omnia acute denticulata funt. Ex fummis foliorum alis tres, quatuorve flores, qui caulem altitudine fuperant, \& finguli fingulis fuis pediculis innituntur. Calyx quinque lineares dentes producit. Flos pulcher amplus ex albo purpureus, cum vexillo fatis amplo purpureo venis intenfioris coloris virgato, qui fimilis eft flori Anonidis quæ a Morifono (a) appellatur Anonis purpurea, perennis, foliis latioribus, rotundioribus, profunde ferratis. Fructus maturus fuperat eam magnitudinem, quæ icone exhibetur, leviter villofus eft, \& femina fæpius "quinque compreffa, cordata cum hilo excifo continet, ruffi coloris .

Eritne hæc Anonis non Jpinoja, minor, italica Barrelieri (b), quam citatus Auctor in Italia, Jufiæus in Tarantafiæ finibus invenit? aut Anonis purpurea non Jpinofa minor ejufdem Bas-

re-

(2) Hif. oxon. p. 2. 170.

(b) Ic. $394 \cdot 0 b \int .831$. 
$4^{8}$

relieri? (c). Prima pediculos foliorum habet breviores; folia etiam recedunt, fi illud potiffimum confideretur, quod naturali pingitur magnitudine; præterea ftipularum alæ incifæ non funt, majoremque efformant angulum, neque folia acute, \& denfe dentata funt. Quod vero ad alteram pertinet, adverti cum noftra convenire quidem alis longis, \& incifis; fed fclia breviora effe; verum cum flores deficiant in icone Barelieri, \& breviffima fit defcriptio, nil certi tatui poteft. Anonis quidem Alpina, pumila, glabra, non Jpinofa purpurea Tour. (d) ad noftram probabiliter pertinebit.

In defcenfu montis Cenifii fupra Lanebourg, deinde fecus viam ad Braman; tum frequenter in claris \& apricis filvis in vallibus S. Mariini, \& Lucernen $\sqrt{2}$ obvia mihi fuit.

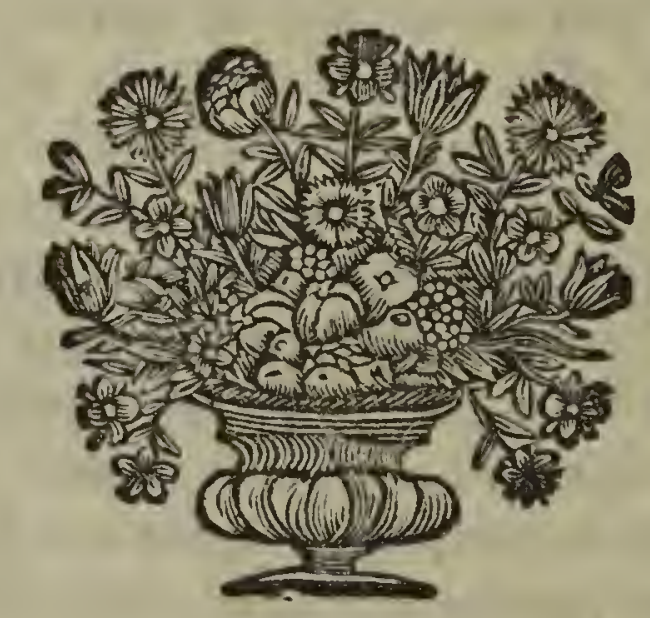

(c) Ic. $1106.0 b 5.83 \%$

(d) Inf. 508 . 


\section{ALSINE UNIFLORA, ET GRANDIFLORA FOLIIS ACUMINATIS, PETALIS I N T E GR I S.}

T А в. $X$.

A LsINE, cujus defcriptio tradenda venit, frequens eft in fumA mis Alpibus Montium editiffimorum Vallium Valdenfum, \& montis Cenifii .

Radix, quæ perennis eft, \& repens, cefpites format cauliculorum biuncialium, qui nunc fimplices funt, nunc varie ramofi. Cauliculi verfus radicem valde foliofi, foliis ex adverfo nafcentibus; fed denfiffime. Cauliculorum magna pars pene nuda cum unam, aut duas ad fummum habeat tantum foliurum conjugationes. Summus Cauliculus florem magnum producit pentapetalum cum bracteis integerrimis ovatis albis venofis. Calyx componitur ex quinque ovato acutis concavis amplis foliolis. Calyx diu perfiftit : florem fequitur fructus conicus, qui quinque dentibus aperitur, folia funt lineari - acuminata in rigidam fpinulam abeuntia, aliquantulum hirfutula .

$\mathrm{Ab}$ Alfine foliis fulcatis aculeatis, petiolis unifloris, petalis integris Hall. (a) diverfa eft: in hac enim cauliculi duriores ramis, \& foliis maxime divergentibus, folia ex luteo virent, firmiora funt, glabra, ampliora, breviora, \& minus acuminata. Calycis præterea folia in Alfine Halleri memorata funt fimilia caulinis; in noftra funt a caulinis diverfa.

Noftra erit ne Myofatis tenuiffrmo folio rigido Tournefortii?

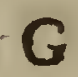

PE-

(a) Enum belv. p.388. 


\section{PEDICULARIS FOLIIS BIS PINNATIS, CALYCE NON CRISTATO, FLORIBUS OCHROLEUCIS IN SPICAM NUDAM CONGESTIS .}

\section{T A B. XI.}

Aulrbus fe fe erigit hæc Pedicularis palmaribus, aut paulo altioribus, rotundis, ftriatis, obfcuri coloris, intus cavis. Folia habet duplicato-pinnata nervo non foliofo, \& tenuia. Longe elliptico-acuminatam formam habent folia , qux conftituunt pinnæ viginti, \& ultra, poftremis confluentibus. Pinnulæ iterum pinnatæ funt pinnis fex aut feptem, atque hæ fecundæ pinnulæ funt acuti longi dentes, nunc fimplices, nunc ramofí. Prima folia longe petiolata funt, fecunda fefilia; omnia juxta caulem afcendentia. Sub ficica plura adfunt fere in orbem pofita. Spica caulem terminans floribus componitur, quibus galea non eft omnino obtufa, cum tubo fat longo, hiatu parvo. Lutei, aut ochroleuci coloris funt : cuilibet flori fubjicitur foliolum nonnifi deductis floribus fere vifibile. Calyx floris tubulatus eft tantifper inflatus, ore inæqualiter quinquedentato. Tota planta villis quibufdam albis ornatur .

Valde fimilis eft pediculari foliis alternis, pinnis pinnatis, floribus ex fpica florigera longe eminentibus Halleri (a) potifimum foliis, quæ fimiliter omnino inciduntur; fed noftra caules habet duplo certe quoad craflitiem minores, folia obfcuriora, nec fubtus pallent; nulla folia fpica longe emittit, itaut pro diverfa confiderari poffit, nifi fortaffe memorata Halleri varier, nec conftantifime habeat ficicam, uti icone Halleriana exhibetur, foliofam .

Nafcitur abunde in pratis alpinis a montibus Feneftrellarum ufque ad montem Cenifum inclufive.

(2) P. 623. T. 17. f. 2. 


\section{I \\ PEDICLLARIS FOLIIS ALTERNIS, PINNIS SEMIPINNATIS, FLORIBLS ROS'TRA'T IS OCHROLEUCIS DENSE SIICA'TIS.}

\section{T A B. XI.}

R Adrcem hujus pedicularis formant plures oblongi bulbuli, 12 ex quibus pedalis prodit caulis rotundus, primum rubens, dein virens. Folia ex radice pauca petiolata, circumfcriptione oblongo-elliptica, pinnata pinnis 18 ad 20 .: pinnæ dentibus alte, \& acute excifis femipinnatæ fiunt. Caulina folia alterna, rara, \& fimilia radicalibus; fed fuperiora feffilia, non petiolata. In fummo caule fpica florum, quorum galea roltrata eft roftro acuto, barba integris tribus fegmentis divifa, medio fegmento minore. Calyx qunquedentatus, non critatus. Fructus ovato - turbinatus, compreffus. Floribus folia non interponuntur, flores feffiles funt.

Habitat in pratis fummis editiffimi, prope Annecium, in Sabaudia montis la Tournette. Radice, \& foliorum forma parum, aut vix quidem diverfa apparet ab ea, cui Hallerus (a) nomen inftituit Pedicularis alpine, foliis alternis pinnatis, floribus ex atrorubentibus in fpicam denfam congeftis, fed præter floris colorem repugnat forma galeæ, quæ in Halleriana obtafa eft.

(2) Ensm. bely. T. 16. f. 2. 


\section{PEDICULARIS PINNIS FOLIORUM ACUTE PINNA'TIS, FLORIBUS OBTUSIS, PURPUREIS, SPICATIS,}

\section{TA B. XII.}

R ADIx lignofa, nigra, ex qua varia capita, \& veluti ce1 Cpres foliorum; folia longe petiolata, petiolo compreffo, $\&$ intus excavato', biuncialis, \& ultra longitudinis. Pinnata funt pinnulis uno, altero, vel etiam tribus dentibus acute, \& profunde incifis; pinnæ vero I2. ad I 4 .. Inter hæc cauliculus rotundo-itriatus, firmus erigitur, qui fuftinet fpicam uncialem. Spica formatur ex floribus, foliolis denfe interpofitis. Calyx floris ore eft quinque-fido, fegmentis capillaribus, brevibus, multum lanuginofus; unde fpica fit incana, \& lanuginofa. Caulis, folia, \& eorum pediculi potiffimum fplendide nigrefcunt; \& ad caput radicis fquammæ plurimæ, feu reliquiæ foliorum emortuorum. Folia in caule rara, \& brevi, raroque villo tum caulis, tum foliorum pediculi decorantur. Flores prælongo tubo e Calyce exeunt galea obtufa, \& alata: obfolete purpurei coloris funt; galea intenfus colorata; barba floris trifida eft ut in cæteris pedicularibus.

Frequens eft in fummis nivofis jugis montis Cenifil, \& alpium Jaillon, \& le Vallon; prope deliquefcentem nivem in fcopulofis habitat.

Puto hanc pedicularim eamdem effe cum ea, quæ $(a)$ ab Ammanno nominatur pedicularis humilior, foliis tenuiffime divifis, floribus spicatis purpureis. Suadent rem ita effe notæ in hujus defcriptione traditæ, neque locus natalis repugnat. Quamvis Ammanni pedicularim Gmelinus collegerit in fylvis inter Jeravvnien-

(a) Rar. Ruth. p. 32 . 
vvnienfe, \& T Tchitinienfe munimentim ut \& ad Ingodam , \& Schilkam. fluvios in Dauria; quis ignorat herbas alpinas in Septentrione pratenfes, \& campeftres etiam fieri ? Plantce alpince calidarum regionum in feptentrionalibus pratenfes funt, inquit Gmelinus ( $b)$, \& Linnæus (c) obfervat in Oelandia campeftri fpontaneum effe Aftragalum Pyrenaicum non ramofum, barba jovis folio, flore ochroleuco glomerato (Tourn.) Scheuchzeri (d), qui apud nos, $\&$ in Helvetia femper alpinus eft . De eodem Aftragalo illud etiam adnotavi, quod in alpibus Valdenfibus nonnifi in fummis jugis fit reperiundus inter poAtremas ftirpes; in monte Cenifio autem, qui feptentrionalior eft, $\&$ in quo frigus longe majus, abunde nafcatur in pratis planitiei montis Cenifit, quæ obfervatio eodem in loco de aliis etiam ftirpibus inftitui poteft.

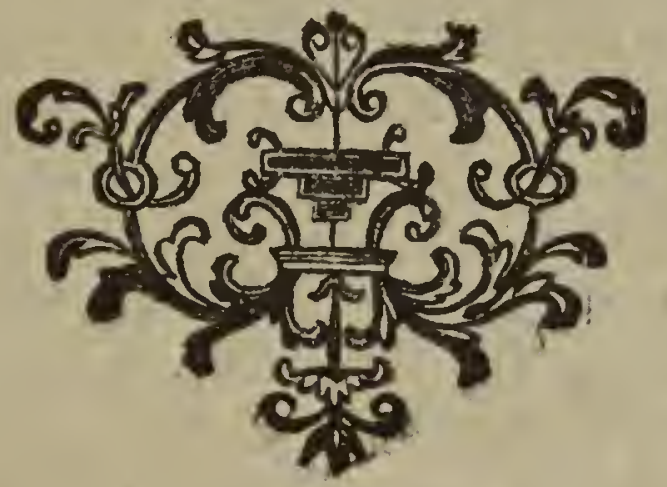

PE-

(b) Pref. ad fl. fib. cxiv.

(c) Flor. Svec. p. 214 .

(d) It. Alp. 14.p. $33^{0}$. cum icone. 


\title{
PEDICULARIS FOLIIS ALTERNIS, PINNIS
} SEMIPINNALIS, FLORIBUS LAXE, ET' LONGISSIME SPICATIS.

\author{
T A B. XII.
}

D Ostrema hoc libello exhibenda ftirps eft minus nota quæ1 dam pedicularis, qua nil frequentius eft noftris ubique in pratis alpinis, tum \& in fummis nivofis jugis.

Hæc radices poffidet lignofas, filiformes, quæ uno capite colliguitur, ex quo nunc unis, nunc duo exeunt caules cubitales in altioribus fpeciminibus. Rotundi funt, firmi, glabri, Atriati, \& rubro-nigricantes. Folia ex radice pauca longe petiolata, pinnata pinnis viginti, \& ultra cum ultimis confluentibus; pinnæ ad medium ufque fecantur dentibus acutis in Spinulam fere abeuntibus; dentes ifti aliquando, fed raro iterum novo dente inciduntur. Folia caulina radicalia omnino referunt; alterne fita, \& rara. Poftrema folia feffilia funt. Flores in caule feffiles aliquo intervallo alterne fiti laxam, \& longam fpicam efficiunt. Flores obfcuri funt, parvi, purpureo-rubentes galea obfcuriore. Galea multum roftrata, labium inferius trifidum cum laciniis fubrotundis, medio minori, \& virgati coloris purpurei . Calyx profunde quinquefidus. \& lanuginofus; univerfa imo Caulis portio florigera eft lanuginofa; folia floralia funt pinnato-dentata, \& fingulis floribus unum fubjicitur.

Pedicularis alpina foliis alternis pinnatis, floribus atro-rubentibus in Spicam denfan congeftis Halleri (a) diverfa ab enunciata elt, floribus minime roftratis $\&$ in denfam fpicam conge-

ftis.

(a) P. 623. Tab. 16. f. 2 
Atis. Pedicularis noftra fuperius de cripta $(b)$, tum eafdem ob rationes, tum propter floris colorem etiam ab hac ultima dittinguenda. Erit ne Pedicularis alpina purpurea, frigofior, Spica oblunga, incana, floribus alternatis, E per intervalla pofitis Burf. (c) 2. Nomen certo ex integro congruit.

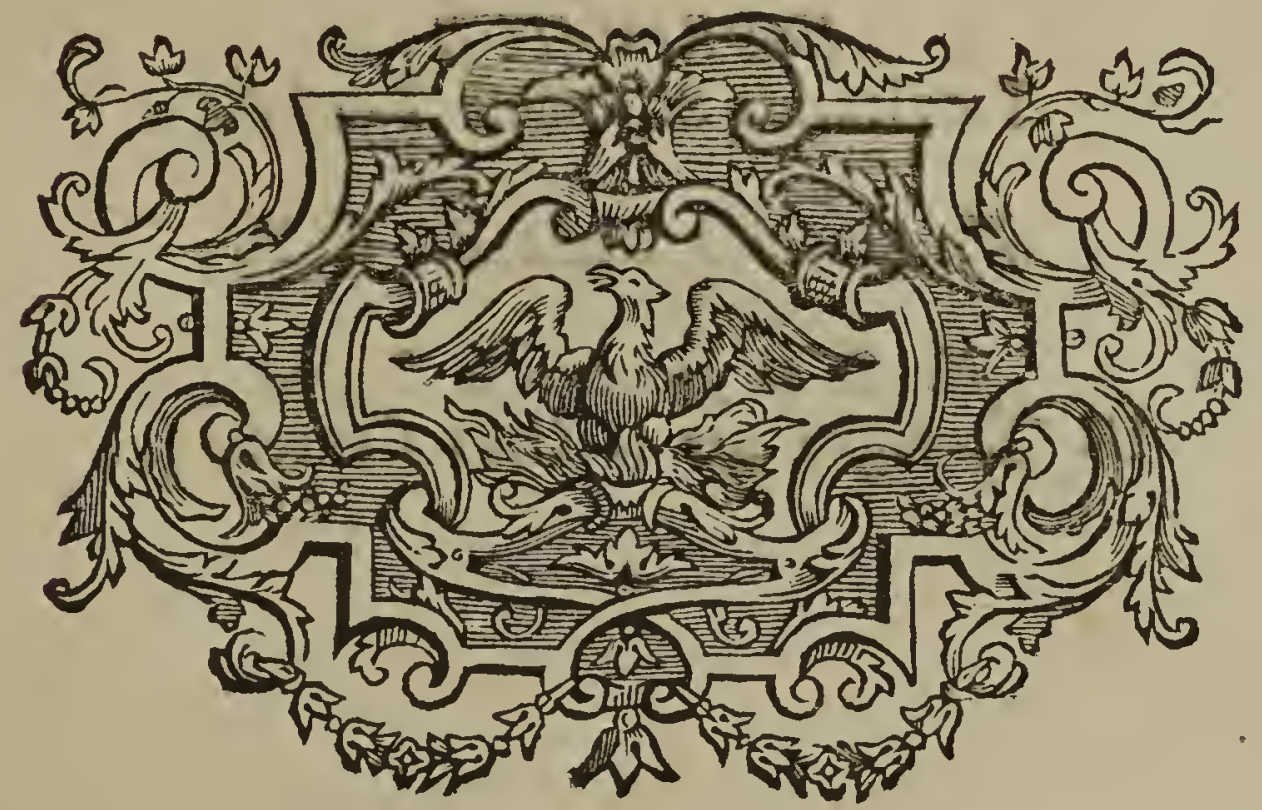

(b) V. Tab. xi, f. 2。

(c) V. Lin. Amoen. Acad. p. 153. 


\author{
IMPRIMATUR : \\ Provicarius S. Officii Taurini: \\ $V$. Antonius Rezia P., \& R. \\ $V$. Se ne permette la Stampa \\ Di Quaregna per la Gran Cancellería.
}


Tab. I.

Abronthiun alpinum fpicarum, foliis periolatis, radicalibus bis frifldis, caulinis pinnatis.

Alifuru pyrenaicum perenne minimum

fulitis trifidis. Tourn.

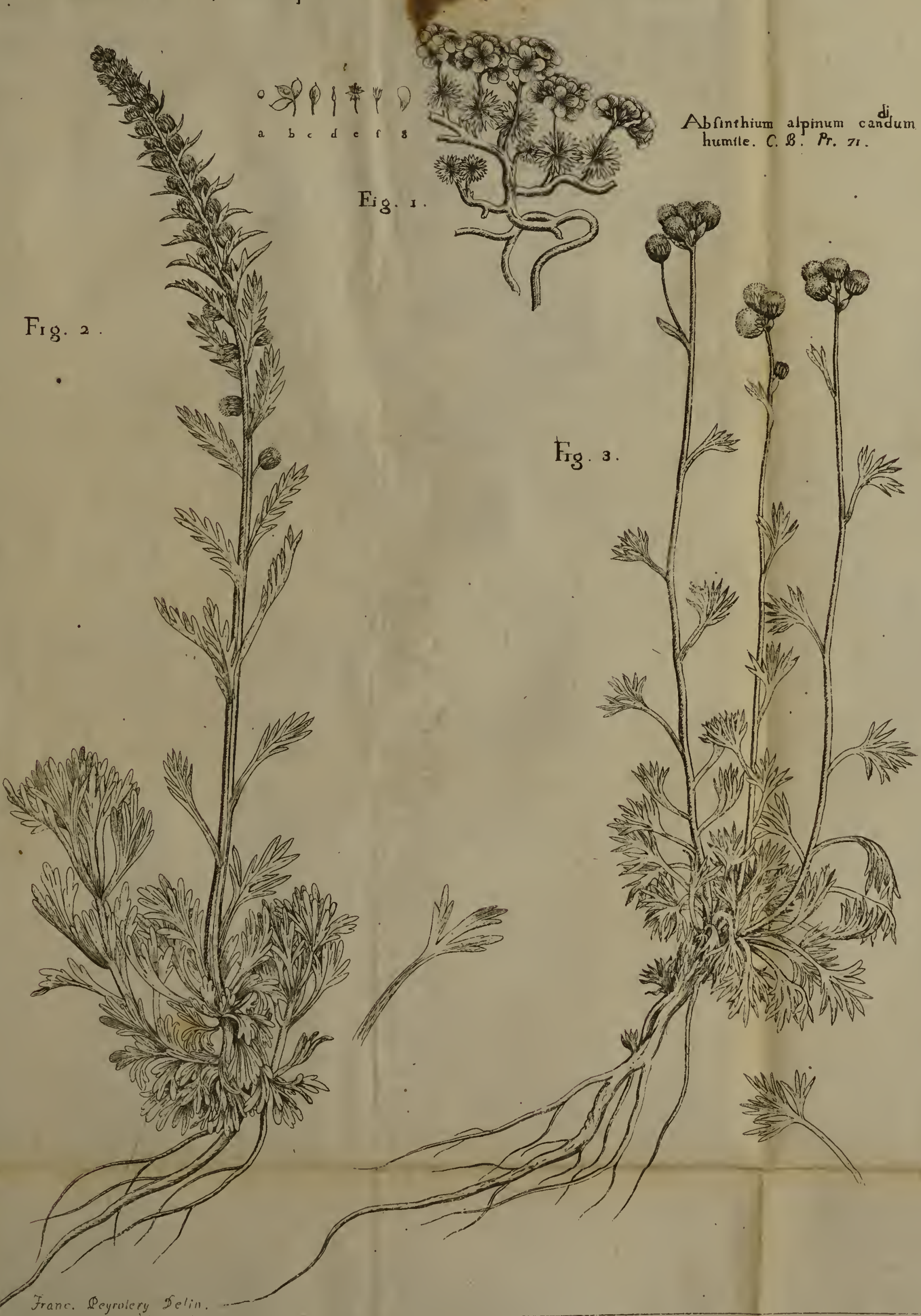





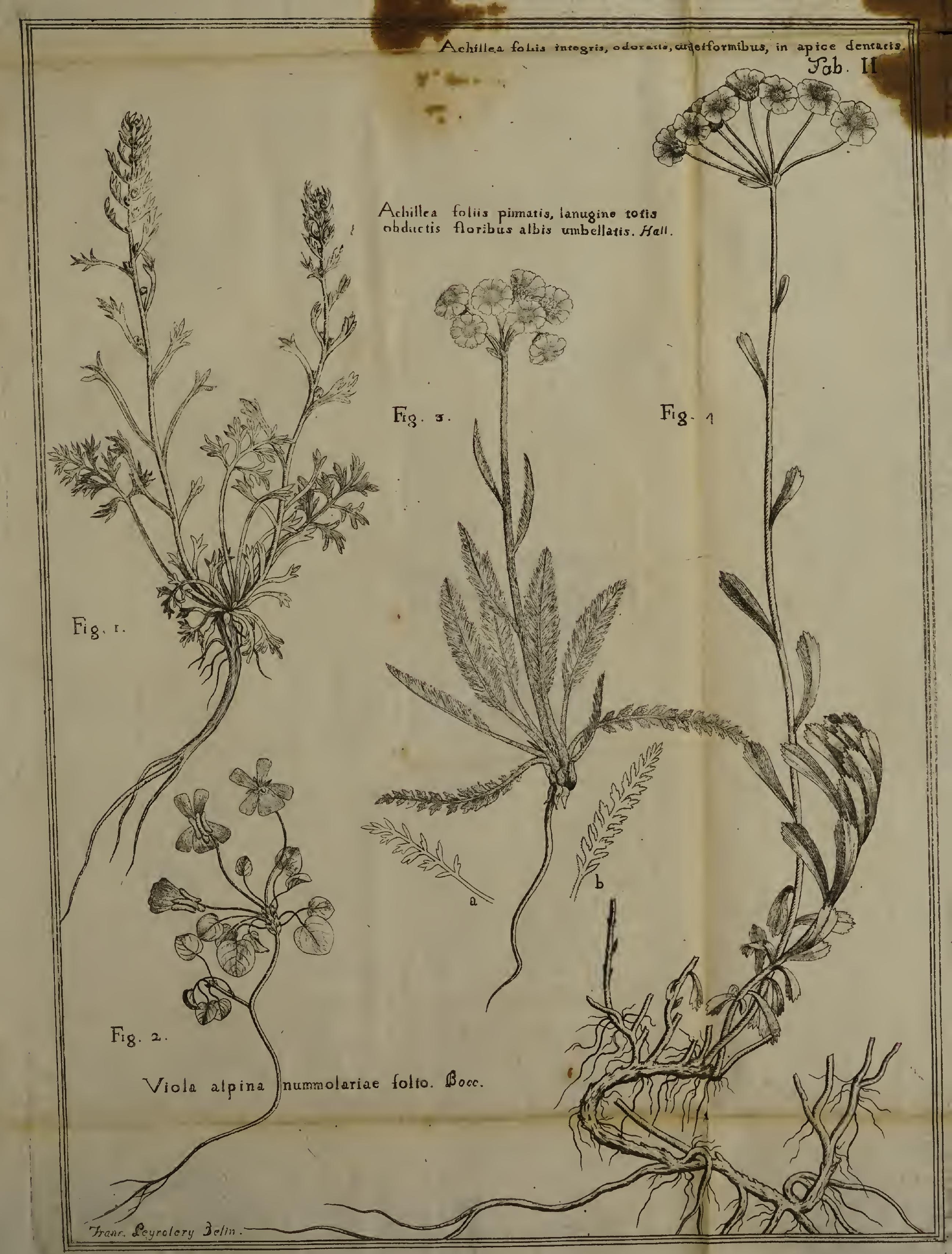





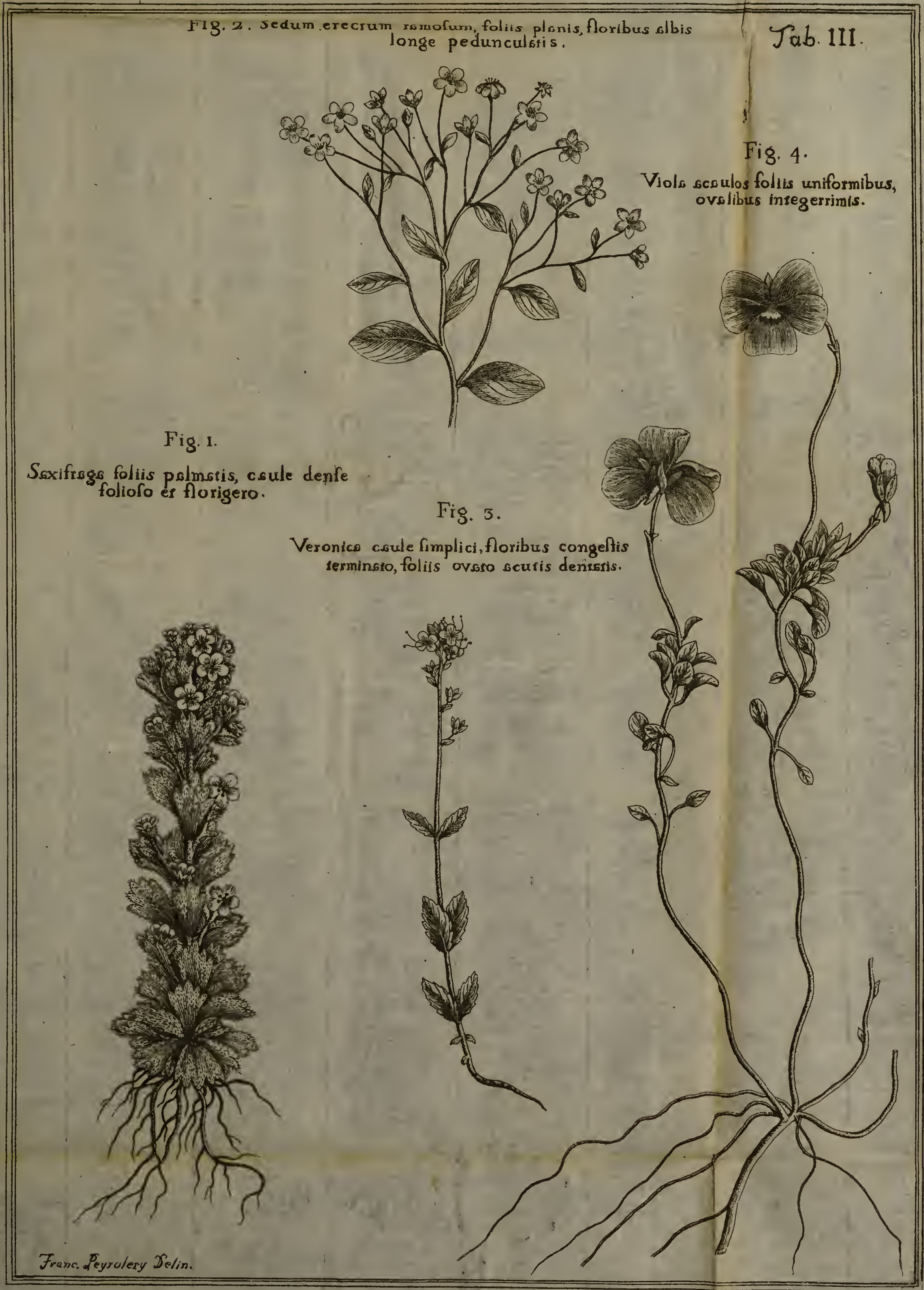


Lepidruin caule repente, foliis ovatis amplexicaulibus. frall. helu. P. 546 . Fig. I
Veronicat repens, ex alis iptcars, foltis rotundis,

firm1s, gláb ris, denticulatis. Tab. IIII.

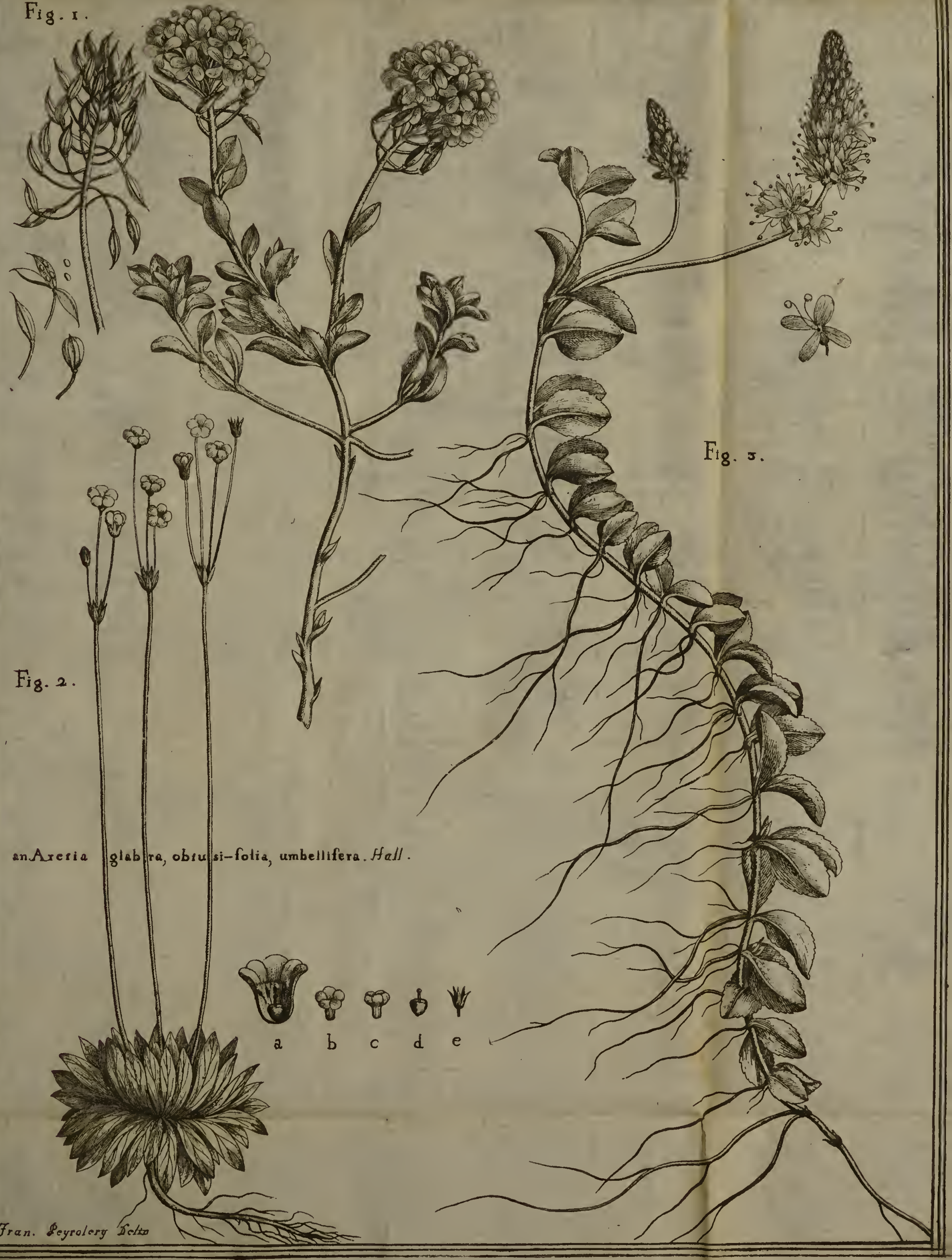




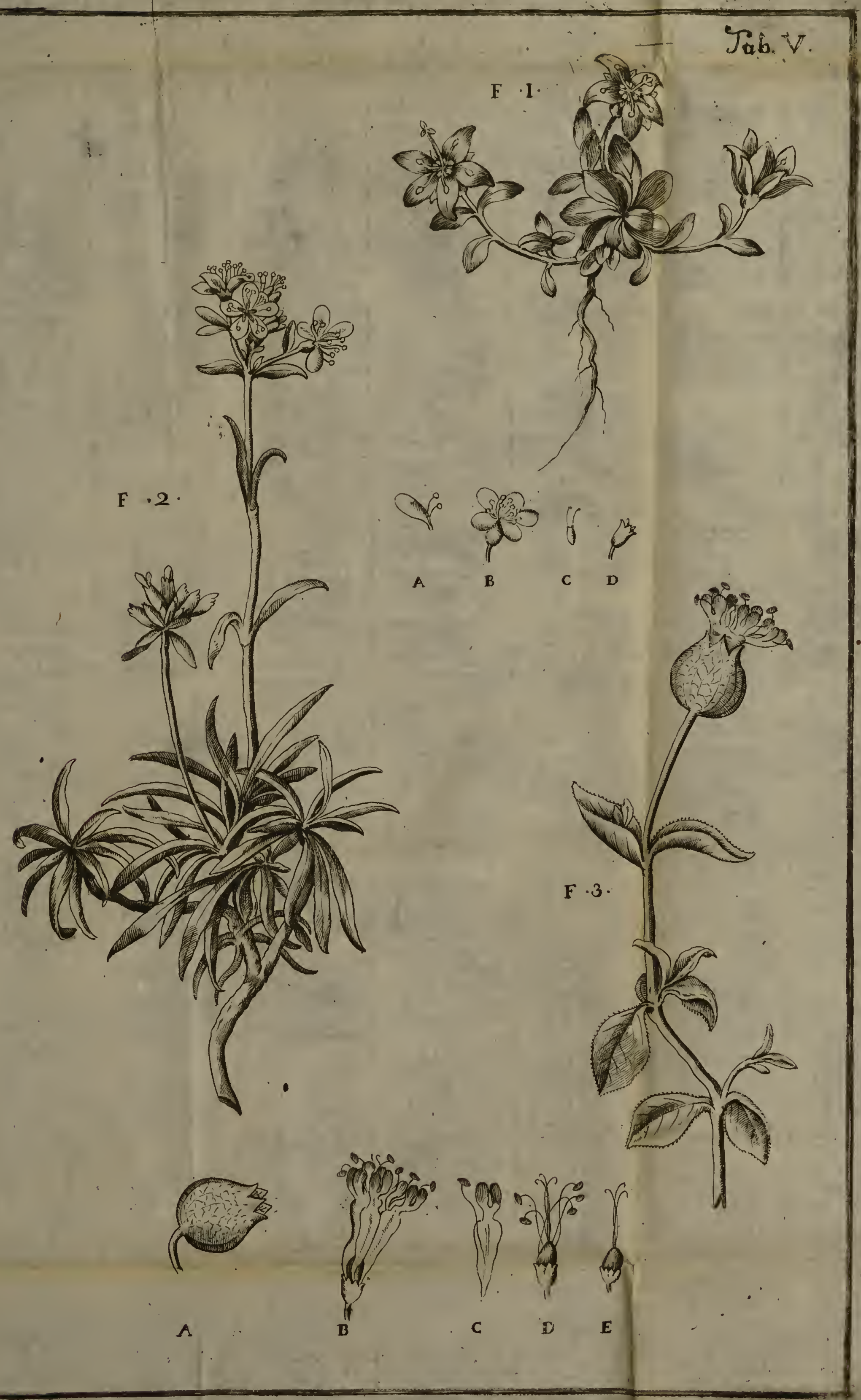


,

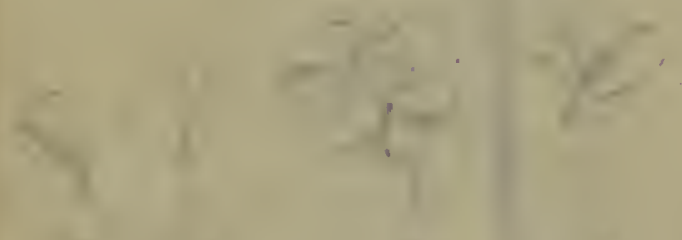

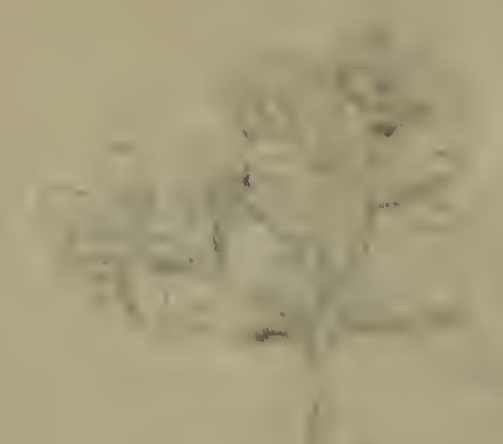

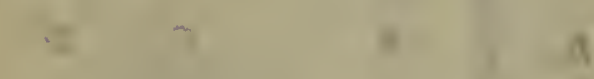
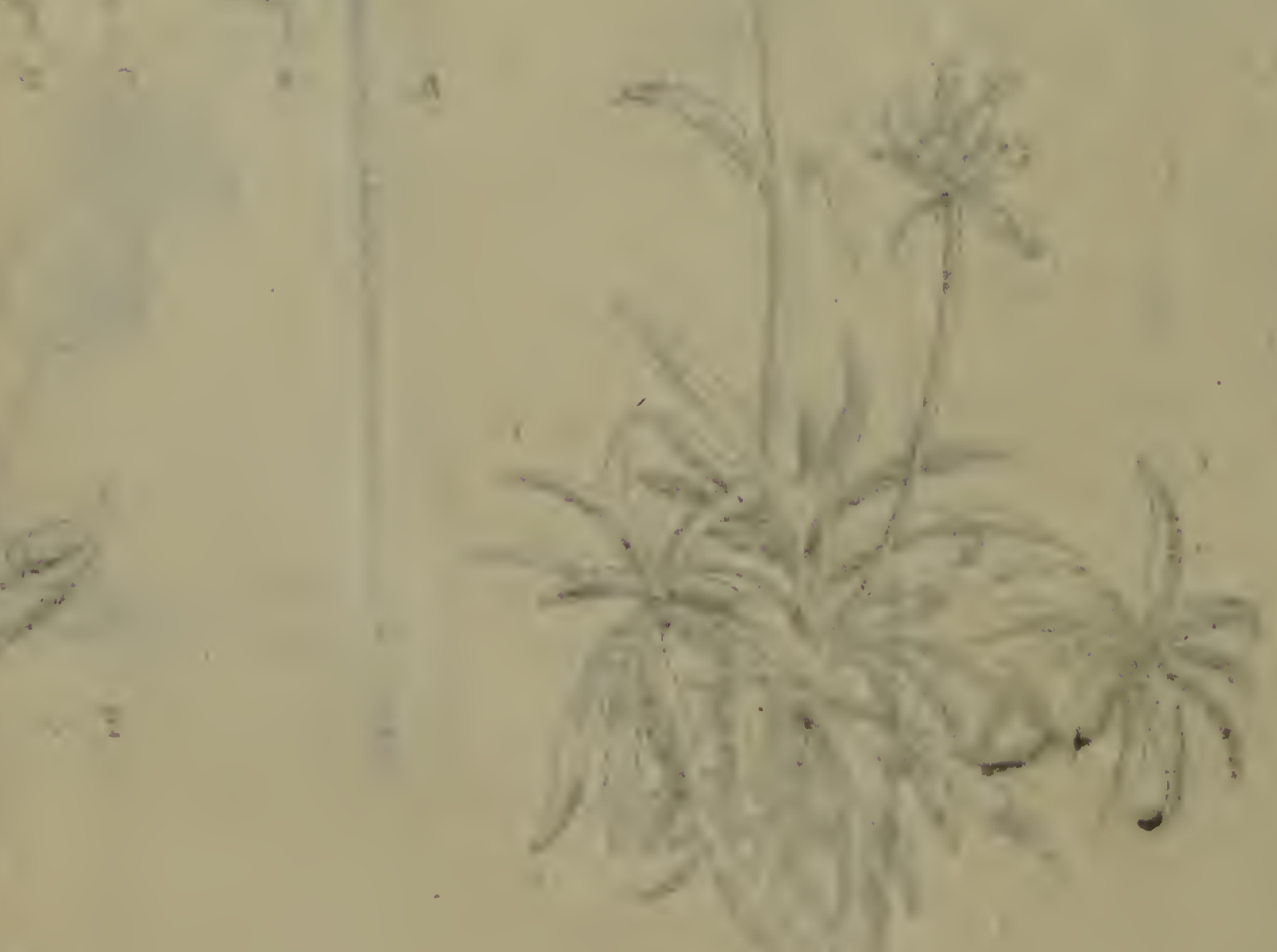

1)

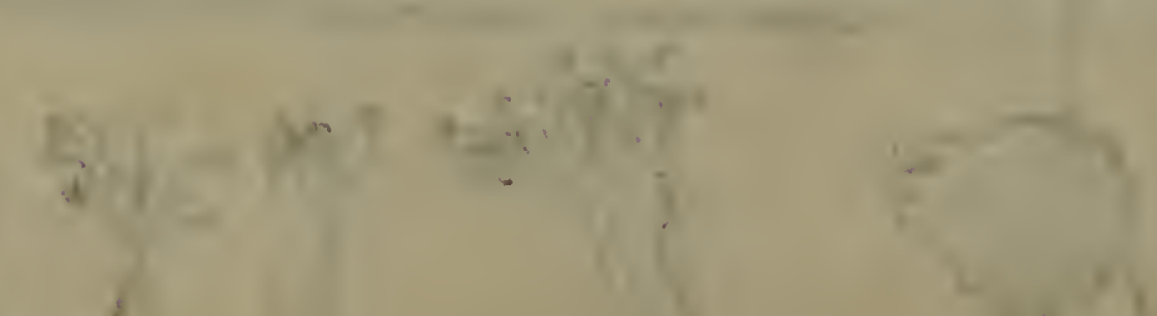


$\mathrm{Fi}_{8} \cdot 2$

Campanula fotits ellipition lancólatis hirfuris raro denticulatis caule tenfloto.
$\mathrm{F}_{\mathrm{g}} \cdot \mathrm{x}$

Jab. VI.

Alyffum pyrenatcum perenne minimum

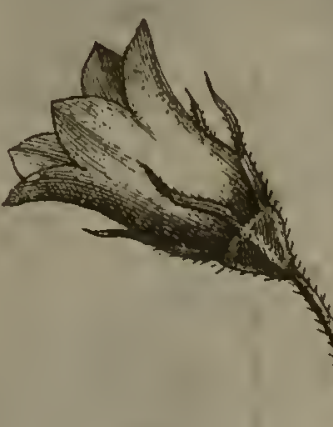

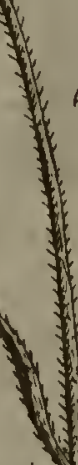
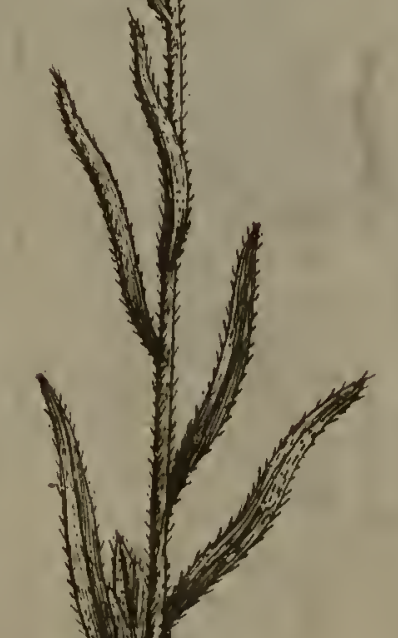

8

a

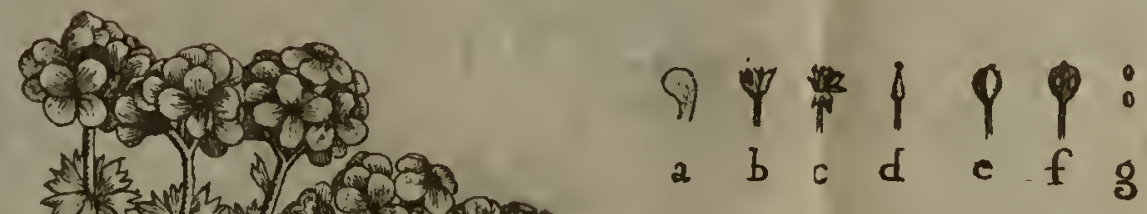

Frg. 5 .

Campanula foliis hufpidis, caule unifloro. Fall. 


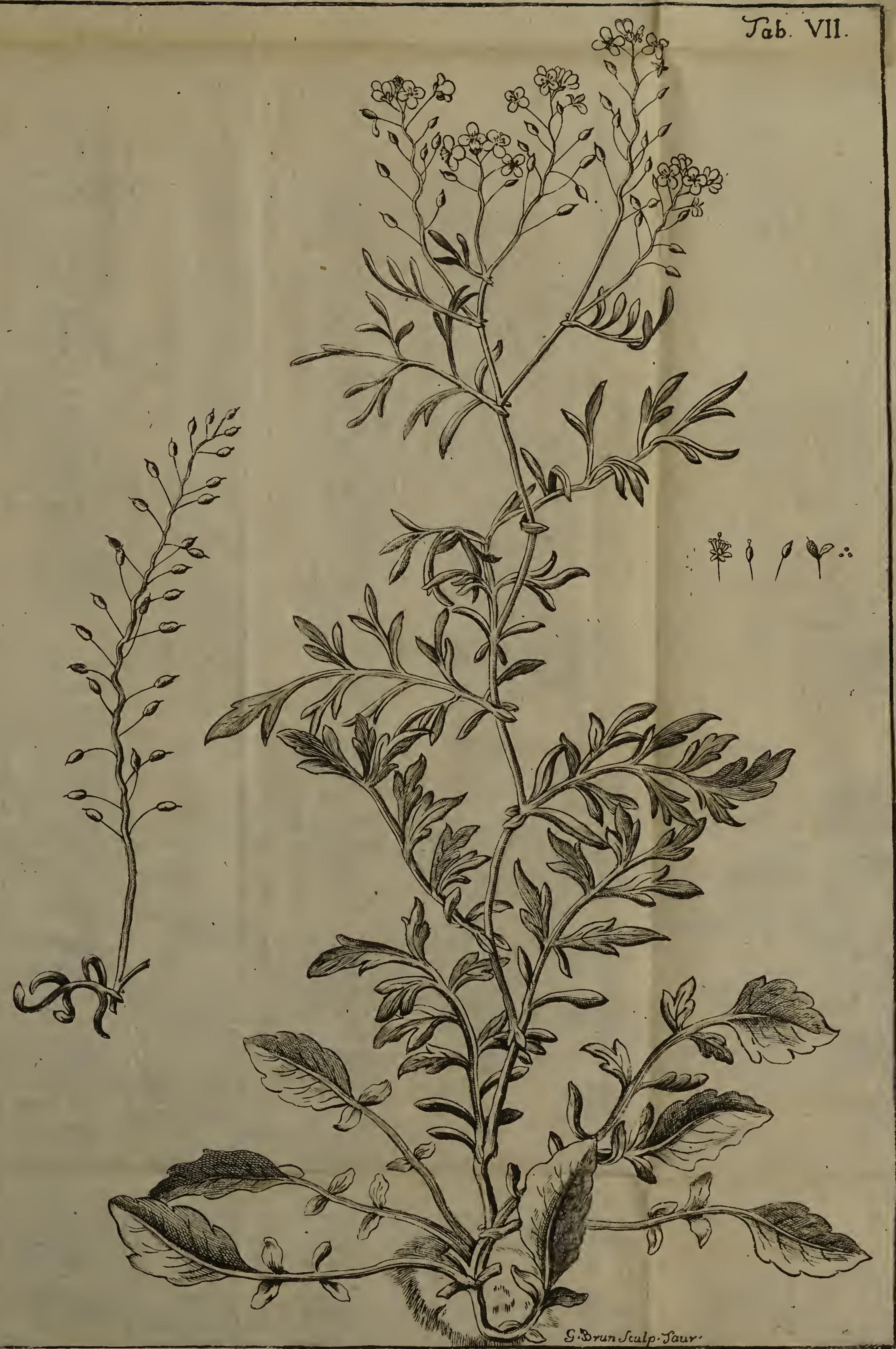




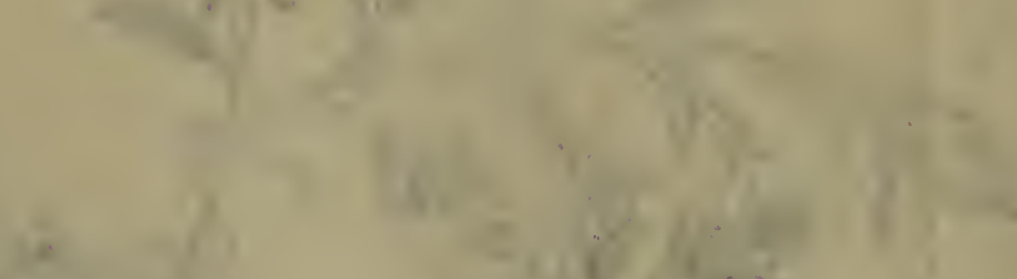

$\sin ^{2}$

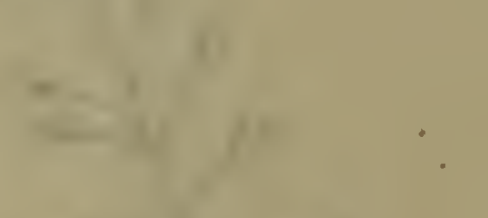

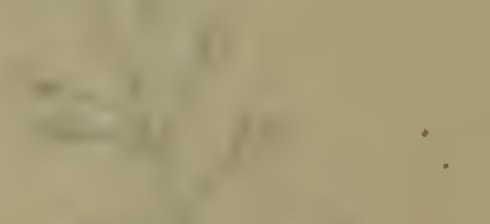

$$
\begin{aligned}
& 2+2 x^{2} \\
& \text { 4.: in ro } \\
& \frac{1}{4.4}
\end{aligned}
$$$$
-4.13 x
$$

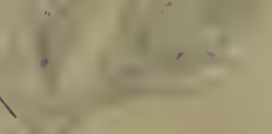

.

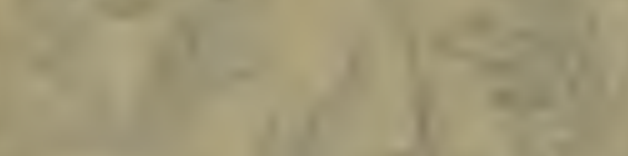

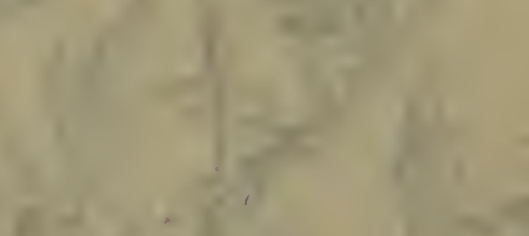

$f^{4}+x^{2}$

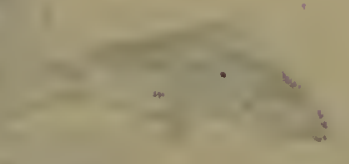

$2=-1$

$1=0$
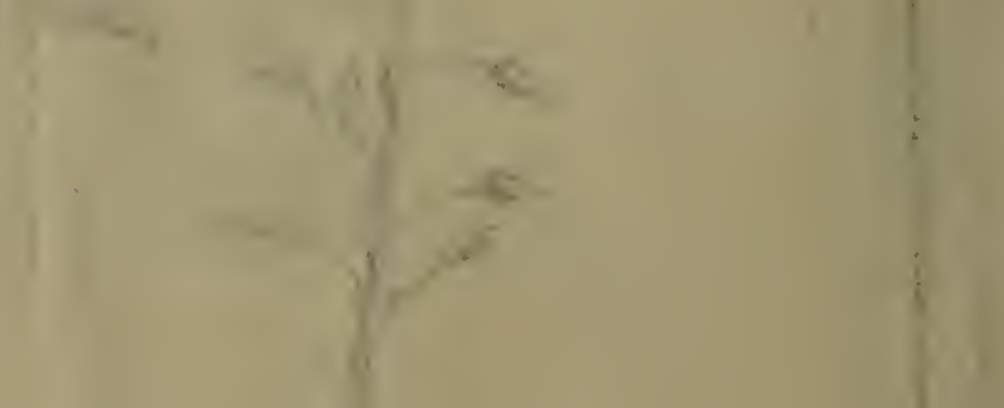

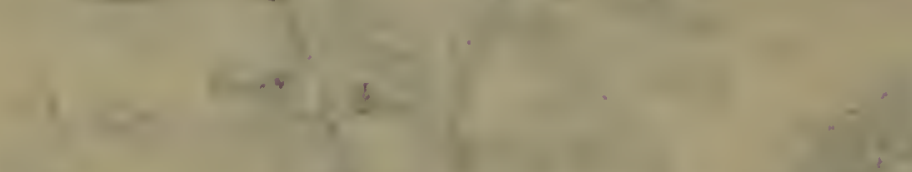




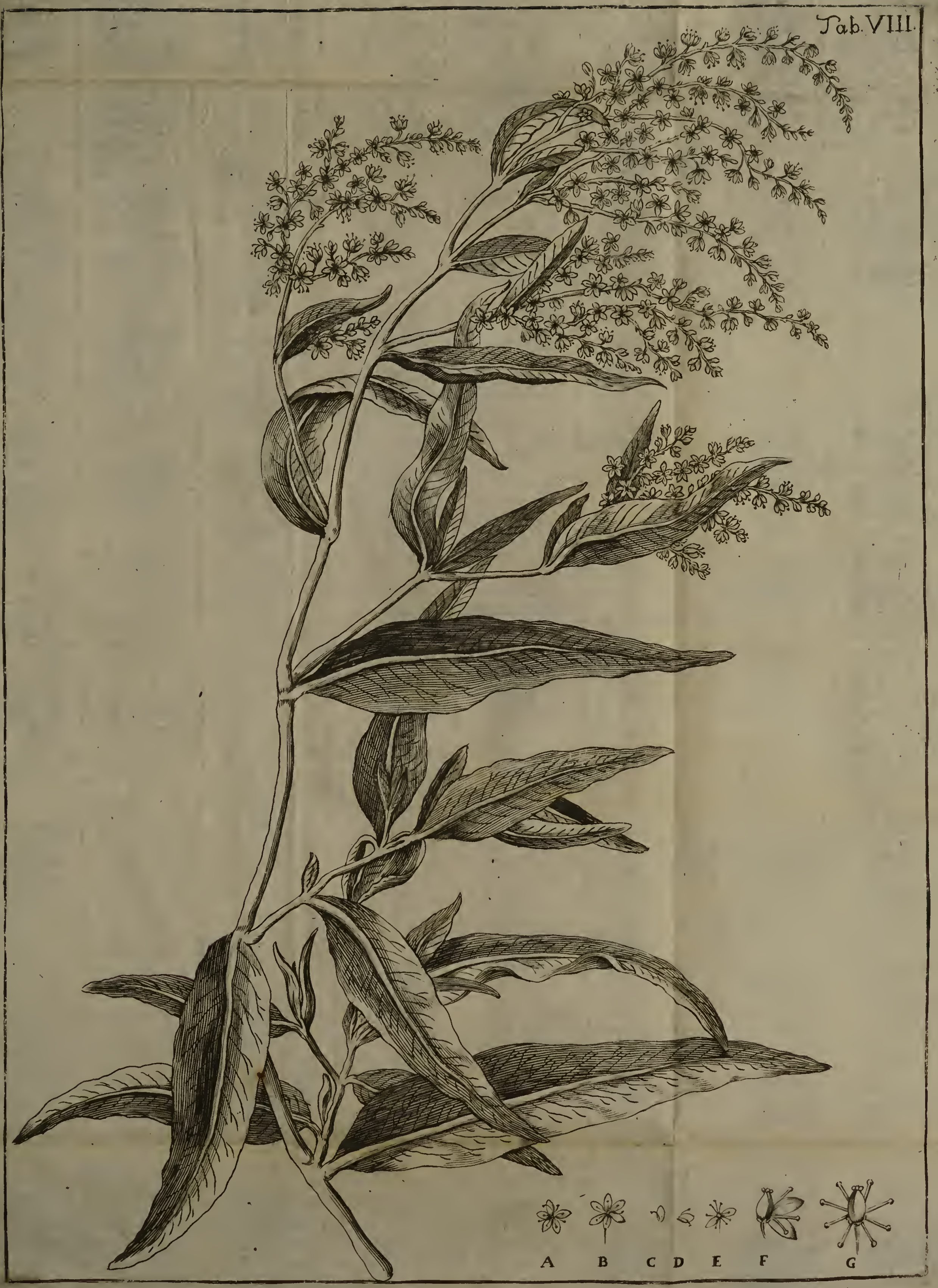



Fig. 1.

Tab. VIIII

an Helianshemum alpinum mirshifolium hirfurum. Hall.
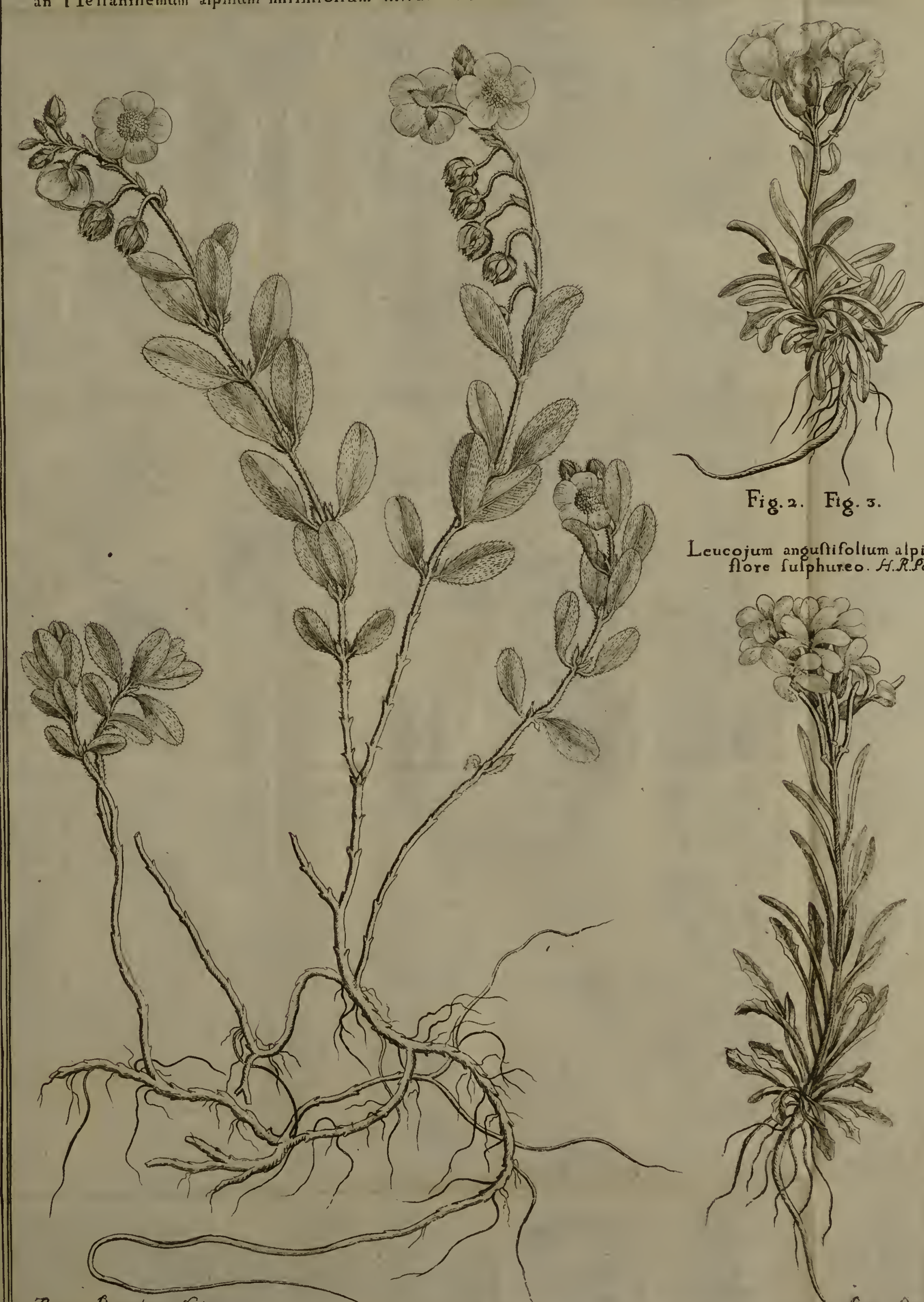

Fig. 2. Fig. 3.

Leucojum anountifolium alpinum fore fulphureo. F. R.P.

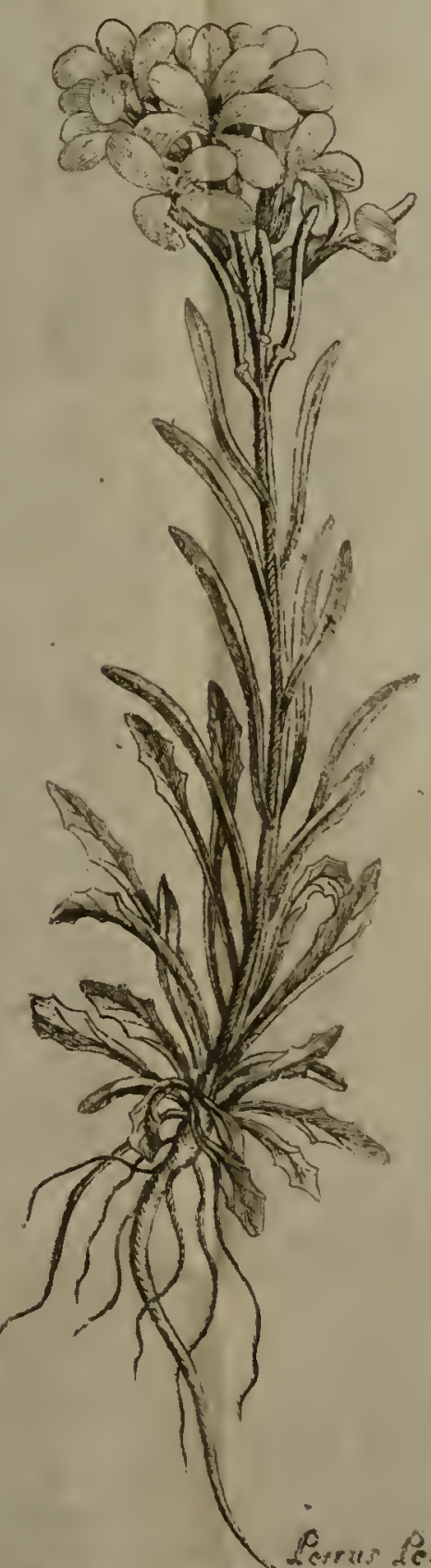



Alfue unifora ex grandiflora, folis acum inatis, peralis integris.

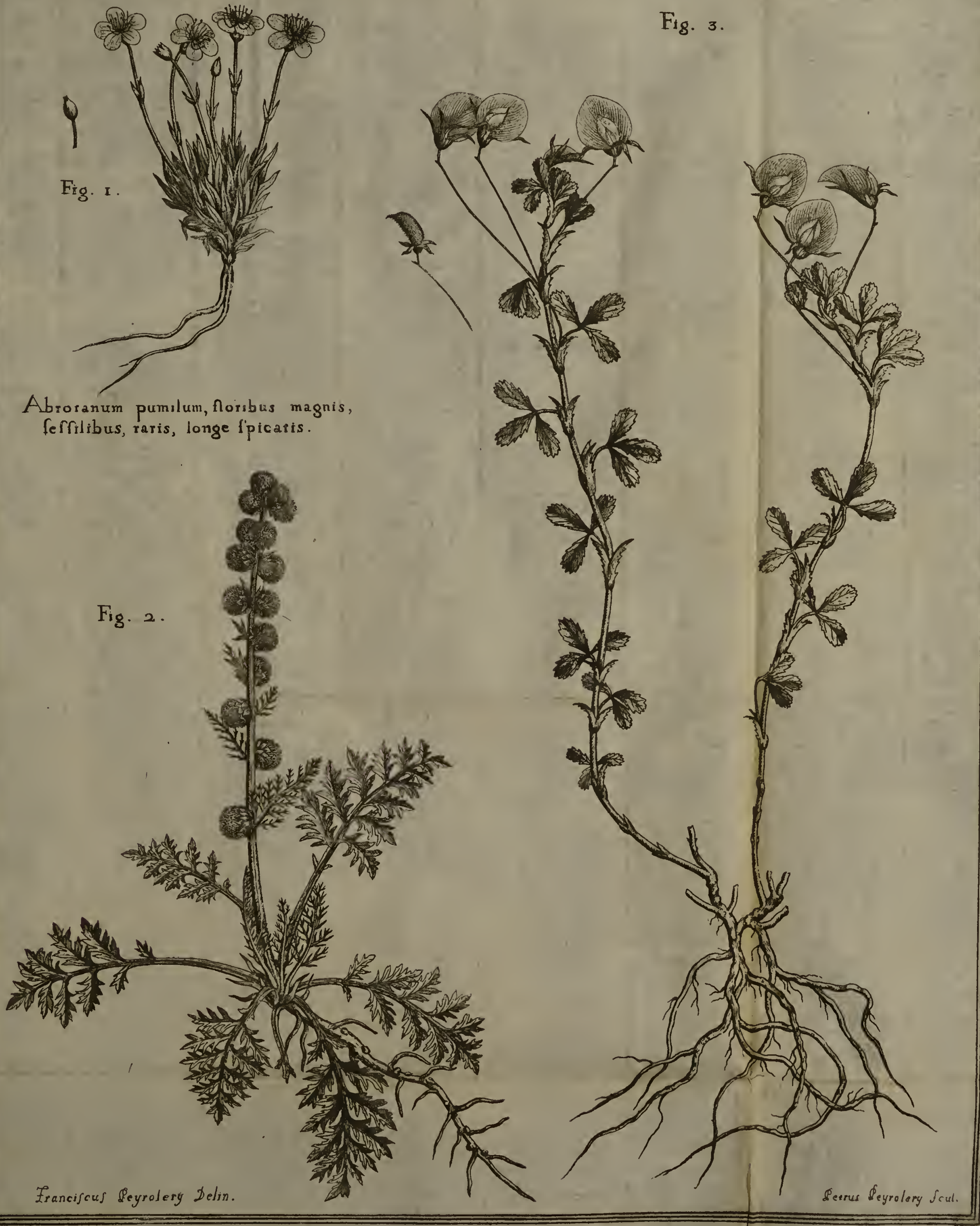

Anonis glabra, inermis, pediculis longitrimis unifloris, vagints foliorum criftalts.

Fig. 3. 
$\therefore 3$

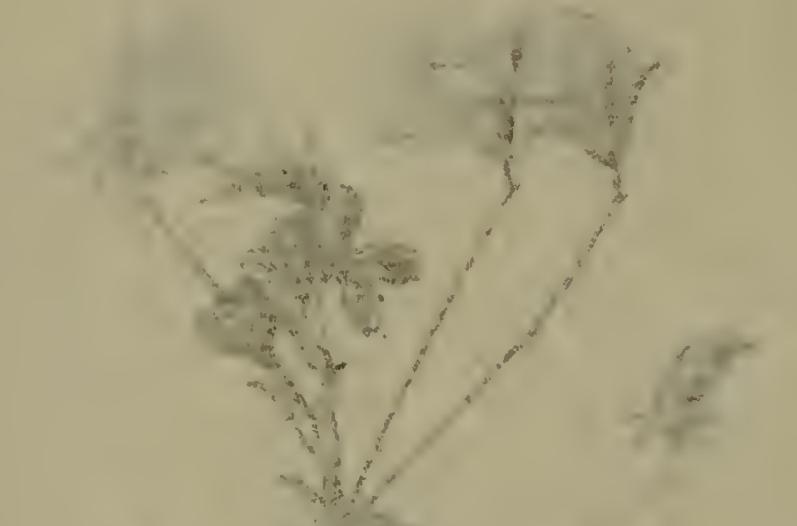

Q.
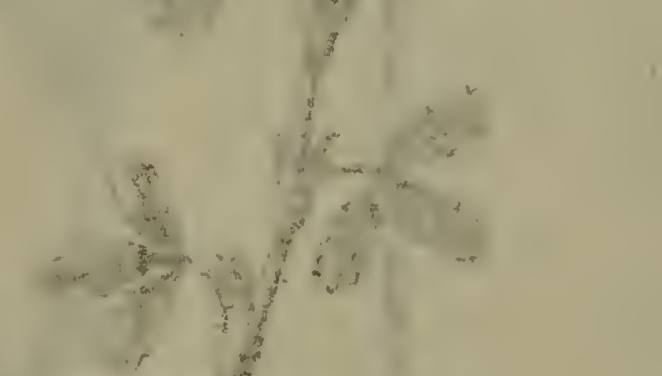

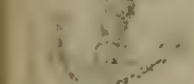

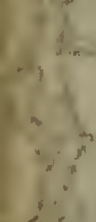

(3)

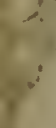

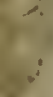

$-4,3.9$
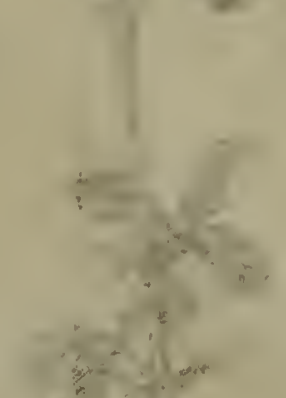

i.

$$
\text { (a) }
$$
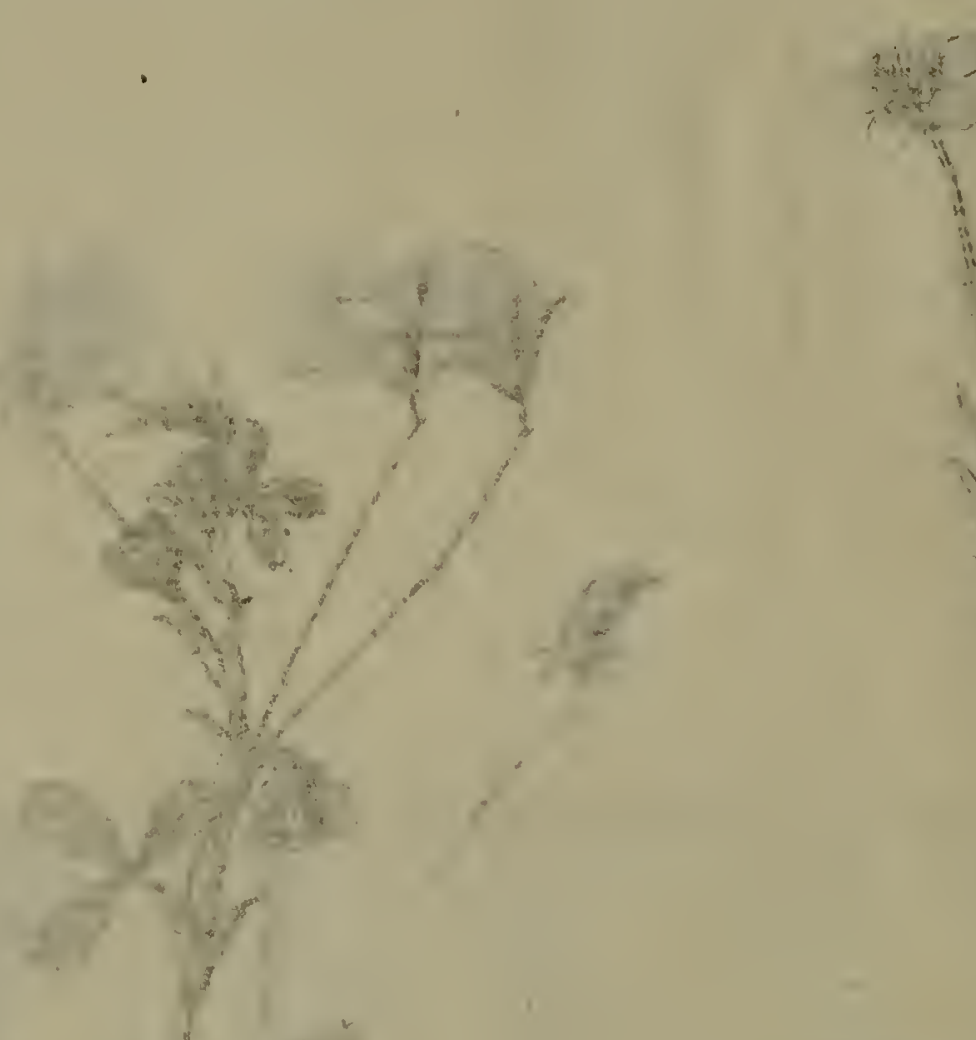

10

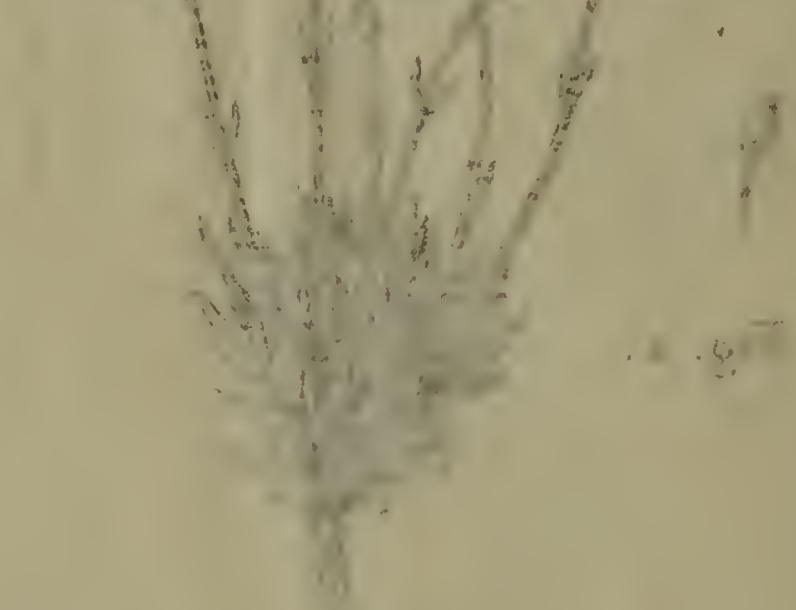

i

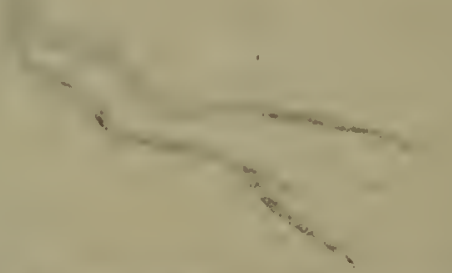

4.

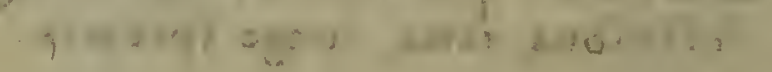

$-\because a^{2}$
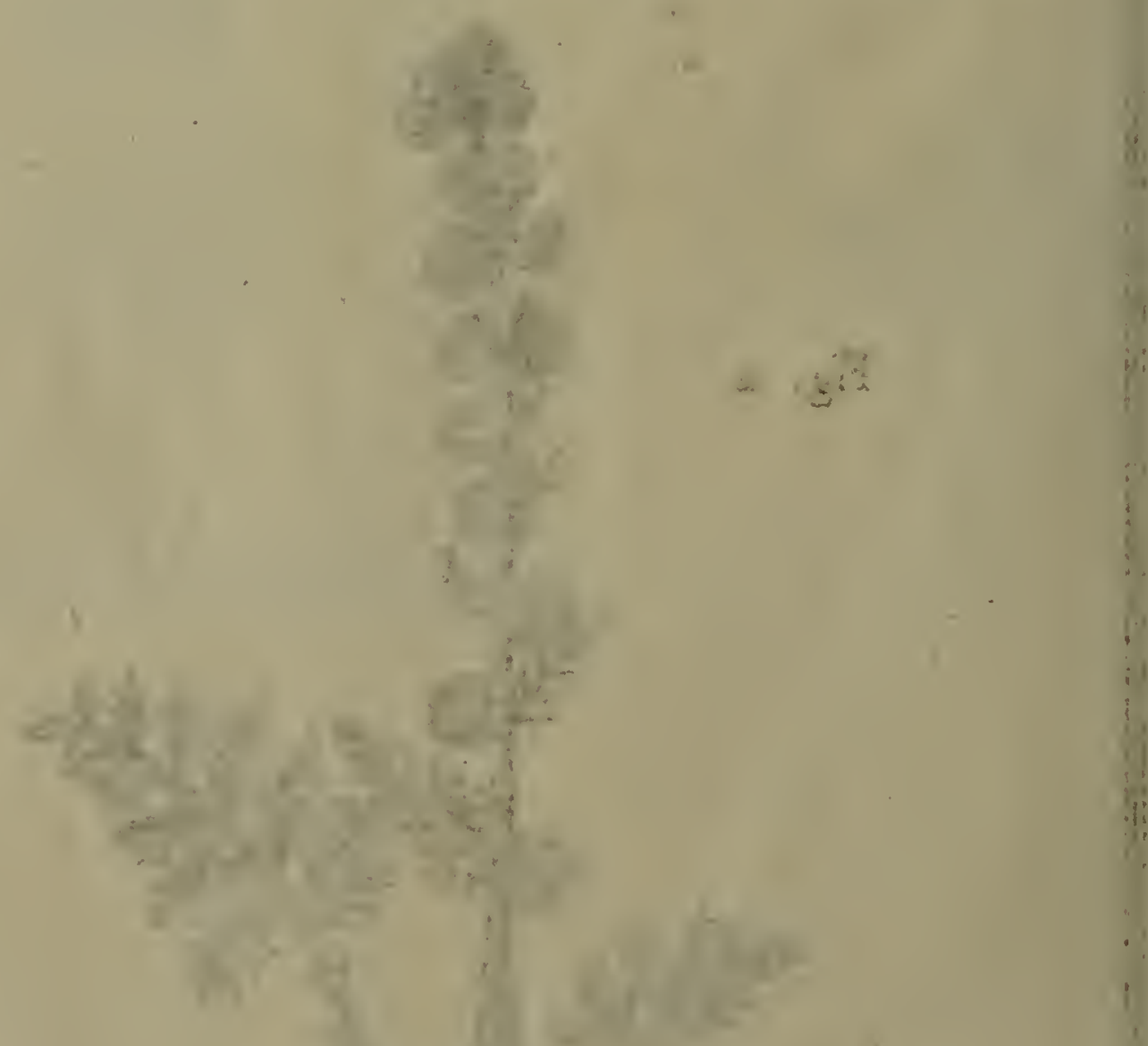

i. 1

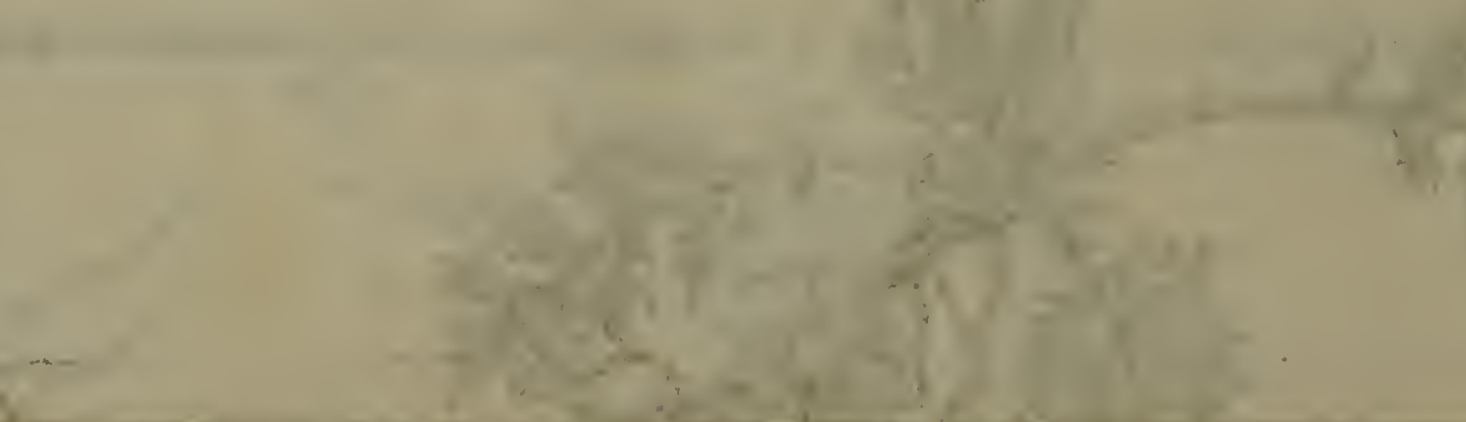

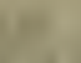
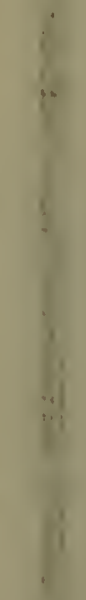


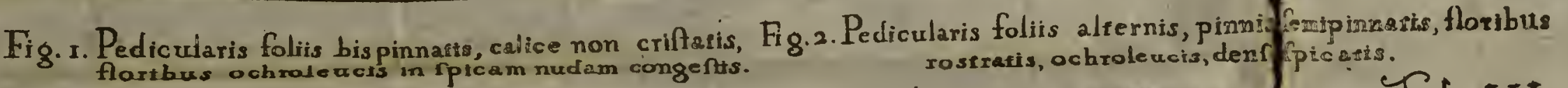

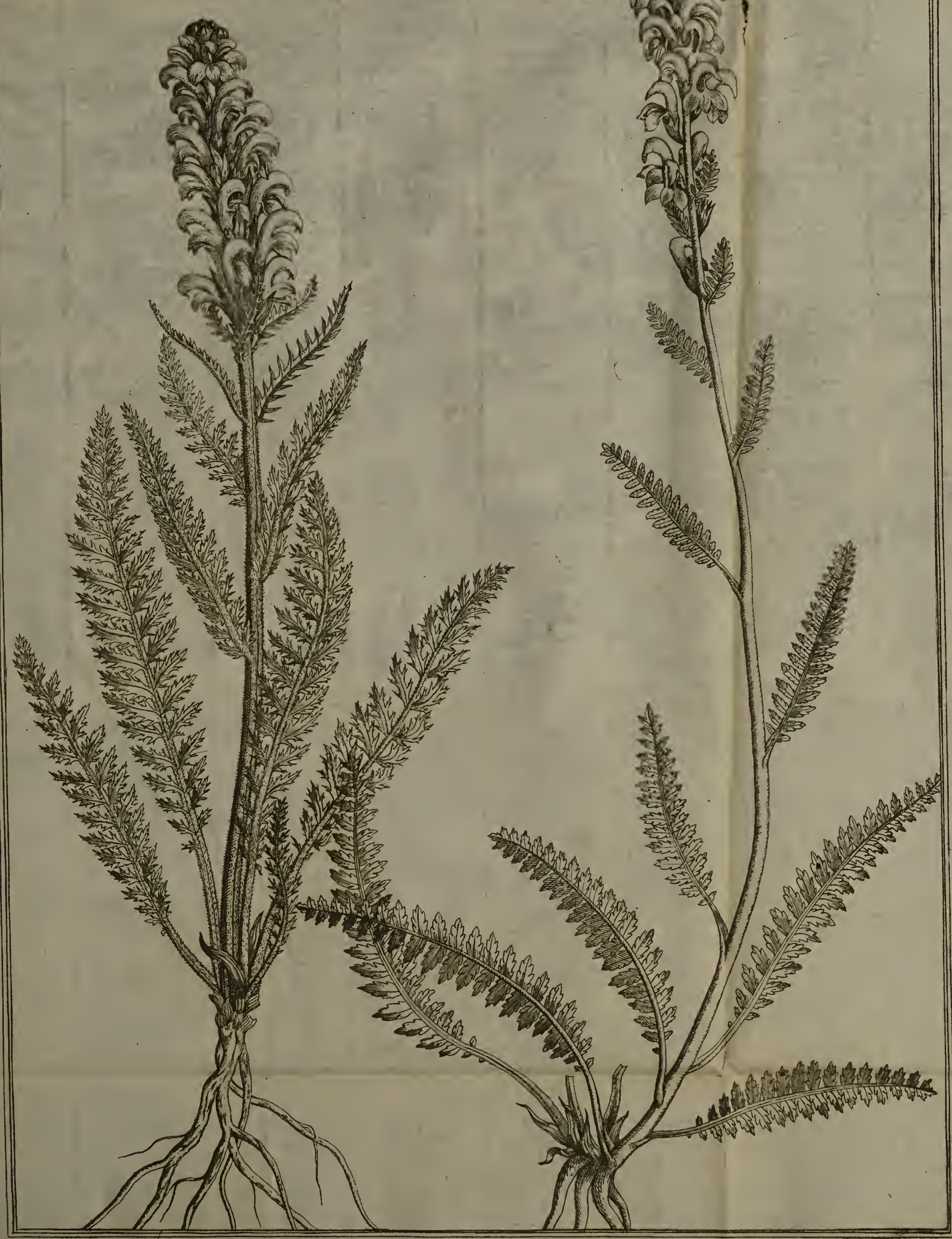

Franc. Soyrolery $\mathrm{De} / \mathrm{m}$. 
Fig. I.

Pedicularis pinnis foliorum acure pinnatts, floribus obeufis, purpureis, fpicatis.
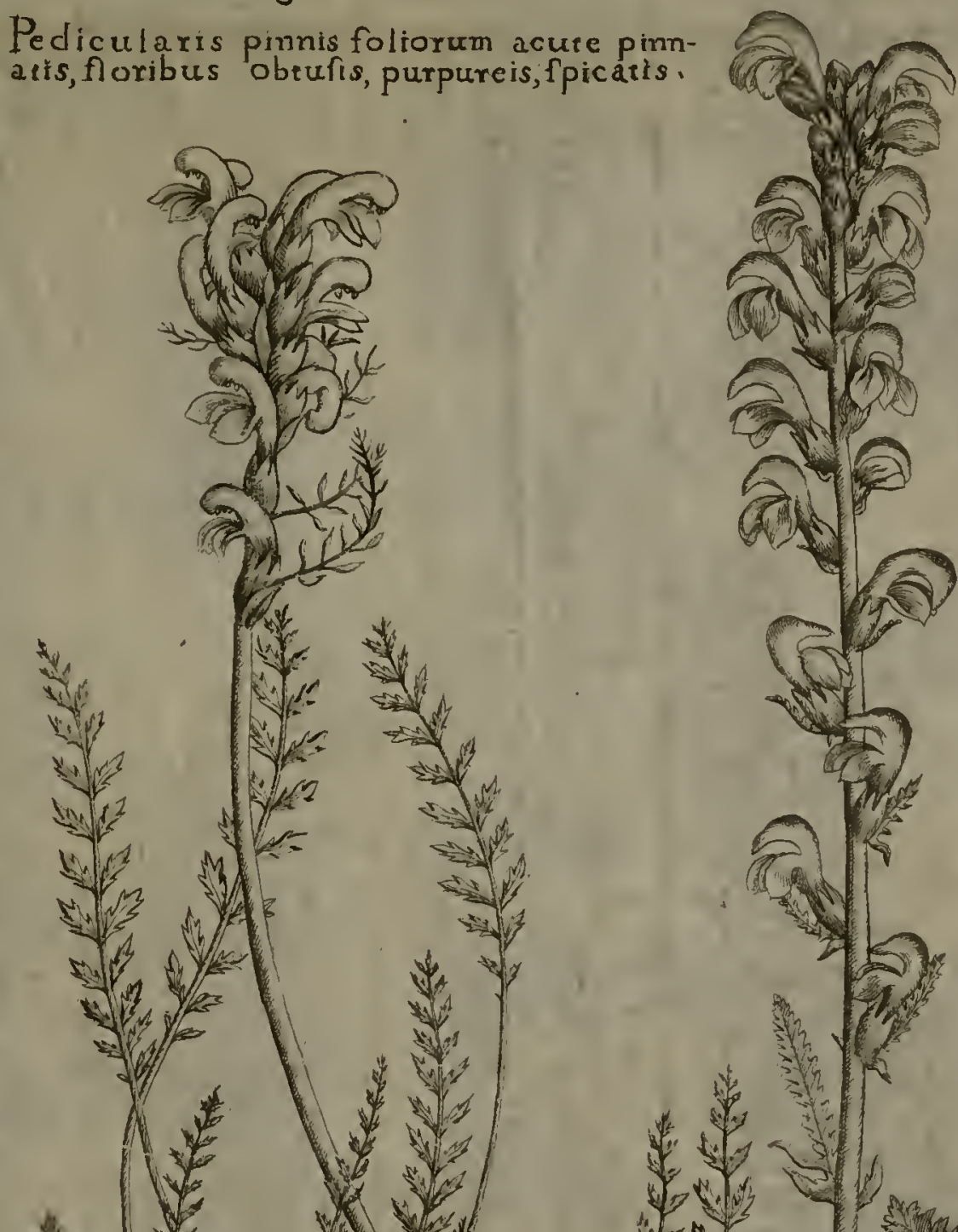

Fig. 2

Tab.XII.

Pedicularts folits alternis, pinnis femipinnatis, floribus softratis laxe, ex longiffrme fpicatis.
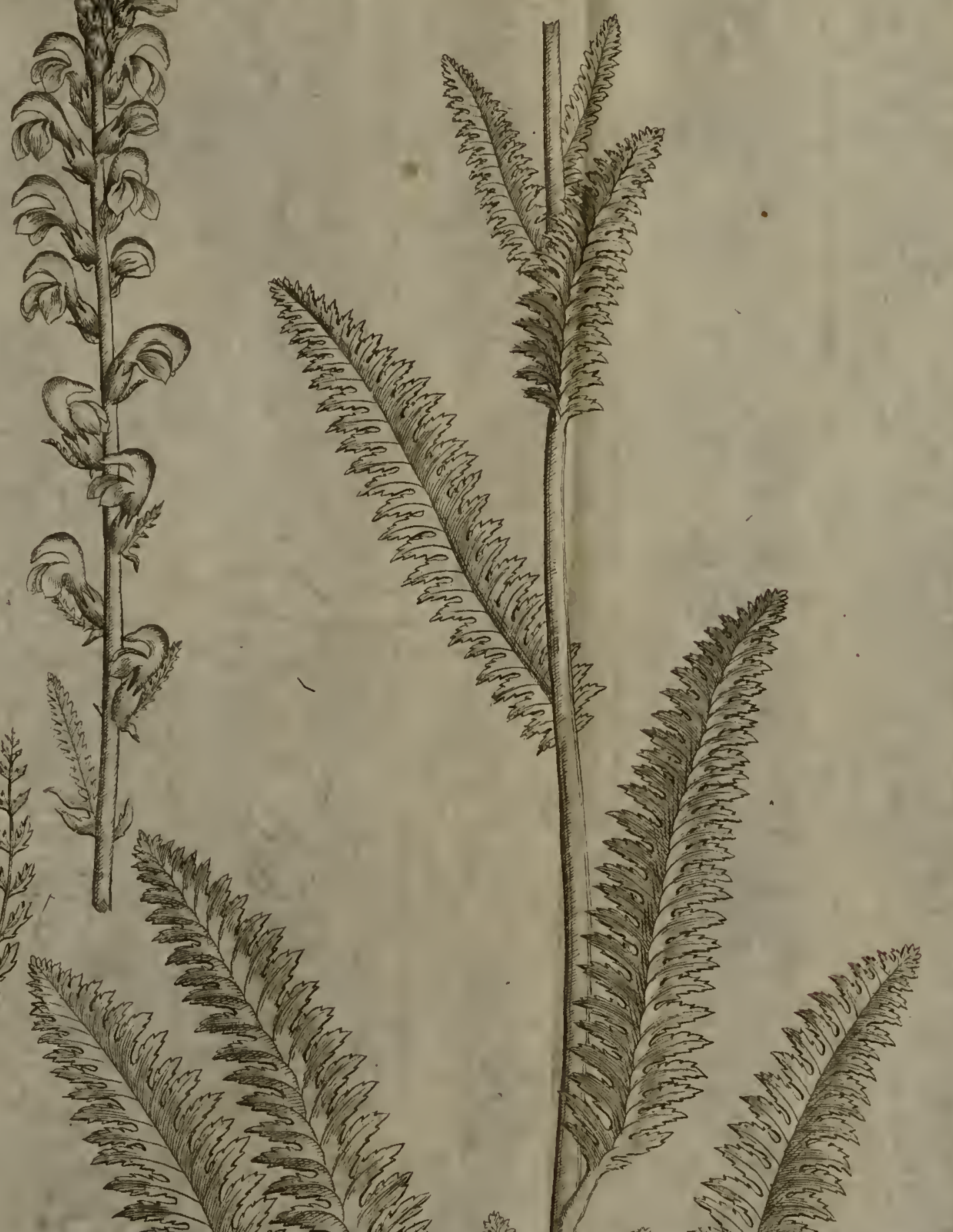


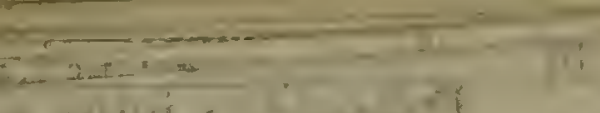

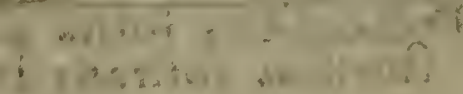

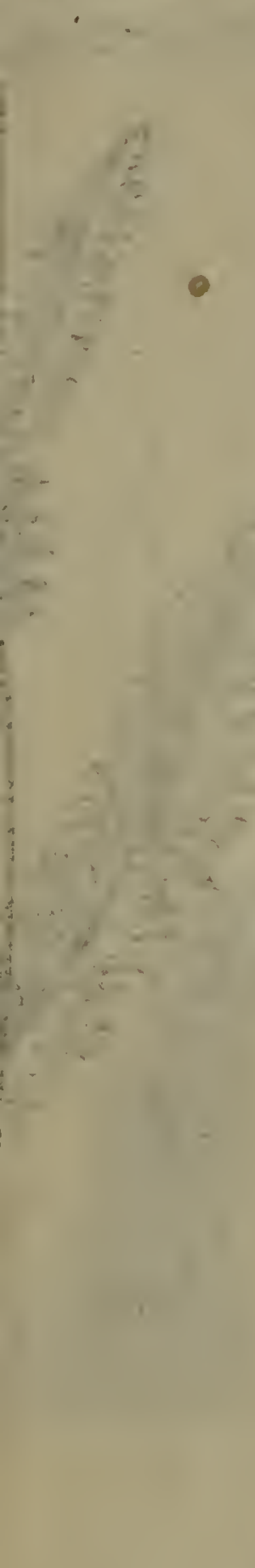

6

X

$\cdots$

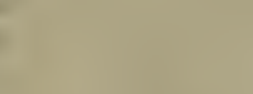

$$
\text { 然 }
$$
: $3:-2=$
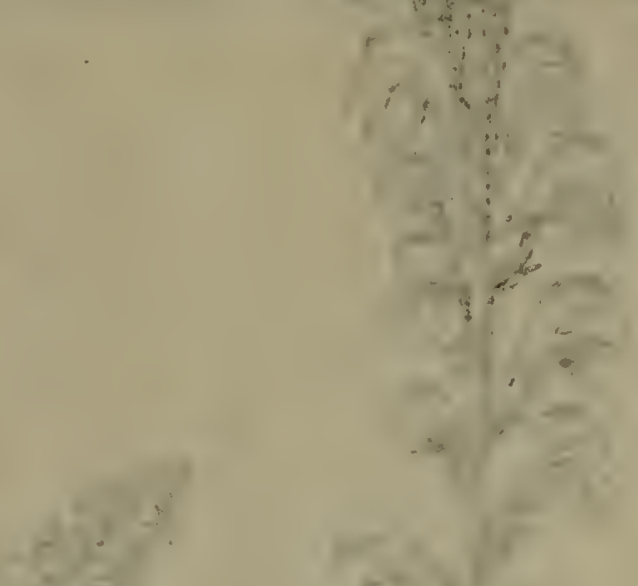

$r^{+1}$
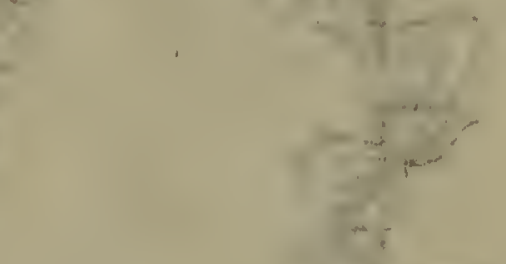$$
\text { (2) }
$$

(102) 203

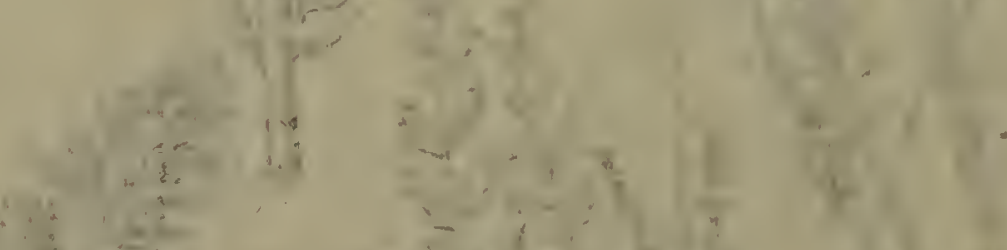

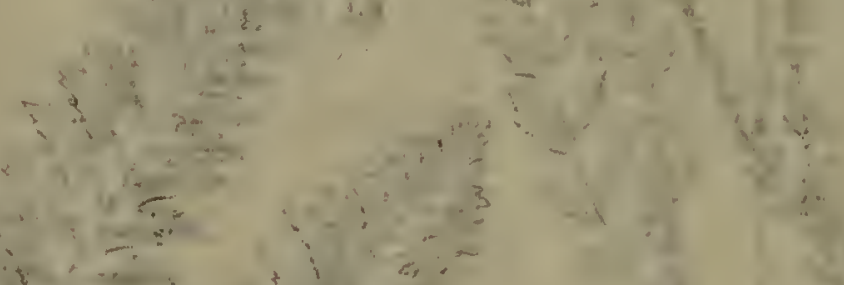

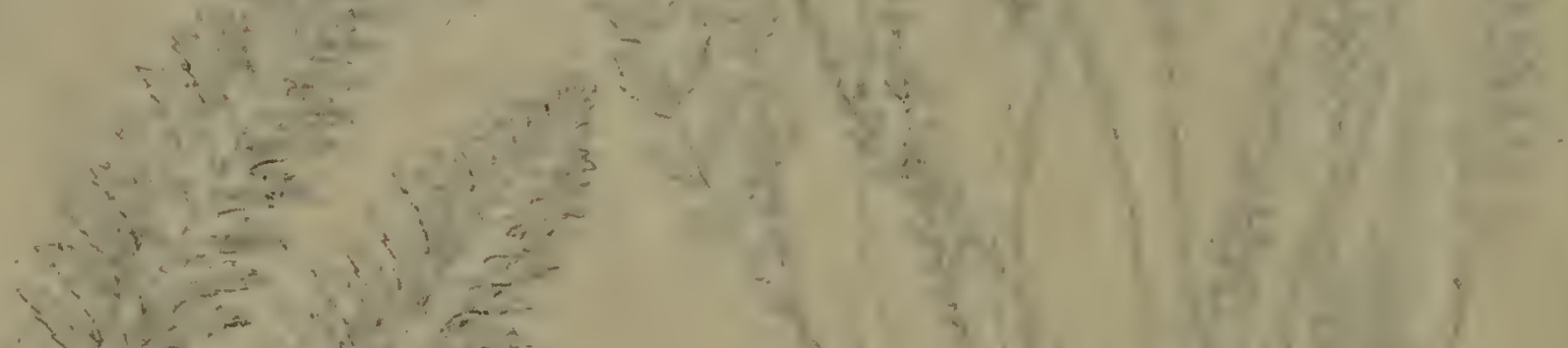

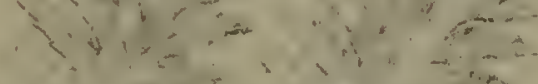

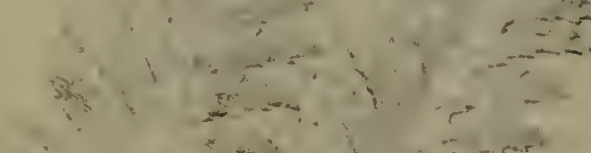

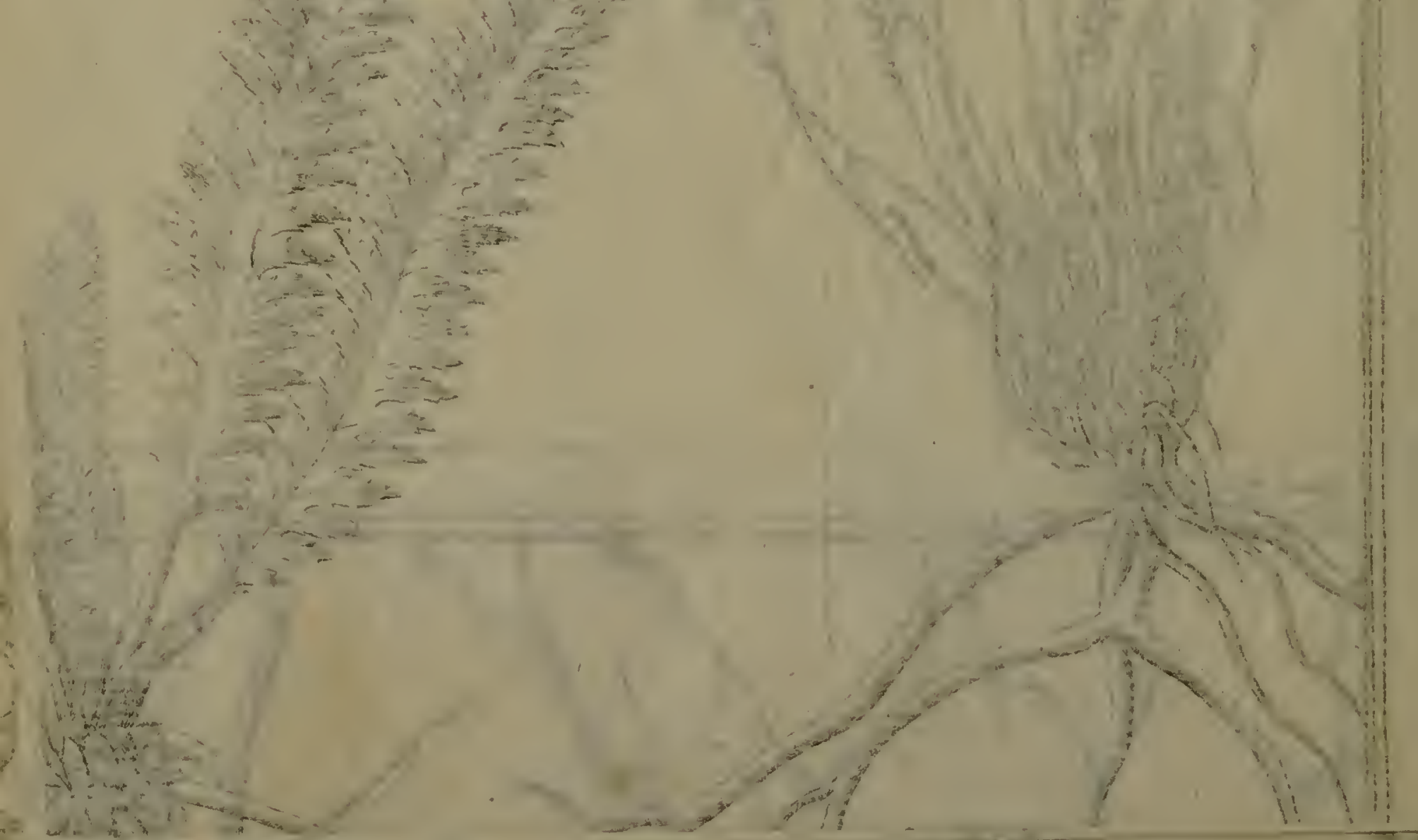

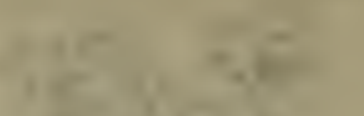

$-4 \lim ^{2}$

$x_{1}=\frac{1}{8}-$

$y^{2}+4=$
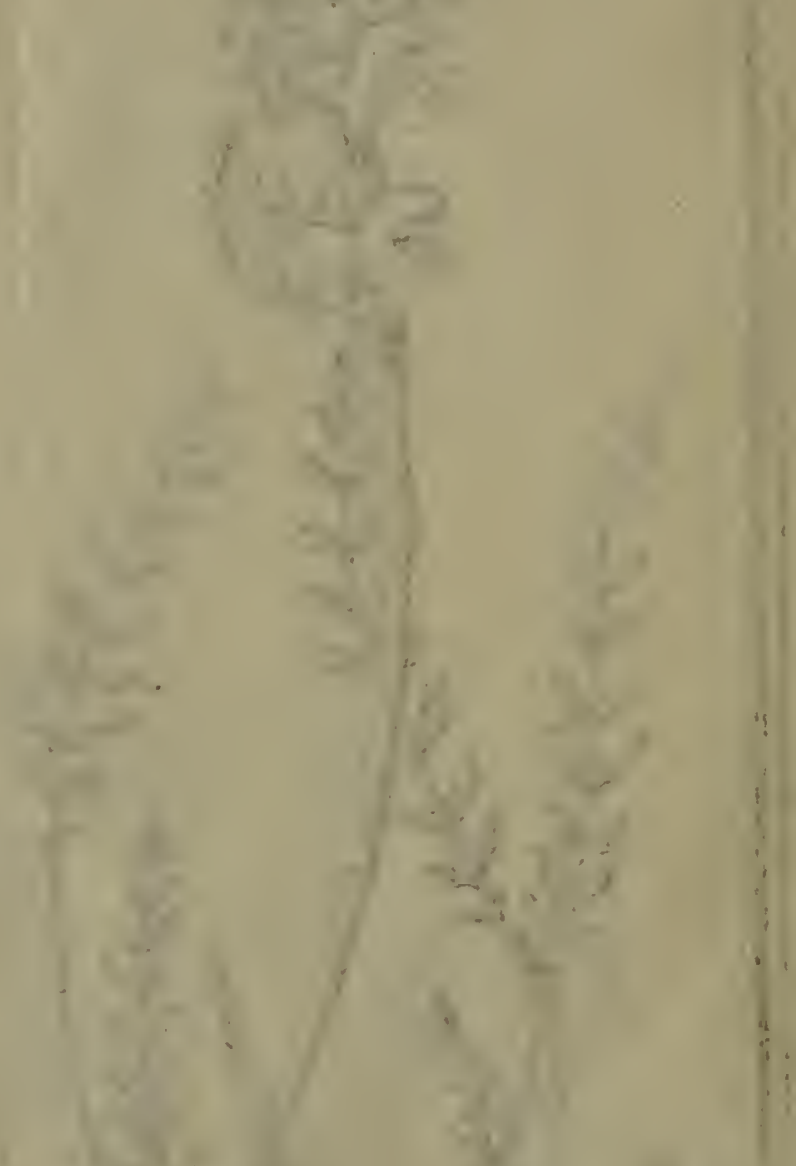

